SERVIÇO DE PÓS-GRADUAÇÃO DO ICMC-USP

Data de Depósito: $\quad 26.11 .2001$

Assinatura: et no Paula lampacie inegene

\title{
Escalonamento de aplicações paralelas: interface AMIGO-CORBA
}

\author{
Ricardo Ribeiro dos Santos
}

Orientador: Prof. Dr. Marcos José Santana

Dissertação apresentada ao Instituto de Ciências Matemáticas e de Computação - ICMC-USP, como parte dos requisitos para obtenção do título de Mestre em Ciências de Computação e Matemática Computacional.

USP - São Carlos

Novembro/2001 
A Comissão Julgadora:

Prof. Dr. Marcos José Santana

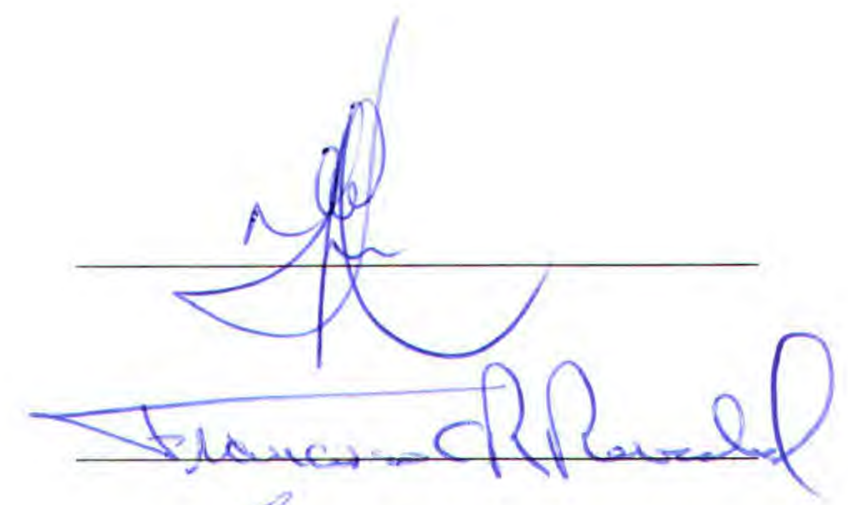

Prof. Dr. Francisco Reverbel

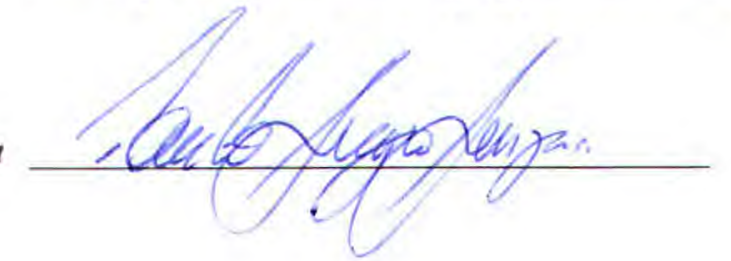

Prof. Dr. Paulo Sérgio Lopes de Souza 


\section{Dedicatória}

Aos meus pais, Nelson e Nadir.

À minha irmã, Rejane.

À minha avó, Ana Rosa (in memoriam). 


\section{Agradecimentos}

Em primeiro lugar gostaria de agradecer a DEUS, pois, mais uma vez, concedeu-me forças para ultrapassar as adversidades da vida e chegar até aqui.

Aos meus pais, Nelson e Nadir, que diante de tantas dificuldades e barreiras encontradas pela frente, sempre se esforçaram ao máximo para dar a seus filhos, ao menos, o mínimo necessário. Pelo incentivo para que eu continuasse com os estudos e por suportarem a saudade. Pai e mãe, vocês são uma lição de vida.

Ao Prof. Dr. Marcos José Santana, pela confiança creditada em mim ao me aceitar no Programa de Pós-Graduação. Pelo respeito e paciência com as minhas limitações e, por sempre nos contagiar com sua motivação e espírito de luta.

À Prof. Dra. Regina Helena Carlucci Santana pelos ricos ensinamentos e sugestões dadas a este trabalho.

Ao Prof. Dr. Nivaldi Calonego Júnior, da Universidade de Cuiabá, pelo suporte e constante incentivo durante o período de graduação.

Ao amigo Paulo Sérgio Lopes de Souza, pelos trabalhos realizados, pela sempre boa vontade em ouvir minhas opiniōes (mesmo que fossem as mais absurdas possiveis) e pela ajuda inestimável para o desenvolvimento deste trabalho.

À familia Rossales, minha família em São Carlos. Em especial à Sra. Ivani, Sr. Manoel e seus filhos César, Selma e Saulo, pelos almoços e jantares nos fins de semana e por me acolherem como um filho. Só mesmo DEUS poderá recompensar a vocês, todo o carinho e preocupação a mim dispensados.

Aos Profs. José Carlos Maldonado e Paulo Sérgio Lopes de Souza pelas contribuições apresentadas durante o Exame de Qualificação.

Aos grandes amigos que encontrei no LaSDPC (citados sem a pretensão de estabelecer algum tipo de ordem): Álvaro, Célia, Daniel, Edmilson, Eliane (Naninha), Fernando, Hermes e Douglas (a dupla HD), João Carlos (JC), Jorge, Kalinka e Sarita (minhas fiéis companheiras no Lab. Queops), Luciano, Mara, Mário (pelas perguntas nos seminários e disposição em discutir assuntos relacionados a objetos distribuídos), Omar, Renata, Tatiana (muito obrigado pela ajuda com o funcionamento do LAM), Tomás e Vera.

Aos amigos e companheiros de bandejão: Márcio e Arion. Pelo constante bom humor e disposição em ajudar.

Ao amigo Renato Francês, pelos cafézinhos da tarde e pelas trocas de idéias que, sem dúvida, contribuíram para o meu conhecimento e crescimento pessoal. 
Aos companheiros de trabalhos, seminários e exercícios durante o período de disciplinas aqui no ICMC: Adenilso (pela ajuda com o LaTEX), Fernando Miranda, Dalton, Luciano Nascimento, Orlando, Otávio, Rúbia e Valmir.

Aos amigos que conheci aqui em São Carlos e que contribuíram muito para a minha adaptação: Alexandre, Assuero, Cláudia, Cristiane e Simone (Rio Claro), Flávio, Himer, João, Júnior, Lucas, Ludmila, Miguel, Miriam, Misael, Pedro e Tiago.

À USP por, realmente, fazer jus ao slogan: "Educação para o Brasil".

À Fapesp, pelo apoio finaceiro sem o qual este trabalho não poderia ser realizado. 


\section{Resumo}

Este trabalho apresenta o projeto e implementação de uma interface de comunicação entre o ambiente de escalonamento AMIGO e TAO, que é uma implementação da especificação CORBA. Essa interface permite que aplicações desenvolvidas com TAO utilizem os serviços de escalonamento providos pelo AMIGO. O ambiente AMIGO oferece uma maneira flexível e dinâmica de escalonamento, possibilitando um melhor desempenho para aplicações do usuário. A ferramenta TAO possibilita o desenvolvimento de aplicaçōes distribuídas em conformidade com a especificação CORBA e, também, aplicações paralelas distribuídas através do modelo callback de mensagens assíncronas.

Em trabalhos anteriores realizados no grupo de Sistemas Distribuídos e Programação Concorrente do ICMC-USP, foram implementadas com sucesso interfaces para os softwares PVM e LAM-MPI. Os resultados alcançados por esses trabalhos motivaram a implementação de uma nova interface, entre o AMIGO e uma ferramenta CORBA, com o objetivo de explorar o desenvolvimento de aplicaçōes paralelas distribuídas na arquitetura CORBA e, conseqüentemente, oferecer serviços aprimorados de escalonamento para essas aplicações.

Após a implementação da interface CORBA-AMIGO neste trabalho, foi possível verificar os ganhos que o uso de técnicas aprimoradas de escalonamento podem trazer sobre o desempenho final da aplicação. Além disso, os resultados obtidos mostraram que a ferramenta TAO é uma solução viável para o desenvolvimento de algumas classes de aplicaçōes paralelas distribuídas podendo, inclusive, alcançar desempenho comparável ao desempenho observado com ferramentas construídas especificamente para essas classes de aplicações. 


\section{Abstract}

This work presents the design and implementation of a communication interface between the AMIGO scheduling environment and TAO, that is an implementation of CORBA specification. This interface allows applications developed with TAO to use the scheduling services provided by AMIGO. The AMIGO environment offers a flexible and dynamic scheduling, aiming at providing a better performance to user applications. TAO allows the development of distributed applications in compliance with the CORBA specification and parallel distributed applications through the callback asynchronous messaging model.

In previous works developed in the Concurrent Programming and Distributed Systems Group of the ICMC-USP, interfaces to PVM and LAM-MPI softwares have been successfully implemented. The results reached by these works motivated the building of a new interface between the AMIGO and a CORBA tool, aiming at exploring the development of parallel distributed applications within the CORBA architecture and consequentely to offer better scheduling services to these applications.

After the implementation of the CORBA-AMIGO interface in this work, it was possible to assess the gains that enhanced scheduling techniques can bring to the final application performance. Moreover, the results obtained showed that TAO is a viable solution to the development of some distributed parallel application classes, 'being able to reach performance comparable to those observed for others tools built specifically to deal with these classes of applications. 


\section{Sumário}

1 Introdução 1

2 Computação Paralela Distribuída 5

2.1 Considerações iniciais . . . . . . . . . . . . . . . 5

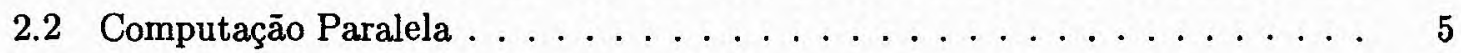

2.2.1 Conceitos básicos de Computação Paralela . . . . . . . . . . 6

2.2.2 Arquiteturas Paralelas . . . . . . . . . . . . . . 7

2.3 Programação Concorrente . . . . . . . . . . . . . . . . 14

2.4 Sistemas Distribuídos . . . . . . . . . . . . . . . . 16

2.4 .1 Modelos arquiteturais . . . . . . . . . . . . . . . . . 17

2.4 .2 Redes de Comunicação . . . . . . . . . . . . . . 18

2.4 .3 Comunicação entre Processos . . . . . . . . . . . . . 19

2.5 Computação Paralela sobre Sistemas Distribuídos . . . . . . . . . . . 20

2.6 Ambientes de passagem de mensagens . . . . . . . . . . . . . 20

2.7 Considerações finais . . . . . . . . . . . . . . . . . . . 21

3 O ambiente de escalonamento AMIGO 23

3.1 Considerações iniciais . . . . . . . . . . . . . . . . . . . 23

3.2 Softwares para escalonamento de aplicações . . . . . . . . . . . . 24

3.2 .1 LoadLeveler . . . . . . . . . . . . . . . . . 25

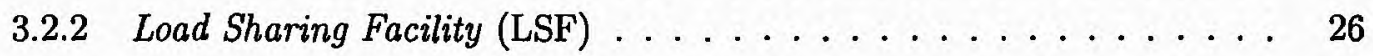

3.2 .3 Condor . . . . . . . . . . . . . . . . . 26

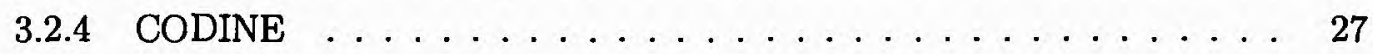

3.2 .5 Load Balancer. . . . . . . . . . . . . . . . . . . . 28

3.3 AMIGO - Conceitos e Características . . . . . . . . . . . . . 29

3.3.1 A Camada Superior do AMIGO . . . . . . . . . . . . . 29 
3.3.2 A Camada Inferior do AMIGO . . . . . . . . . . . . . 30

3.3.3 Comparação entre o ambiente AMIGO e outros softwares de escalona-

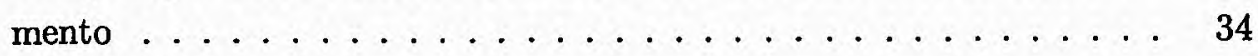

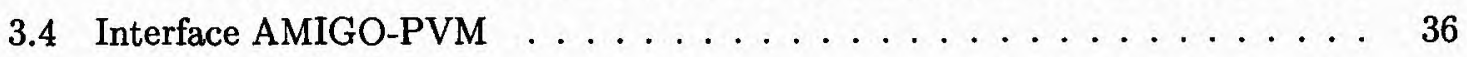

3.5 Interface AMIGO-MPI $\ldots \ldots \ldots \ldots \ldots \ldots \ldots \ldots$

3.6 Considerações finais . . . . . . . . . . . . . . . . 40

4 A Arquitetura CORBA

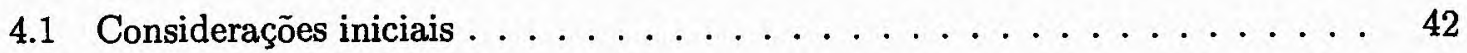

4.2 CORBA - Conceitos e Características . . . . . . . . . . . . 43

4.3 Organização dos componentes na arquitetura CORBA . . . . . . . . . 44

4.4 Escalonamento na arquitetura CORBA . . . . . . . . . . . . . . . 47

4.5 Comunicação assíncrona na arquitetura CORBA . . . . . . . . . . 49

4.5 .1 Modelo Polling . . . . . . . . . . . . . . . . 50

4.5 .2 Modelo Callback . . . . . . . . . . . . . . . 51

4.6 Aplicações paralelas na arquitetura CORBA . . . . . . . . . . . 52

4.7 Implementações CORBA . . . . . . . . . . . . . . . . . 56

4.8 Considerações finais . . . . . . . . . . . . . . 57

5 Interface AMIGO-CORBA 59

5.1 Considerações iniciais . . . . . . . . . . . . . . . . 59

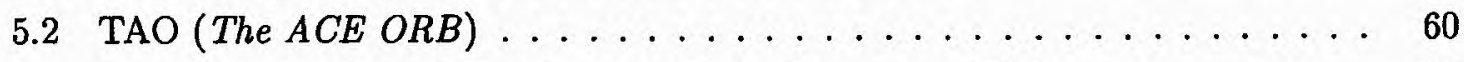

5.2.1 Repositório de Implementação da ferramenta TAO . . . . . . . . 62

5.3 Desenvolvimento da estrutura de suporte à interface AMIGO-CORBA . . . . 64

5.3.1 Implementação do gerenciamento distribuído no Repositório de Implementação ....................... 65

5.3.2 Implementação do escalonamento . . . . . . . . . . . . . 67

5.4 Desenvolvimento da interface AMIGO-CORBA $\ldots \ldots \ldots . \ldots 68$

5.5 Considerações finais . . . . . . . . . . . . . . . 70

6 Avaliação de Desempenho e Resultados

6.1 Considerações iniciais . . . . . . . . . . . . . . . . . . . . 72

6.2 Plataforma utilizada para realização dos experimentos . . . . . . . . . 73

6.3 Experimentos realizados ... . . . . . . . . . . . . . 74

6.3 .1 O problema do Caixeiro Viajante . . . . . . . . . . 76

6.3 .2 Método do trapézio composto . . . . . . . . . . 78

6.4 Análise estatística considerada . . . . . . . . . . . . 78 
6.5 Resultados obtidos . . . . . . . . . . . . . . . . 81

6.6 Considerações finais . . . . . . . . . . . . . . . . 90

7 Conclusões e Trabalhos Futuros $\quad 92$

7.1 Considerações finais . . . . . . . . . . . . . . . . . . . 92

7.2 Contribuições deste trabalho . . . . . . . . . . . . . . 93

7.3 Dificuldades encontradas . . . . . . . . . . . . . . . . . . 94

7.4 Propostas para trabalhos futuros $\ldots \ldots \ldots \ldots \ldots \ldots$

$\begin{array}{ll}\text { Referências Bibliográficas } & 96\end{array}$

A Descrição das mensagens definidas e utilizadas pelo AMIGO 104

B Testes de Hipóteses realizados 106

C Código fonte das aplicações LAM-MPI, TAO e PVM 110 


\section{Lista de Figuras}

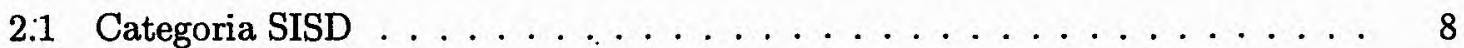

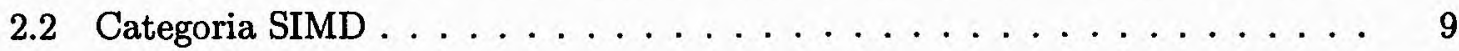

2.3 Categoria MISD . . . . . . . . . . . . . . . . . . 10

2.4 Categoria MIMD . . . . . . . . . . . . . . . . 10

2.5 Classificação de Duncan . . . . . . . . . . . . . . . . 11

2.6 Arquitetura MIMD com memória compartilhada . . . . . . . . . . . . 12

2.7 Arquitetura MIMD com memória distribuída . . . . . . . . . . . . . 13

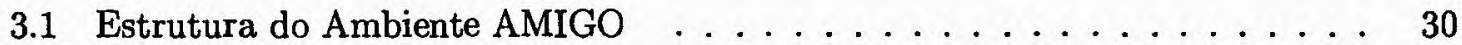

3.2 Módulos pertencentes à camada inferior do ambiente AMIGO $\ldots \ldots \ldots . . .31$

3.3 Comunicação entre os módulos da camada inferior do ambiente AMIGO . . . 33

3.4 Seqüência para realização do escalonamento no PVM . . . . . . . . . . 37

3.5 Alteração realizada para que o escalonamento do PVM fosse realizado com o auxílio do AMIGO . . . . . . . . . . . . . . . . 38

4.1 Arquitetura CORBA . . . . . . . . . . . . . . . 45

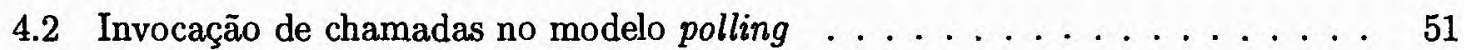

4.3 Invocação de chamadas no modelo callback . . . . . . . . . . . . 52

4.4 Arquitetura do sistema $\mathrm{PCB} \ldots \ldots \ldots \ldots \ldots \ldots \ldots$

5.1 Arquitetura do framework ACE . . . . . . . . . . . . . . . 60

5.2 Estrutura básica da implementação TAO . . . . . . . . . . . . . . 61

5.3 Organização dos arquivos que compõem o Repositório de Implementação . 63

5.4 Iteração do Repositório de Implementação com o Serviço de Nomes . . . . . 67

5.5 Escalonamento na ferramenta TAO utilizando uma política round-robin . . . 68

5.6 Escalonamento na ferramenta TAO utilizando o AMIGO . . . . . . . . . 70

6.1 Grafo orientado com 04 nós (vértices) e $12 \operatorname{arcos}$ (arestas) . . . . . . 77 
6.2 Passos utilizados para execução da aplicação do trapézio composto . . . . . . 79

6.3 Desempenho da aplicação do trapézio composto utilizando a ferramenta TAO com escalonamento round-robin e definido pelo AMIGO em um sistema ocioso 81

6.4 Desempenho da aplicação do trapézio composto utilizando a ferramenta PVM com escalonamento round-robin e definido pelo AMIGO em um sistema ocioso 81

6.5 Desempenho da aplicação do trapézio composto utilizando a ferramenta LAM-MPI com escalonamento round-robin e definido pelo AMIGO em um sistema ocioso . .

6.6 Desempenho da aplicação do caixeiro viajante utilizando a ferramenta TAO com escalonamento round-robin e definido pelo AMIGO em um sistema ocioso . . . . .

6.7 Desempenho da aplicação do caixeiro viajante utilizando a ferramenta PVM com escalonamento round-robin e definido pelo AMIGO em um sistema ocioso . . . . .

6.8 Desempenho da aplicação do caixeiro viajante utilizando a ferramenta LAMMPI com escalonamento round-robin e definido pelo AMIGO em um sistema

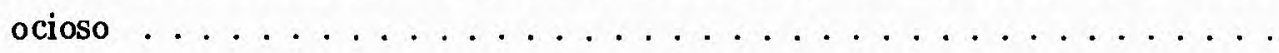

6.9 Desempenho da aplicação do trapézio composto utilizando a ferramenta TAO com escalonamento round-robin e definido pelo AMIGO em um sistema com perfis de carga diferentes . . . . . . . . . . . . . . .

6.10 Desempenho da aplicação do trapézio composto utilizando a ferramenta PVM com escalonamento round-robin e definido pelo AMIGO em um sistema com perfis de carga diferentes . . . . . . . . . . . . . . .

6.11 Desempenho da aplicação do trapézio composto utilizando a ferramenta LAMMPI com escalonamento round-robin e definido pelo AMIGO em um sistema com perfis de carga diferentes . . . . . . . . . . . .

6.12 Desempenho da aplicação do caixeiro viajante utilizando a ferramenta TAO com escalonamento round-robin e definido pelo AMIGO em um sistema com perfis de carga diferentes . . . . . . . . . . . . . . . . .

6.13 Desempenho da aplicação do caixeiro viajante utilizando a ferramenta PVM com escalonamento round-robin e definido pelo AMIGO em um sistema com perfis de carga diferentes . . . . . . . . . . . . . .

6.14 Desempenho da aplicação do caixeiro viajante utilizando a ferramenta LAMMPI com escalonamento round-robin e definido pelo AMIGO em um sistema com perfis de carga diferentes . . . . . . . . . . . .

6.15 Desempenho da aplicação do trapézio composto utilizando as ferramentas LAM-MPI, TAO e PVM com escalonamento round-robin em um sistema com perfis de carga diferentes . . . . . . . . . . . . . . 
6.16 Desempenho da aplicação do trapézio composto utilizando as ferramentas LAM-MPI, TAO e PVM com escalonamento definido pelo AMIGO em um sistema com perfis de carga diferentes . . . . . . . . . . . .

6.17 Desempenho da aplicação do caixeiro viajante utilizando as ferramentas LAMMPI, TAO e PVM com escalonamento round-robin em um sistema com perfis de carga diferentes . . . . . . . . . . . . . . .

6.18 Desempenho da aplicação do caixeiro viajante utilizando as ferramentas LAMMPI, TAO e PVM com escalonamento definido pelo AMIGO em um sistema com perfis de carga diferentes $\ldots \ldots \ldots \ldots \ldots \ldots$ 


\section{Lista de Tabelas}

3.1 Comparação das características do AMIGO com outros softwares de escalonamento ............................ 35

6.1 Configuração do ambiente computacional utilizado na avaliação de desempenho 73

6.2 Definição dos perfis de carga utilizados nos experimentos . . . . . . . . . . 75

6.3 Detalhamento e conclusões sobre os experimentos 1 e $2 \ldots \ldots \ldots$

6.4 Detalhamento e conclusões sobre os experimentos 3 e $4 \ldots \ldots$. . . . . 87

6.5 Detalhamento e conclusões sobre as Figuras 6.15 a $6.18 \ldots \ldots \ldots$. . . . . 90

A.1 Mensagens trocadas entre $o(s)$ software(s) que gerencia(m) as aplicações e o AMIGOD . . . . . . . . . . . . . . . . . . . . 104

A.2 Mensagens trocadas entre AMIGODs . . . . . . . . . . . . . 105

A.3 Mensagens trocadas entre o AMIGOD e a política de escalonamento local . . 105

B.1 Valores calculados para o desempenho obtido com a aplicação do trapézio composto utilizando TAO com diferentes políticas de escalonamento em um sistema ocioso . . . . . . . . . . . . . . . . . . 106

B.2 Valores calculados para o desempenho obtido com a aplicação do trapézio composto utilizando PVM com diferentes políticas de escalonamento em um sistema ocioso . . . . . . . . . . . . . . . . 107

B.3 Valores calculados para o desempenho obtido com a aplicação do trapézio composto utilizando LAM-MPI com diferentes políticas de escalonamento em um sistema ocioso . . . . . . . . . . . . . . . . . . 107

B.4 Valores calculados para o desempenho obtido com a aplicação do caixeiro viajante utilizando TAO diferentes políticas de escalonamento em um sistema

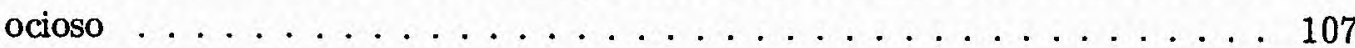


B.5 Valores calculados para o desempenho obtido com a aplicação do caixeiro viajante utilizando PVM com diferentes políticas de escalonamento em um sistema ocioso . . . . . . . . . . . . . . . . 107

B.6 Valores calculados para o desempenho obtido com a aplicação do caixeiro viajante utilizando LAM-MPI com diferentes políticas de escalonamento em um sistema ocioso . . . . . . . . . . . . . . . 108

B.7 Valores calculados para o desempenho obtido com uma aplicação TAO do trapezio composto com escalonamento round-robin e o AMIGO em um sistema com perfis de carga diferentes . . . . . . . . . . . . . . . . 108

B.8 Valores calculados para o desempenho obtido com a aplicaçāo PVM do trapézio composto com escalonamento round-robin e o AMIGO em um sistema com perfis de carga diferentes . . . . . . . . . . . . . . . 108

B.9 Valores calculados para o desempenho obtido com a aplicação LAM-MPI do trapézio composto com o escalonamento round-robin e o AMIGO em um sistema com perfis de carga diferentes . . . . . . . . . . . . . . . . . 108

B.10 Valores calculados para o desempenho obtido com a aplicação TAO do caixeiro viajante com o, escalonamento round-robin e o AMIGO em um sistema com perfis de carga diferentes. . . . . . . . . . . . . . . . . . . . . 109

B.11 Valores calculados para o desempenho obtido com a aplicação PVM do caixeiro viajante com o escalonamento round-robin e o AMIGO em um sistema com perfis de carga diferentes . . . . . . . . . . . . . . . 109

B.12 Valores calculados para o desempenho obtido com a aplicação LAM-MPI do caixeiro viajante com o escalonamento round-robin e o AMIGO em um sistema cóm perfis de carga diferentes . . . . . . . . . . . . . . . . . 109 


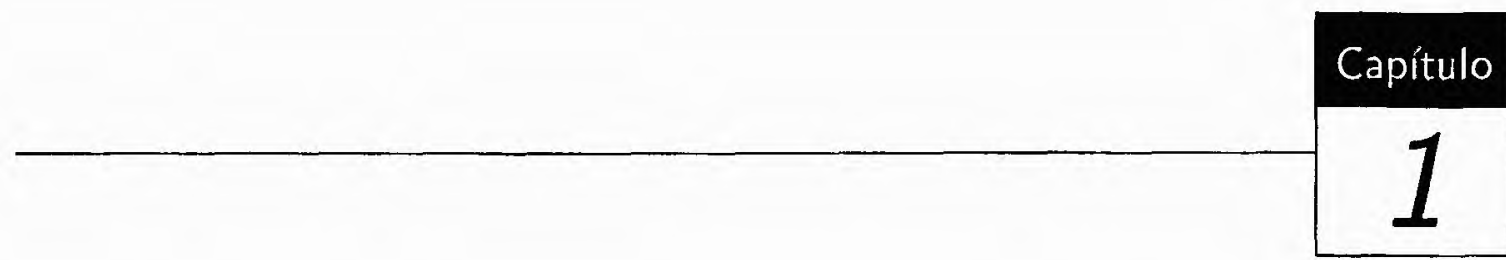

\section{Introdução}

Diversos foram os fatores que contribuíram para que a computação se tornasse tão usual e até imprescindível nos dias atuais. Automatização, flexibilidade e rapidez na realizaçāo de tarefas são alguns fatores de fácil mensuração. No entanto, as facilidades atualmente encontradas nada mais são do que o resultado de décadas de pesquisas e desenvolvimentos, objetivando fornecer soluções para problemas de considerável complexidade e, muitas vezes, até inviáveis de resolução sem as tecnologias atualmente disponibilizadas.

Assim, pode ser notado que as diversas linhas de pesquisas em computação, ocupam lugar de destaque no que diz respeito ao provimento de tecnologias à sociedade de maneira geral. Dentre essas diversas linhas de pesquisas têm-se as contribuições de áreas de vanguarda como sistemas distribuídos e computação paralela, quando são tratadas isoladamente ou mesmo quando abordadas de forma conjunta, por meio do que é conhecido como computação paralela distribuída.

Os sistemas computacionais distribuídos surgiram na década de 70, como uma evolução natural para substituir os sistemas centralizados (os tradicionais sistemas de compartilhamento de tempo), graças ao avanço registrado pela microeletrônica, que permitiu a integração em larga escala e com isso o aparecimento dos primeiros microprocessadores e, conseqüentemente, dos computadores pessoais. Esse fato possibilitou um aumento significativo no número de usuários de sistemas computacionais, fazendo com que os objetivos iniciais (compartilhamento de recursos e informações) dos sistemas distribuídos constituíssem uma realidade do dia a dia, cada vez mais ampla com a expansão constante da Internet. Novos 
objetivos, novas aplicações e novos desafios surgem, principalmente no que se refere à busca de melhor desempenho e melhor confiabilidade.

Com sua constante evolução, os sistemas distribuídos mostraram-se extremamente vantajosos e, em pouco tempo, conquistaram um lugar de destaque no cenário computacional. Ao longo dos tempos esses sistemas foram aprimorados a fim de oferecerem aos usuários sistemas amigáveis e com alto desempenho.

A computação paralela evoluiu de modo distinto aos sistemas distribuídos, sempre tendo como objetivo a redução do tempo de processamento em algumas classes de aplicações. Computação paralela e arquiteturas paralelas sempre foram assuntos conjugados, isto é, computação paralela sempre foi feita sobre arquiteturas paralelas.

Na década de 80, ficou claro para a comunidade envolvida com pesquisas em computação paralela e sistemas distribuídos, que a plataforma distribuída de um sistema fracamente acoplado, poderia ser utilizada com vantagens como uma arquitetura paralela do tipo MIMD (Multiple Instructions Multiple Data), surgindo o que se denominou de máquinas paralelas virtuais. Isso marca a convergência das áreas de pesquisa, com um melhor aproveitamento do hardware instalado nos sistemas distribuídos.

Embora a computação paralela e os sistemas distribuídos tenham surgido com objetivos diferentes, observou-se que um era complemento do outro, sob diferentes pontos de vista. Assim, poder-se-ia se unir a disponibilidade de hardware oferecido pelos sistemas distribuídos e o al to desempenho fornecido pelo processamento paralelo, originando o que atualmente se conhece por computação paralela distribuída.

Aliados a essa nova área, foram desenvolvidos softwares que viabilizassem os objetivos da computação paralela distribuída. Esses softwares, conhecidos por ambientes paralelos virtuais, permitem aos sistemas distribuídos desempenharem a função de uma máquina paralela (virtual).

As vantagens são evidentes, porém, junto a elas encontram-se diversos problemas. Dentre eles destaca-se o escalonamento de processos e suas implicações no desempenho final do sistema. No tocante ao escalonamento de processos, diversos trabalhos desenvolvidos nos últimos anos tiveram como foco principal o estudo e a apresentação de propostas para escalonar processos de maneira eficiente, utilizando-se para isso políticas de escalonamento específicas ou através da adoção de políticas genéricas. Essas e outras propostas têm contribuído sobremaneira na tentativa de oferecer melhores desempenhos para aplicações distribuídas e/ou paralelas distribuídas. 
Uma dessas propostas culminou no projeto e desenvolvimento de um ambiente de escalonamento flexível e dinâmico denominado AMIGO (dynAMical flexIble scheduling envirOnment) [Souza, 2000]. O ambiente AMIGO tem o intuito de possibilitar flexibilidade, transparência ao usuário e ganhos de desempenho através de políticas de escalonamento específicas para determinadas classes de aplicações. Inicialmente, essa proposta concentrouse no escalonamento de aplicações paralelas distribuídas desenvolvidas para softwares que permitem o desenvolvimento desse tipo de aplicação, como é o caso de PVM (Parallel Virtual Machine) [Beguelin et al., 1994] e LAM-MPI (Local Area Multicomputer-Message Passing Interface) [Burns \& Daoud, 1995]; [Snir et al., 1996]. No entanto, não foi descartada a utilização desse ambiente para aplicações (somente) distribuídas ou paralelas.

Para utilizar os serviços de escalonamento fornecidos pelo AMIGO, faz-se necessário implementar interfaces de comunicação entre esse ambiente e o software responsável pelo desenvolvimento/gerenciamento da aplicação. Em trabalhos anteriores desenvolvidos no.Grupo de Sistemas Distribuídos e Programação Concorrente do ICMC-USP, foram implementadas interfaces entre o AMIGO e os softwares PVM e LAM-MPI [Araújo, 1999]; [Figueiredo, 2000]. Os resultados obtidos nesses trabalhos mostraram a possibilidade de obter ganhos de desempenho quando adota-se um escalonamento aprimorado, que leva em consideração o tipo da aplicação que está sendo utilizada.

O trabalho apresentado nesta dissertação pode ser inserido, nesse contexto, uma vez que aborda a possibilidade de utilizar (através de uma interface de comunicação) o AMIGO com uma ferramenta que implementa a arquitetura CORBA [Schmidt \& Vinoski, 1995]; [Mowbray \& Malveau, 1997]; [Mowbray \& Ruh, 1997]. Com isso, o objetivo aqui considerado é permitir que aplicações desenvolvidas sobre a arquitetura CORBA possam também usufruir dos serviços do AMIGO e, conseqüentemente, alcançar melhor desempenho. Para tanto, houve a necessidade de serem adicionadas algumas características sobre uma ferramenta CORBA adotada, visando contemplar os requisitos definidos pelo AMIGO. Somente após a implementação dessas características é que foi possivel desenvolver a interface de comunicação.

Esta dissertação está organizada visando fornecer o embasamento necessário para contextualizar o trabalho, para discutir os diversos aspectos que envolveram o desenvolvimento do mesmo e, por fim, apresentar os resultados obtidos com relação ao desempenho de aplicações que utilizaram essa nova interface. Dessa forma, o texto dos próximos capítulos está organizado da seguinte maneira: 
- O Capítulo 2 aborda os conceitos gerais e mais relevantes sobre computação paralela e sistemas distribuídos, as vantagens e problemas encontrados na utilização da computação paralela distribuída e o funcionamento dos ambientes de passagem de mensagens;

- O ambiente de escalonamento AMIGO é apresentado no Capítulo 3. As primeiras seções do Capítulo 3 abordam as características de diversos softwares disponíveis para escalonamento de processos. Posteriormente, são apresentados alguns detalhes sobre o projeto e implementação do AMIGO, e comparações entre as principais características desse ambiente com as existentes em outros softwares de escalonamento. Nas últimas seções, comenta-se sobre a implementação das interfaces AMIGO-PVM e AMIGOMPI;

- O assunto principal do Capítulo 4 diz respeito à arquitetura CORBA. Esse Capítulo é dividido em seçōes que tratam sobre os principais componentes que compõem essa arquitetura, as possibilidades de realizar escalonamento e desenvolvimento de aplicações paralelas. Por fim, são apresentadas algumas opções de ferramentas/implementações CORBA disponíveis;

- O Capítulo 5 aborda o desenvolvimento da interface AMIGO-CORBA. Assim, algumas considerações são feitas sobre a ferramenta CORBA adotada, as decisões de projeto e os detalhes de implementação envolvendo a estrutura de suporte e a interface com o ambiente AMIGO;

- No Capítulo 6 são apresentados os resultados sobre a avaliação de desempenho realizada com aplicações TAO utilizando os recursos implementados no Capítulo 5 (estrutura de suporte e a interface AMIGO-CORBA). Além disso, discorre-se sobre os resultados obtidos com experimentos que utilizam o escalonamento round-robin e o AMIGO em um sistema com diferentes perfis de carga;

- Finalizando, as conclusões e contribuições do trabalho, as dificuldades encontradas durante o desenvolvimento do mesmo e as sugestões para trabalhos futuros são discutidas no Capítulo 7. 


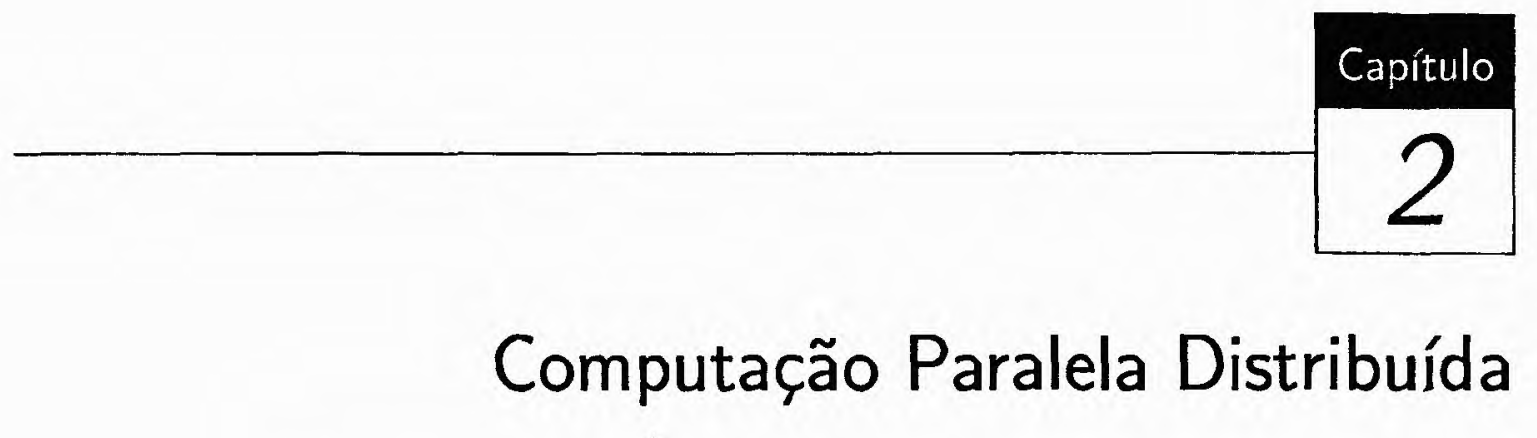

\subsection{Considerações iniciais}

Neste Capítulo são apresentados conceitos e características sobre computação paralela, programação concorrente, sistemas distribuídos e computação paralela distribuída, buscando também retratar as principais vantagens e o relacionamento existente entre essas áreas.

Além desses conceitos, abordam-se também os ambientes de passagem de mensagens, os quais fornecem os mecanismos necessários para a construção de aplicações paralelas sobre plataformas distribuídas.

\subsection{Computação Paralela}

Muitas das diversas áreas nas quais a computação se aplica requerem cada vez mais potência computacional, em virtude dos algoritmos complexos que são utilizados e do tamanho do conjunto de dados envolvido no processamento. Dessa forma, a busca por um melhor tempo de resposta e, conseqüentemente, um melhor desempenho na execução das aplicações, constitui o fator principal que impulsiona o desenvolvimento da computação paralela.

Segundo Almasi [Almasi \& Gottlieb, 1994], a computação paralela consiste, basicamente, em elementos de processamento, que cooperam e comunicam-se entre si para 
solucionarem problemas mais complexos, de maneira mais rápida do que se estivessem sendo solucionados seqüencialmente. Por essa definição pode-se notar que o fator motivador para a computação paralela é a constante busca por melhor desempenho. No entanto, essa motivação também ocasiona o surgimento de uma série de novas características (por exemplo, gerenciamento e organização dos processadores e manutenção da coerência da informação) que não são encontradas na computação seqüencial e que, dessa forma, contribuem para aumentar a complexidade da computação paralela.

\subsubsection{Conceitos básicos de Computação Paralela}

Os conceitos apresentados a seguir influenciam diretamente o desenvolvimento e o desempenho de aplicações paralelas.

\section{Paralelismo e Concorrência}

Segundo Almasi [Almasi \& Gottlieb, 1994], a concorrência existe quando, em um determinado instante, dojs ou mais processos (executando em um ou mais processadores) começaram a sua execução mas, devido à disputa pela utilização do processador e/ou outros recursos do sistema, ainda não terminaram. Essa definição induz a idéia de que pode existir concorrência em sistemas com um único processador ou com vários processadores.

Por outro lado, o paralelismo (ou paralelismo físico) só existe quando se tem mais de um processador e, portanto, mais de um processo é executado no mesmo intervalo de tempo. Dentre as várias formas de se classificar o paralelismo, têm-se [Cenapadne, 1999]:

- Paralelismo de Dados, onde o processador executa as mesmas instruções sobre dados diferentes;

- Paralelismo Funcional, onde o processador executa diferẹntes instruções que podem ou não operar sobre o mesmo conjunto de dados;

- Paralelismo de Objetos, que utiliza o conceito de objetos distribuídos por uma rede, capazes de serem acessados por métodos em diferentes processadores, para uma determinada finalidade.

\section{Níveis de Páralelismo}

O tamanho da tarefa executada pelo processador define o seu nível de paralelismo ou a sua granulosidade, que pode ser classificada em fina, média e grossa. 
A granulosidade fina indica um paralelismo em nível de operações, sendo geralmente implementada em hardware. Quando o paralelismo é atingido entre as subrotinas do programa, tem-se uma granulosidade média. Finalmente, quando se paralelizam processos, obtémse uma granulosidade grossa [Hwang \& Briggs, 1984]; [Navaux, 1989]; [Kirner, 1991]; [Almasi \& Gottlieb, 1994].

\section{Speedup e Eficiência}

O Speedup e a Eficiência são duas medidas utilizadas para verificar a qualidade dos algoritmos paralelos implementados. De maneira mais específica, essas medidas procuram mostrar a vantagem na utilização da computação paralela comparando a execução seqüencial com a paralela [Quinn, 1994]. O Speedup $(S p)$ fornece o ganho de velocidade quando se executa um determinado processo (paralelo) em p processadores, em relação à execução desse mesmo processo (seqüencial) em um processador, sendo calculado por:

$$
\mathrm{Sp}=\mathbf{T} 1 / \mathbf{T p}
$$

onde: $T 1$ é o tempo de èxecução em um processador e $T p$ é o tempo de execução em $p$ processadores.

A Eficiência $(E p)$ determina a taxa de utilização dos processadores e, assim, depende do Speedup alcançado, sendo calculado por:

$$
\operatorname{Ep}=\operatorname{Sp} / \mathbf{p}
$$

onde: $p$ é o número de processadores.

O ideal é obter $S P=p$ e $E p=1$. No entanto, fatores como sobrecarga de comunicação entre os processadores, parte estritamente seqüencial do código e granulosidade (de código) inadequada, podem interferir no resultado final, levando a uma eficiência não ideal.

\subsubsection{Arquiteturas Paralelas}

Por arquitetura paralela entende-se um sistema computacional com mais de um processador, capaz de executar mais de uma tarefa ao mesmo tempo. Devido à existência de inúmeras arquiteturas que apresentam características diferentes, foram propostas algumas classificações que agrupam arquiteturas com características comuns permitindo, assim, uma melhor definição quanto à diversidade de modelos existentes. 
Dentre as diversas classificações existentes, a classificação de Flynn [Flynn, 1972]; [Flynn \& Rudd, 1996] e de Duncan [Duncan, 1990] se destacam na literatura. A primeira, por ser uma proposta precursora no sentido de agrupar diferentes arquiteturas de computadores. A segunda, por apresentar sub-níveis de classificação e, assim, abranger uma maior quantidade de arquiteturas paralelas.

\section{Classificação de Flynn}

A classificação de Flynn baseia-se no fluxo de instruções e no fluxo de dados. Um fluxo de instruções equivale a uma sequiência de instruções executadas (em uma unidade de processamento) sobre um fluxo de dados aos quais essas instruções estão relacionadas [Flynn, 1972].

As arquiteturas, segundo a classificação de Flynn, estão divididas em quatro categorias:

\section{(1) SISD (Single Instruction Single Data Stream)}

A categoria SISD apresenta um único fluxo de instruções e de dados. Compreendem as máquinas de von Neumann, amplamente utilizadas, cuja execução é sequiencial. A Figura 2.1 apresenta um modelo da categoria SISD.

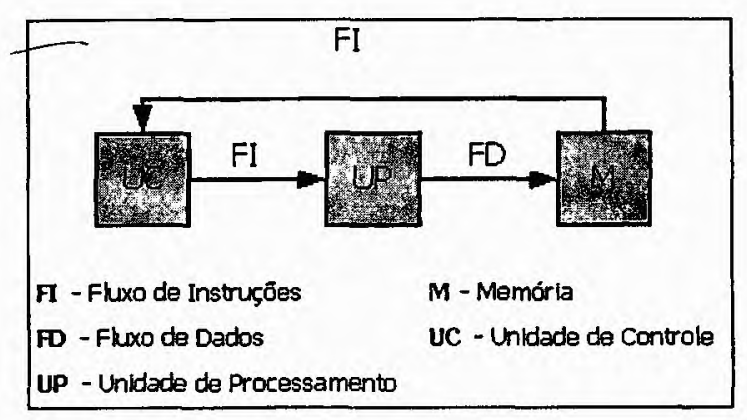

Figura 2.1: Categoria SISD

\section{(2) SIMD (Single Instruction Multiple Data Stream)}

A categoria SIMD apresenta um único fluxo de instruções atuando sobre múltiplos fluxos de dados. Dessa forma, essa arquitetura possui várias unidades de processamento supervisionadas por uma única unidade de controle, conforme pode ser observado na Figura 2.2. Nesse tipo de arquitetura encontram-se os processadores matriciais. 


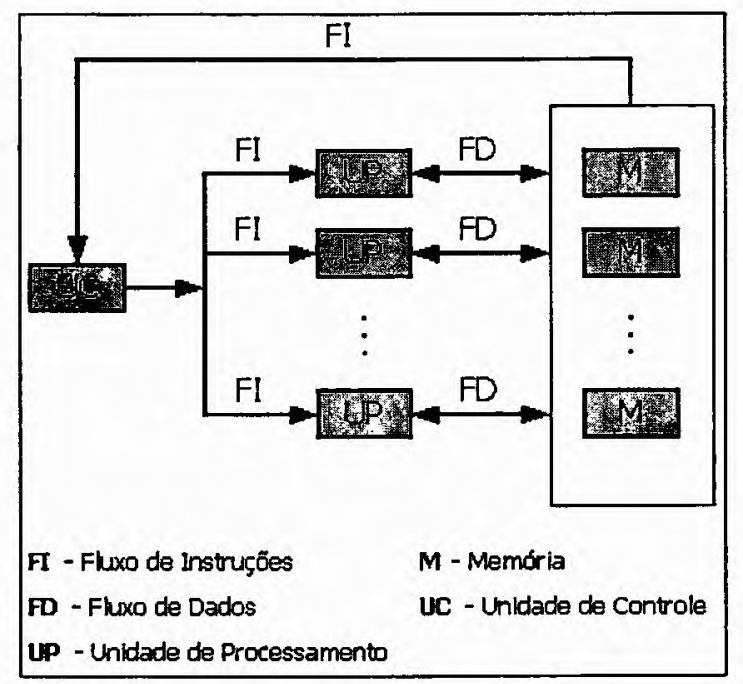

Figura 2.2: Categoria SIMD

\section{(3) MISD (Multiple Instruction Single Data Stream)}

A categoria MISD apresenta múltiplos fluxos de instruções atuando em um único fluxo de dados. Dessa forma, o fluxo de dados passaria por todas as unidades de processamento, sendo que o resultado de uma seria a entrada para a próxima unidade. Não existem exemplos precisos de máquinas MISD na literatura, entretanto, alguns autores [Navaux, 1989]; [Almasi \& Gottlieb, 1994] consideram o pipeline como representante dessa categoria. Baseando-se na idéia de pipelines a Figura 2.3 exemplifica a categoria MISD.

\section{(4) MIMD (Multiple Instruction Multiple Data Stream)}

A categoria MIMD apresenta múltiplos fluxos de instruçōes atuando em múltiplos fluxos de dados. Portanto, essa arquitetura envolve várias unidades de processamento executando diferentes instruções, em diferentes conjuntos de dados, de maneira independente. Englobam a maioria das arquiteturas paralelas. A Figura 2.4 apresenta um exemplo da categoria MIMD.

Segundo Duncan [Duncan, 1990], a classificação de Flynn não é abrangente o suficiente para incluir.alguns computadores modernos (como processadores vetoriais e máquinas a fluxo de dados) e não é facilmente extensível devido à falta de hierarquia da classificação (não apresenta sub-níveis). Com isso, há necessidade de definir e utilizar outras classificações visando contemplar arquiteturas mais modernas. 


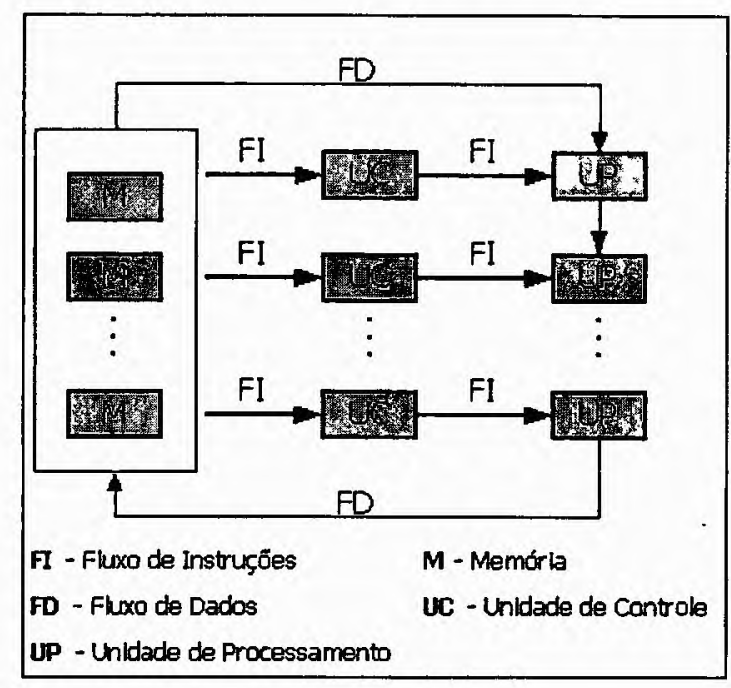

Figura 2.3: Categoria MISD

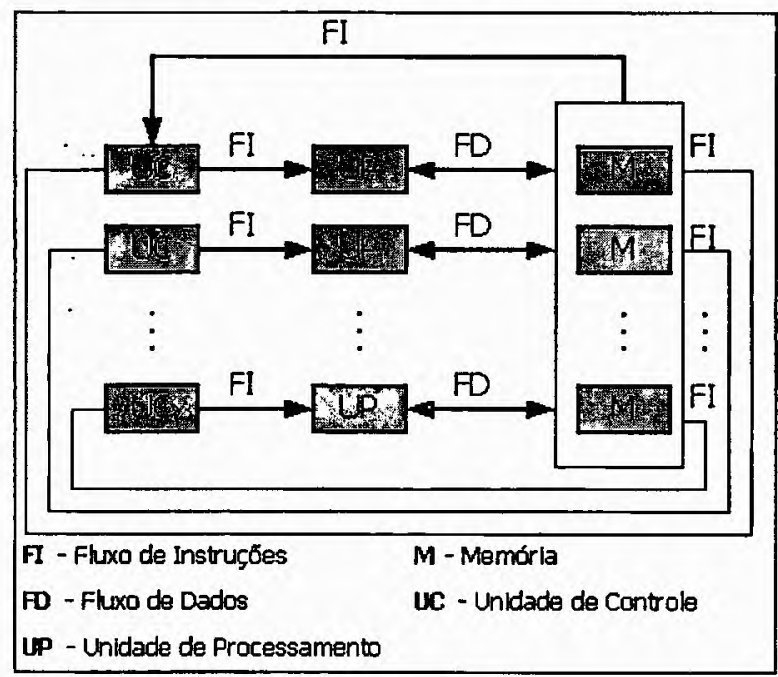

Figura 2.4: Categoria MIMD

\section{Classificação de Duncan}

A classificação de Duncan tem por objetivo remover a dificuldade de acomodar as novas arquiteturas dentro da classificação de Flynn, excluindo arquiteturas que apresentem apenas mecanismos de paralelismo de baixo nível, que já se tornaram lugar comum nos computadores modernos. 
Duncan [Duncan, 1990] propõe dois grandes grupos: Arquiteturas Síncronas, que coordenam suas operações concorrentes sincronamente em todas as unidades de processamento, através de relógios globais, e Arquiteturas Assíncronas, que caracterizam-se pelo controle descentralizado de hardware. As subdivisões desta classificação podem ser vistas na Figura 2.5.

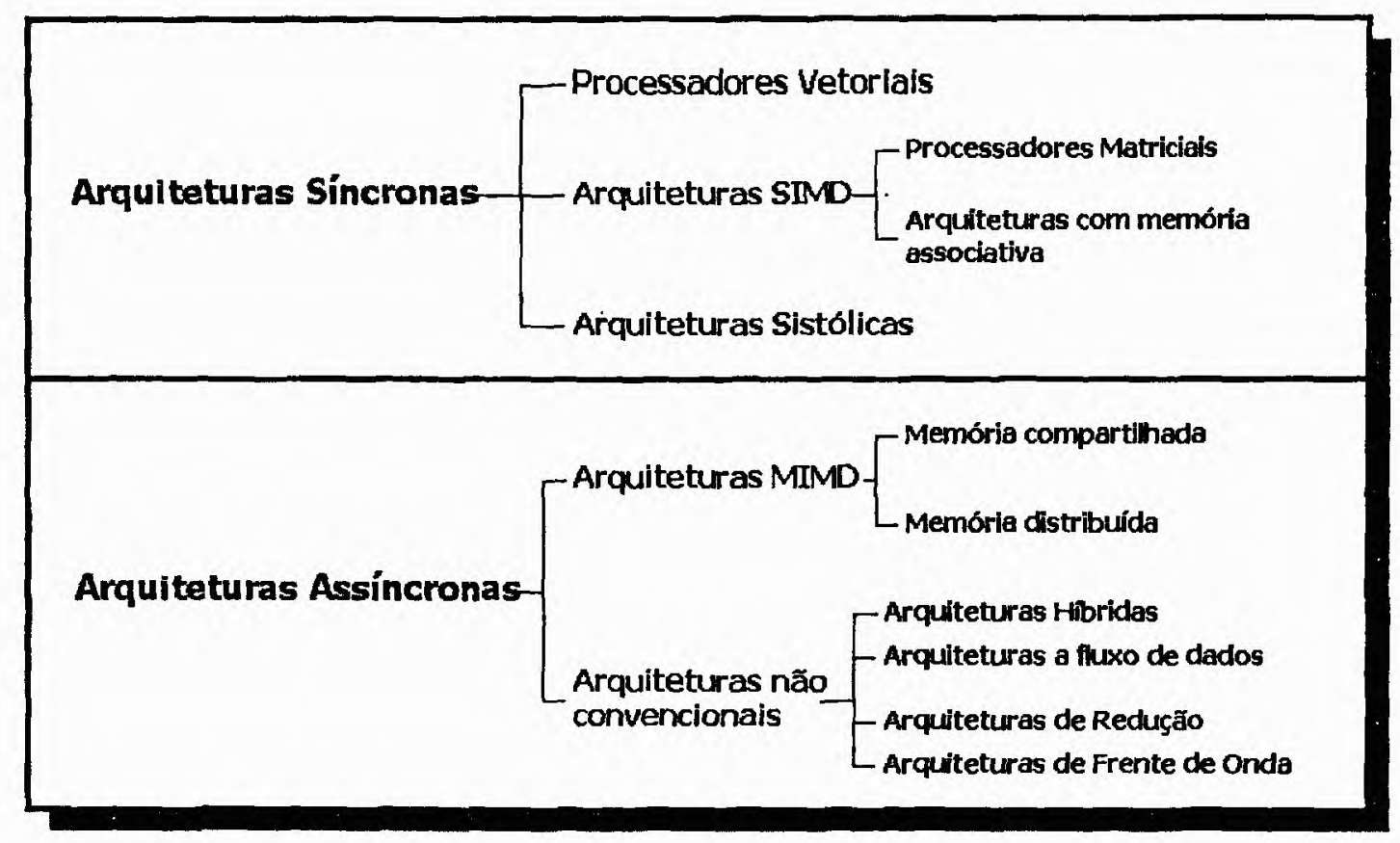

Figura 2.5: Classificação de Duncan

\section{(1) Arquiteturas Síncronas:}

- Processadores Vetoriais - possuem um hardware específico capaz de executar seqüências de instruçōes idênticas sobre vetores, de forma mais rápida do que uma seqüência de operações escalares.

- Arquiteturas SIMD - seguem o mesmo princípio já descrito na classificação de Flynn, em que há um único fluxo de instruçōes atuando sobre dados diferentes. Há uma única unidade de controle responsável por enviar uma instrução para os diversos processadores do sistema.

- Processadores matriciais são empregados em problemas onde devem ser realizados cálculos científicos intensos. 
- Arquiteturas com memória associativa utilizam uma lógica de comparação de acordo com o conteúdo da memória para acessar em paralelo os dados armazenados.

- Arquiteturas Sistólicas - possuem vários processadores enfileirados (pipeline), onde a informação trafega por todos eles antes de retornar à memória. O nome sistólica foi escolhido porque os dados são movimentados de processador a processador de forma síncrona.

(2) Arquiteturas Assíncronas:

- Arquiteturas MIMD - são formadas por várias unidades de processamento executando diferentes instruções sobre diferentes dados, conforme visto na classificação de Flynn. Porém, são subdivididas segundo a organização da memória, que determina o sincronismo e a forma de comunicação entre as unidades de processamento, podendo ser compartilhada (entre todos os processadores) ou distribuída (cada processador possui sua própria memória).

- Nas Arquiteturas MIMD com memória compartilhada (também chamadas multiprocessadores), a comunicação é baseada no compartilhamento de posições de memó ria. Um esquema hipotético desse tipo de arquitetura pode ser observado na Figura 2.6.

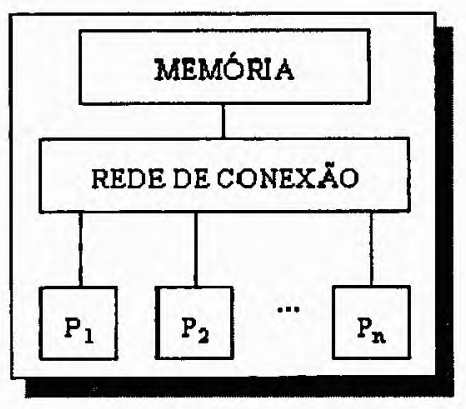

Figura 2.6: Arquitetura MIMD com memória compartilhada

- No caso de Arquiteturas MIMD com memória distribuída (ou multicomputadores), a comunicação é feita através de troca de mensagens por meio de uma rede de conexão. A Figura 2.7 representa um modelo hipotético desse tipo de arquitetura. 


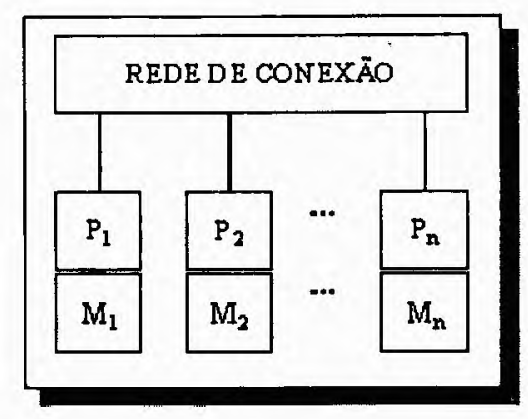

Figura 2.7: Arquitetura MIMD com memória distribuída

- Arquiteturas Não Convencionais - englobam arquiteturas que apresentam aspectos MIMD porém com características próprias, impedindo que sejam classificadas apenas como MIMD.

- As Arquiteturas Híbridas (MIMD/SIMD) são compostas basicamente por uma arquitetura MIMD que possui algumas partes controladas por mecanismos semelhantes aos existentes em máquinas SIMD.

- As Arquiteturas a Fluxo de Dados (dataflow) se caracterizam por habilitarem a execução das instruções apenas quando seus operandos estiverem disponiveis e, portanto, estão baseadas na dependência de dados.

- Arquiteturas de Redução (ou dirigidas por demanda) são assim chamadas, por substituírem porções do código fonte original de um programa pelo seu significado e, portanto, os processadores só executam os comandos quando as expressões necessitam do seu cálculo.

- As Arquiteturas de Frente de Onda caracterizam-se por apresentarem uma estrutura sistólica de processadores, combinada ao paradigma assíncrono de execução baseado no fluxo de dados.

Embora a classificação de Duncan apresente sub-níveis e, portanto, seja considerada mais completa, Flynn [Flynn \& Rudd, 1996] demonstrou que sua classificação pode também contemplar os diferentes tipos de computadores paralelos exemplificados por Duncan [Duncan, 1990]. Argumenta-se, assim, que ambas as classificações permitem uma visão geral dos estilos de organização para diferentes arquiteturas de computadores paralelos. 


\subsection{Programação Concorrente}

A programação concorrente é uma parte fundamental no apoio à construção de programas paralelos, pelo fato de oferecer recursos que podem ser utilizados visando obter melhor desempenho e melhor utilização do hardware paralelo disponível [Quinn, 1994].

Um programa concorrente especifica dois ou mais programas seqüenciais que podem ser executados, explorando a concorrência monoprocessadora (vários programas concorrendo pela execução em um único processador) ou multiprocessadora (vários programas concorrendo pela execução em mais de um processador). No que diz respeito à concorrência multiprocessadora, Quinn [Quinn, 1994] sugere três maneiras de se construir um algoritmo paralelo:

- Detectar e explorar algum paralelismo inerente a um algoritmo seqüencial existente. Essa estratégia apresenta baixo speedup, mas é bastante utilizada;

- Criar um algoritmo paralelo novo. Essa é a técnica que possibilita melhor desempenho necessitando, porém, de uma reestruturação completa do algoritmo;

- Adaptar outro algoritmo paralelo que resolva um problema similar. Nesse caso, tem-se bom desempenho, exigindo menor trabalho do programador em relação à construção completa do algoritmo.

De forma geral, pode-se argumentar que a programação concorrente é regida pela idéia de dividir determinadas aplicações em partes menores e que cada parcela resolva uma porção do problema. Assim, a programação concorrente pode ser considerada como outra manifestação da técnica "dividir e conquistar" para construção de programas [Snow, 1992]. Entretanto, para essa divisão, há a necessidade de certos recursos adicionais, como: ativação, comunicação e sincronização de processos, não necessários na programação seqüencial.

Para que os processos concorrentes sejam ativados, há necessidade de um conjunto de ferramentas que determine exatamente que porção do código será paralela e qual será seqüencial. Inúmeras construções para a ativação e término de processos concorrentes têm sido propostas, apresentando características e finalidades distintas [Almasi \& Gottlieb, 1994]. Alguns exemplos dessas construções são: corotinas, utilizadas para ativação de processos concorrentes sob um único processador, fork/join e cobegin/coend, para a ativação de processos paralelos e doall para a ativação paralela de instâncias de loops [Snow, 1992]; [Almasi \& Gottlieb, 1994]. 
Outro fator que exerce influência sobre a programação concorrente é a coordenação e especificação da interação entre os processos, pois os processos que cooperam entre si para a resolução de um determinado problema, devem comunicar-se e sincronizar-se, a fim de que ocorra alguma interação entre eles.

Nesse sentido, a comunicação possibilita que um processo em execução possa comunicar-se com outro, ou pelo uso de variáveis compartilhadas (em memória compartilhada), ou através de passagem de mensagem (em memória distribuída).

A sincronização se faz importante para que o acesso simultâneo não torne os dados, que são compartilhados, inconsistentes e para que seja possível o controle na seqüência da execução paralela. No caso de sincronização em arquiteturas com memória compartilhada pode-se fazer uso de mecanismos como espera ocupada (busy-waiting), semáforos e monitores. No caso de arquiteturas com memória distribuída a sincronização pode ocorrer através de mecanismos de troca de mensagens, por exemplo: RPC (Remote Procedure Call-Chamadas de Procedimentos Remotos), Rendezvous e Comunicaçāo Ponto-a-Ponto [Quinn, 1994]; [Snow, 1992]; [Almasi \& Gottlieb, 1994].

Conhecendo-se os mecanismos de ativação de processos concorrentes e de comunicação, um ponto extremamente importante é a escolha do tipo de ferramenta que será usada para a construção de um programa fonte, que represente o algoritmo paralelo. Essas ferramentas podem ser: linguagens de programação concorrente, ambientes de paralelização automática e ambientes de passagem de mensagens.

As linguagens de programação contêm os comandos específicos que os algoritmos paralelos necessitam. Os ambientes de paralelização automática possibilitam "traduzir" um programa seqüencial em um paralelo sem a necessidade de interferência por parte do programador. Os ambientes de passagem de mensagem (ou interfaces de passagem de mensagem) são compostos por bibliotecas de comunicação que implementam os mecanismos necessários à execução paralela, agindo como extensões das linguagens seqüenciais existentes [Almasi \& Gottlieb, 1994].

De forma.geral, a escolha por uma dessas ferramentas deve levar em conta diversos fatores, como: características de comunicação e processamento da aplicação paralela, a arquitetura de computador adotada e o tipo de usuário (programador) que utilizará a ferramenta. Ainda com relação a essa escolha, Almasi [Almasi \& Gottlieb, 1994] comenta que o programador deve também levar em conta o tempo de aprendizado e o desempenho 
desejado com a aplicação paralela, uma vez que uma relação adequada entre esses dois fatores deve ser alcançada com a ferramenta escolhida.

\subsection{Sistemas Distribuídos}

Os avanços tecnológicos ocorridos durante a década de 80 tiveram, de maneira geral, grande influência sobre a computação. A área de sistemas distribuídos também foi participante do desenvolvimento ocorrido nessa época, motivada principalmente por dois aspectos: o desenvolvimento e disponibilidade de microprocessadores mais potentes e de menor custo e o avanço na tecnologia de comunicação de dados, propiciando, assim, a utilização de redes de computadores de alta velocidade [Coulouris et al., 1994]; [Tanenbaum, 1995]. Esses dois aspectos têm estimulado consideravelmente o interesse na utilização de sistemas distribuídos, em razão de que tais sistemas possuem diversas vantagens quando comparados aos sistemas centralizados. Algumas dessas vantagens são o alto desempenho, a disponibilidade de recursos e a extensibilidade a um baixo custo [Shivaratri et al., 1992]; [Tanenbaum, 1995].

Apesar de serem amplamente disseminados atualmente e existirem diversas linhas de pesquisas, verifica-se que não há um consenso sobre uma definição única e exata para sistemas distribuídos. Mesmo diante da divergência quanto ao conceito, há alguns pontos (por exemplo, interligação de computadores através de uma rede de comunicação e o gerenciamento por um software de sistema distribuído) em comum que sempre são apresentados no que diz respeito a sistemas distribuídos. Isso pode ser notado pela definição de Coulouris [Coulouris et al., 1994] dada a seguir:

"Um sistema distribuído consiste em um conjunto de computadores autônomos interligados por uma rede de comunicação e equipados com um sistema operacional distribuído. Esse sistema operacional distribuído é o responsável por coordenar as atividades desenvolvidas e compartilhar os recursos do sistema (como hardware, software e dados)."

Assim, como no caso da definição, diversos autores descrevem um conjunto de características que um sistema deve possuir para que possa ser considerado distribuído. Dentre as principais, destacam-se [Tanenbaum \& Renesse, 1985]; [Coulouris et al., 1994]:

- Compartilhamento de recursos - constitui uma das características fundamentais dos sistemas distribuídos, cuja finalidade é disponibilizar aos usuários os componentes de hardware e de software do sistema. O principal objetivo concentra-se na melhor utilização dos componentes e redução de custos; 
- Transparência - a transparência está relacionada com a visão que os usuários e o desenvolvedor da aplicação têm do sistema. Dessa forma, um sistema é considerado transparente se é percebido (por seus usuários) como um "todo" ao invés de uma coleção de elementos independentes;

- Tolerância a falhas - consiste em evitar que possíveis falhas no sistema produzam resultados incorretos ou dados inconsistentes. Isso pode ser feito considerando-se aspectos como redundância de hardware (replicação de componentes) e recuperação de software (programas para recuperação de falhas);

- Escalabilidade - essa característica descreve a possibilidade de aumentar a capacidade computacional de um sistema sem grandes alterações no que se refere aos seus aspectos de hardware e software. Nesse sentido, o projeto de um sistema que contempla a escalabilidade deve também tratar do desempenho envolvendo o software e hardware (incluindo a rede de interconexão) utilizados. Assim, deseja-se que o sistema distribuído possa atender as demandas por escalabilidade, sem, no entanto, haver degradações no desempenho;

- Concorrência - ocorre quando os processos disputam pela utilização dos recursos (necessariamente o número de processos deve ser maior que o número de recursos disponíveis);

- Abertura - um sistema é considerado aberto se novos recursos (hardware ou software) podem ser facilmente adicionados a ele sem causar prejuízo aos módulos já existentes.

Embora essas características possam variar de autor para autor, notam-se que três delas, compartilhamento de recursos, transparência e tolerância a falhas, são amplamente citadas e, assim, constituem partes fundamentais para o desenvolvimento dos sistemas distribuídos.

Além dos conceitos e características, é importante destacar também os modelos arquiteturais, as redes de comunicação e a comunicação entre processos, pois esses tópicos exercem grande influência sobre a implementação e o desempenho dos sistemas distribuídos.

\subsubsection{Modelos arquiteturais}

Há diversos modelos arquiteturais para a implementação de sistemas distribuídos, variando suas características de software e hardware, destacando-se [Mullender, 1993]; [Coulouris et al., 1994]; [Tanenbaum, 1995]: 
1. Estação de Trabalho/Servidor - Consiste em estações de trabalho interligadas através de uma rede de comunicação, onde máquinas com melhores configurações operam, geralmente, como servidores do sistema e máquinas mais simples são utilizadas para executar aplicações de usuários. Esse modelo apresenta como inconveniente variações na potência computacional do sistema (que ora pode estar ociosa, ora insuficiente para a aplicação), porém possui baixo custo de implementação.

2. Banco de Processadores - Consiste em um conjunto de terminais e um banco de processadores, onde um ou mais processadores podem ser alocados conforme a necessidade da aplicação e, posteriormente, liberados para utilização por outros usuários. É necessário um servidor de processamento que controle a alocação e liberação dos processadores. Esse modelo otimiza a potência computacional do sistema, porém mostra-se inadequado para aplicações muito interativas, devido ao tráfego gerado na rede.

3. Modelo Híbrido - Representa a combinação do modelo Estação de Trabalho/Servidor com o modelo Banco de Processadores, explorando as vantagens de ambos e minimizando suas desvantagens.

4. Modelo Integrado - Desenvolvido para interligar minicomputadores com estações de trabalho e terminais através de uma rede de comunicação, onde cada computador possui software adequado para desempenhar as funções de servidor e de execução das aplicações.

O modelo preferencial é, sem dúvida, o modelo Estação de Trabalho/Servidor por atender a maioria das necessidades dos usuários e por apresentar relativo baixo custo. No entanto, a tendência é expandir o modelo Estação de Trabalho/Servidor com o uso de estações inativas, com o objetivo de fazer com que máquinas ociosas ou com baixas cargas de processamento funcionem como um banco de processadores temporário. Uma outra tendência busca sedimentar o modelo Orientado a Objetos (que utiliza o paradigma da orientação a objetos), generalizando os conceitos envolvidos no modelo Estação de Trabalho/Servidor.

\subsubsection{Redes de Comunicação}

Os sistemas distribuídos podem ser considerados uma arquitetura MIMD com memória distribuída sendo necessário, portanto, uma rede de comunicação que permita a conexão entre as unidades de processamento independentes. 
Essa rede de comunicação pode ser dedicada (geralmente utilizada em computadores paralelos para comunicação entre os processadores, por apresentar alto desempenho e confiabilidade) ou de propósito geral (correspondendo às redes de computadores). Em se tratando de sistemas distribuídos, houve uma demanda pela adoção de redes de computadores em razão da evolução na velocidade de comunicação e a considerável redução dos custos [Coulouris et al., 1994].

\subsubsection{Comunicação entre Processos}

A comunicação entre processos envolve operações de transferência de dados e sincronização. Em sistemas distribuídos, a comunicação é feita via troca de mensagens, através das primitivas send (para transmissão) e receive (para recepção). Cada ação de passagem de mensagem envolve a transmissão de um conjunto de dados (de um processo) através de um mecanismo de comunicação (canal ou porta) e o recebimento da mensagem por outro processo envolvido na transação.

O mecanismo de comunicaçã̀o pode ser síncrono (bloqueante) ou assíncrono (nãobloqueante) [Coulouris et al., 1994]. No mecanismo síncrono, os processos encontram-se sincronizados em todas as mensagens envolvidas, de maneira que o processo emissor deve esperar (ficar bloqueado) até que o correspondente receptor esteja apto a receber a mensagem. Por outro lado, no mecanismo assíncrono o processo transmissor não é bloqueado quando sua mensagem é enviada. Para tanto, faz-se uso de um buffer (ou fila) para armazenamento temporário das mensagens .

Os padrões de comunicação mais utilizados na construção de sistemas distribuídos são a comunicação cliente/servidor e a comunicação em grupo.

A comunicação cliente/servidor consiste, basicamente, em um processo cliente solicitando um serviço a um processo servidor, cuja função é executar o pedido e enviar uma mensagem ao cliente como resposta. Um mecanismo bastante utilizado nesse tipo de comunicação é o RPC cujo objetivo é esconder do usuário as técnicas utilizadas para realizar as trocas de mensagens entre processos que estão espalhados pela rede [Stevens, 1996].

A comunicação em grupo é utilizada quando há necessidade de um processo comunicar-se com um grupo de processos, com o intuito de se obter maior tolerância a falhas e maior disponibilidade de recursos. 


\subsection{Computação Paralela sobre Sistemas Distribuídos}

Como já discutido na Seção 2.2 a Computação Paralela possui a vantagem do alto desempenho, embora fatores como alto custo de aquisição e manutenção e, principalmente, dependência ao fabricante têm dificultado sua ampla utilização. Com isso, a utilização dos sistemas distribuídos como plataforma de execução para aplicações paralelas, fornecendo menor custo de implantação, tornou-se viável nos últimos anos, favorecendo fortemente o desenvolvimento da computação paralela em vários domínios de aplicaçōes.

A idéia básica é possuir um grupo de computadores interligados, funcionando como unidades de processamento de uma máquina paralela [Souza, 1996b]. Isso é possível através da utilização de ambientes de passagem de mensagens (também conhecidos por ambientes paralelos virtuais). Uma das principais funcionalidades desses ambientes de passagem de mensagens está em apresentar, ao usuário, o sistema distribuído como se fosse uma única máquina com diversos elementos de processamento. Além disso, tais ambientes devem também tratar dos vários tipos de heterogeneidade encontrados, por exemplo: tipos arquiteturais de cada máquina (CISC ou RISC), formato de dados, potência computacional e carga de trabalho. Por fim, fatores como mecanismos de escalonamento de processos e balanceamento de carga são freqüentemente tratados por esses ambientes, em razão de estarem diretamente relacionados ao desempenho obtido nesse tipo de arquitetura.

\subsection{Ambientes de passagem de mensagens}

Um ambiente de passagem de mensagens consiste basicamente em uma biblioteca de comunicação que, atuando como uma extensão das linguagens seqüenciais (como C e Fortran, por exemplo), permite a construção de aplicações paralelas [Souza, 1996b].

Há um conjunto de rotinas básicas necessárias para a formação de uma biblioteca de comunicação:

- Rotinas de Comunicação Ponto-a-Ponto, responsáveis pela transferência de mensagens entre exatamente dois processos, um transmissor e um receptor;

- Rotinas Coletivas, que se caracterizam pela presença de dois ou mais processos em cada operação de comunicação;

- Rotinas Probe, responsáveis por verificar se uma determinada mensagem já foi recebida; 
- Rotinas Informativas, responsáveis pelo retorno de informações a respeito da última mensagem recebida.

Inicialmente, os ambientes de passagem de mensagem foram desenvolvidos para máquinas com processamento maciçamente paralelo (Massively Parallel Processing - MPP), para efetuar a comunicação entre os diversos processadores. Segundo essa abordagem, tais ambientes estavam diretamente ligados à arquitetura de hardware de seu fabricante e, portanto, não levavam em consideração a portabilidade do software gerado.

Dessa forma, os ambientes de passagem de mensagens foram remodelados objetivando a utilização do potencial dos sistemas distribuídos, a união de plataformas heterogêneas e a portabilidade das aplicações paralelas desenvolvidas.

Fundamentados nesses objetivos, surgiram os ambientes de passagem de mensagens com plataforma portátil e, portanto, independentes da máquina a ser utilizada. Como exemplos destes ambientes, tem-se: Express [Flower \& Kolawa, 1994], Linda [Carriero et al., 1994], P4 [Butler \& Lusk, 1994], PARMACS [Calkin et al., 1994], Zip Code [Skhellum et al., 1994], MPI [Burns \& Daoud, 1995] [Macdonald et al., 1997] e PVM [Beguelin et al., 1994]. Dentre esses, destacam-se o PVM (Parallel Virtual Machine)-devido à sua grande aceitação e utilização e o MPI (Message Passing Interface) que é, na verdade, uma especificação para o desenvolvimento de ambientes de passagem de mensagens.

\subsection{Considerações finais}

Há tempos a computação paralela se faz necessária para solucionar problemas que necessitam de melhor desempenho de execução. No entanto, o alto custo do hardware e a dificuldade em se encontrar software de desenvolvimento para aplicações paralelas constituíam um grande obstáculo. Assim, procurou-se uma maneira de conciliar o alto desempenho, através do uso de processamento paralelo, e o baixo custo da plataforma (hardware) a ser utilizada, com a adoção de sistemas distribuídos. A idéia mostrou-se extremamente vantajosa, de modo que a computação paralela distribuída foi amplamente disseminada, levando à necessidade de se desenvolver ambientes que possibilitassem aos vários elementos de processamento serem utilizados para formação de uma máquina paralela.

O uso de computação paralela sobre sistemas distribuídos, trouxe também diversas questões que devem ser analisadas de maneira diferente, uma vez que os elementos de processamento não estão, necessariamente, tão próximos quanto no caso de computadores paralelos. Um desses problemas diz respeito ao escalonamento de processos, pois, no caso de 
escalonamento em sistemas paralelos distribuídos, questões como: a seleção do processador, o momento de realizar o escalonamento e a seleção da carga de trabalho, podem comprometer o desempenho do sistema se não forem cuidadosamente analisadas.

Ainda com relação à problemática do escalonamento de processos, foi desenvolvido no Laboratório de Sistemas Distribuídos e Programação Concorrente do ICMC-USP um ambiente para gerenciamento do escalonamento de processos denominado AMIGO (dynAMical flexIble schedulinG envirOnment), cujo objetivo é gerenciar a tarefa de escalonar processos em plataformas distribuídas, de maneira transparente ao usuário. Devido à sua importância para este trabalho, o AMIGO será discutido em mais detalhes no Capítulo a seguir. 


\section{Capítulo}

\section{3}

\section{O ambiente de escalonamento AMIGO}

\subsection{Considerações iniciais}

Como já mencionado no Capítulo anterior, uma das principais motivações para a realização da computação paralela é a busca por melhor desempenho. Em se tratando de computação paralela distribuída essa motivação ainda persiste e, com isso, diversos fatores são discutidos uma vez que podem afetar sobremaneira o desempenho das aplicações. Um desses fatores refere-se ao escalonamento de processos, pois, escalonar processos em ambientes distribuídos é uma tarefa complexa e que muitas vezes envolve objetivos divergentes.

Com isso, diversos projetos têm como foco principal o desenvolvimento de softwares que realizem o escalonamento de aplicações em ambientes distribuídos. Dentre os diversos projetos de ambientes de escalonamento encontradas na literatura, podem ser citados: Codine [Kaplan \& Nelson, 1994], Condor [Basney \& Livny, 1999], LSF [Suplick, 1994] e LoadLeveler [IBM, 2000], devido à disseminação que possuem junto à comunidade da área. Além desses, um outro projeto refere-se ao AMIGO (dynAMical flexIble schedulinG envirOnment) [Souza et al., 1999a], um software que atua na gerência do escalonamento de aplicações em sistemas distribuídos procurando unir características como transparência e melhor desempenho para aplicações paralelas distribuídas.

O AMIGO foi especificado e parcialmente implementado através do trabalho de doutorado de Souza [Souza, 2000], e dos trabalhos de mestrado de Araújo [Araújo, 1999], Figueiredo [Figueiredo, 2000] e Campos [Campos, 2001], sendo também uma das bases para o desenvolvimento do presente trabalho. 
A partir do exposto, este Capítulo aborda a atividade de escalonamento de aplicações em plataformas distribuídas através das características de alguns softwares que realizam essa atividade. Em particular, é atribuída maior ênfase aos conceitos, características e definições de projeto e implementação do ambiente AMIGO em razão de sua inerente importância para este trabalho. Visando também comparar as diversas propostas de softwares de escalonamento discutidas ao longo do Capítulo, apresenta-se na Seção 3.3.3 uma tabela comparativa contendo as principais características desses softwares, seguida por uma discussão sobre as diferenças e semelhanças encontradas.

\subsection{Softwares para escalonamento de aplicações}

Os softwares para escalonamento de aplicações são responsáveis, de maneira geral, pela distribuição de aplicações entre as máquinas ${ }^{1}$ de acordo com um ou mais objetivos definidos. Devido à importância desses softwares em áreas como sistemas operacionais, sistemas distribuídos e computação paralela e a complexidade no provimento de funcionalidades, diversos trabalhos [Shivaratri et al., 1992]; [Kaplan \& Nelson, 1994]; [Suplick, 1994]; [Basney \& Livny, 1999]; [Souzá et al., 1999a]; [IBM, 2000]; [Othman et al., 2001] foram desenvolvidos objetivando contribuir para o desenvolvimento da atividade de escalonamento. Além disso, a disseminação dos sistemas distribuídos motivada pelo constante avariço nas tecnologias e pesquisas da área e ao crescente número de usuários, fizeram com que a escolha pela adoção de um software de escalonamento assumisse um papel de destaque tanto para desenvolvedores de aplicações, como também para administradores de sistemas.

A importância em verificar as diversas características de softwares escalonadores pode ser observada em trabalhos como o de [Suplick, 1994], que apresenta o resultado de uma pesquisa realizada com usuários, em que foram apontadas 25 características "desejáveis" para esses softwares. O trabalho de Kaplan [Kaplan \& Nelson, 1994] também preocupou-se em retratar as diversas características de softwares de escalonamento, através da apresentação de resultados que servissem de base para a escolha entre uma ou outra opção. Para alcançar esse objetivo, foram avaliados 12 desses softwares procurando verificar suas principais funcionalidades, limitações e recursos adicionais.

Visando ter um referencial para comparação com o ambiente AMIGO, discutem-se a seguir as funcionalidades de alguns softwares para escalonamento de aplicações. A escolha por

\footnotetext{
${ }^{1} \mathrm{O}$ termo "máquina" é comumente encontrado na literatura da área de sistemas distribuídos. No contexto de computação paralela, o termo geralmente utilizado é elemento de processamento (EP) ou host.
} 
um conjunto restrito de softwares foi motivada por fatores como a documentação disponivel, características implementadas e a ampla disseminação junto à comunidade da área.

\subsubsection{LoadLeveler}

LoadLeveler é um ambiente comercial para escalonamento de tarefas, mantido pela IBM e utilizado principalmente em máquinas SP2 (Scalable PowerParallel) em conjunto com as ferramentas PVMe ou AIX Parallel Environment [Suplick, 1994]. De maneira geral, esse ambiente é formado por processos daemons (responsáveis pelo controle das aplicações escalonadas nesse EP) que executam em cada elemento de processamento (EP), e diversos utilitários que realizam atividades como escalonamento, monitoramento de tarefas e alocação de recursos.

Para realizar o escalonamento, o usuário deve criar um arquivo de comandos (command file) indicando quais processos devem ser escalonados. Esse usuário pode ainda configurar recursos (como memória, sistema operacional, quantidade de espaço em disco) necessários para a execução de sua aplicação. As métricas utilizadas para realizar o escalonamento podem variar de acordo com os parâmetros fornecidọs. Essas métrịcas podem ser baseadas na carga do processador, na quantidade de memória, na disponibịlidade do espaço em disco, ou mesmo no período de tempo em que dispositivos de entrada não foram utilizados pelo usuário [IBM, 2000].

Os elementos de processamento pertencentes à plataforma distribuída são constantemente monitorados através de processos daemons LoadLeveler na tentativa de identificar possíveis falhas, atividades de usuários interativos ou mesmo um aumento na carga de trabalho.

Uma outra característica importante refere-se à possibilidade de configurar políticas de escalonamento durante a execução. Essa característica possibilita que diferentes classes de aplicações sejam executadas simultaneamente no sistema, sem a necessidade de reiniciar o ambiente de escalonamento.

A migração de tarefas também é contemplada pelo LoadLeveler. No entanto, aplicações que necessitam manipular (ler, gravar, abrir e fechar) arquivos devem realizar operações idempotentes, além de evitar o uso de chamadas de criação (como fork e exec) e comunicação (como signal, sigvec, $\dot{k}_{i l l}$ ) de processos. 


\subsubsection{Load Sharing Facility (LSF)}

LSF é um ambiente de escalonamento mantido pela empresa Platform [Suplick, 1994]. Pode ser utilizado com uma variedade de sistemas operacionais (SunOS, SGI IRIX, ULTRIX, ConvexOS) e ferramentas para desenvolvimento de aplicaçōes paralelas e distribuídas (PVM, P4, Linda e HPF). A arquitetura desse ambiente é organizada de maneira hierárquica. Há sempre um daemon mestre, podendo existir um ou mais (conforme o número de elementos de processamento) daemons escravos. O mestre é essencial para o funcionamento do ambiente, em razão de ser o responsável pelo escalonamento das aplicações e por iniciar e remover os escravos. Caso esse daemon mestre termine a execução de forma anormal, os escravos negociam entre si para que um novo mestre seja eleito.

No LSF, o escalonamento ocorre em duas etapas: a primeira consiste em encontrar um conjunto de máquinas adequadas de acordo com os requerimentos dos usuários; a segunda consiste em selecionar a(s) melhor(es) máquina(s) desse conjunto. Essa seleção pode ser baseada em fatores como tamanho da fila, taxa de utilização do processador, número de sessões de login e memória virtual disponível.

Assim como já ocorre com o LoadLeveler, o ambiente LSF também pode suspender a execução de tarefas quando ocorrerem alterações no estado (sessões de login, número de tarefas em execução, entre outros) de um host ou elemento de processamento. Além de suspender, o LSF pode migrar a tarefa para um host que esteja menos carregado.

Além dessas características, LSF também possibilita a mudança de diversas configuraçōes, introduzidas pelo usuário, em tempo de execução.

\subsubsection{Condor}

O ambiente Condor é um software de domínio público desenvolvido por pesquisadores da Universidade de Wisconsin e do Laboratório Brookhaven [Suplick, 1994]. A motivação principal para o projeto e desenvolvimento desse ambiente consiste na possibilidade de utilizar a potência computacional das máquinas ociosas para execução de aplicações dos usuários [Basney \& Livny, 1999]. Para atingir tal objetivo, esse ambiente monitora as atividades realizadas pelas máquinas que compõem o sistema distribuído. Aquelas identificadas como "ociosas" são colocadas em um banco de processadores e, posteriormente, podem ser utilizadas pelo escalonador a medida que requisições são recebidas.

A identificação de máquinas disponíveis para escalonamento é baseada na verificação da utilização dos dispositivos de entrada e no tamanho da fila processos prontos no processador. 
O usuário do ambiente Condor pode especificar os recursos necessários para sua aplicação. Alguns exemplos desses recursos são: arquitetura de hardware, quantidade de memória e sistema operacional. Caso uma máquina, que esteja executando uma aplicação, fique saturada devido a um aumento na sua taxa de utilização ou atividade dos dispositivos de entrada, o ambiente Condor pode suspender essa aplicação e migrá-la para alguma outra máquina disponível.

Uma funcionalidade atrativa nesse ambiente diz respeito à recuperação de aplicações que, por algum motivo, falharam durante a execução. Essa funcionalidade é alcançada através de mecanismos checkpointers $^{2}$ que armazenam informações sobre o estado da aplicação, de maneira que o software de escalonamento tenha condições de reiniciá-la a partir dessas informações armazenadas antes da falha.

Condor também possibilita alterações em tempo de execução, em seus parâmetros de configuração e nas políticas de escalonamento.

\subsubsection{CODINE}

O ambiente CODINE (COmputing in DIstributed Networked Environments) é um software comercial mantido pela empresa Genias Software e.tem como objetivo principal propiciar uma melhor utilização dos recursos computacionais existentes em um sistema distribuído heterogêneo [Kaplan \& Nelson, 1994]. Esse ambiente possui implementações para diferentes arquiteturas de hardware e sistemas operacionais como ConvexOS, Cray UNICOS, HP-UX, DEC OSF/1, IBM AIX, entre outros.

A atividade de escalonamento é baseada em seleção de filas e divide-se em dois estágios. O primeiro consiste em escalonar aplicações de acordo com a ordem das filas. $\mathrm{O}$ segundo consiste em verificar a carga (baseada na taxa de utilização ou o número de processos prontos na fila do processador) de cada máquina em um grupo a fim de identificar qual é a menos carregada e, portanto, que deve receber a aplicação. CODINE oferece diferentes configurações tanto para o primeiro quanto para o segundo estágio de escalonamento. Essas configuraçōes podem ser escolhidas durante a execução do ambiente.

De forma geral, o escalonamento é realizado depois que o escalonador mestre encontra todas as filas que satisfazem as requisições de recursos feitas pelo usuário. Essas requisições são organizadas em duas categorias: hard e soft. A primeira compreende os recursos que devem ser encontrados antes que a aplicação inicie a execução. A segunda compreende os

\footnotetext{
${ }^{2}$ Os ambientes Codine e Loadleveler também oferecem o recurso de checkpointers.
} 
recursos que, se estiverem disponíveis, podem ser alocados para as aplicações. No entanto, essas aplicações ainda podem ser executadas sem eles.

Um usuário do ambiente CODINE possui diversas opções de configuração, que podem variar desde a especificação dos recursos computacionais exigidos pela aplicação até a permissão/restrição de uso das filas. Além disso, informações sobre usuários, filas, máquinas do sistema distribuído e políticas de escalonamento podem ser configuradas durante a execução do ambiente.

A migração de tarefas pode também ser realizada, a partir do instante em que uma máquina seja considerada sobrecarregada (de acordo com um valor limite) ou quando detectase a utilização de dispositivos de entrada. Caso não seja encontrada uma máquina disponível para migração, a aplicação será suspensa até que a carga fique abaixo de um valor mínimo.

\subsubsection{Load Balancer}

Load Balancer é uma ferramenta para escalonamento de aplicações em uma rede de computadores executando o sistema operacional Unix [Kaplan \& Nelson, 1994].

O escalonamento é baseado na utilização de uma fila de prioridades. Os processos recebidos pelo LoadBalancer são colocados na fila de prioridades e à medida que os recursos ficam disponíveis esses processos devem ser escalonados. As métricas de desempenho (porcentagem de utilização do processador, velocidade das máquinas, número de processadores, número de sessões interativas, entre outras) procuram levar em consideração a heterogeneidade existente no ambiente distribuído e, com isso, atribuir a cada máquina uma quantidade de tarefas proporcional a sua capacidade. Em acréscimo a essas métricas, o usuário pode também indicar recursos computacionais necessários para execução de suas aplicações. As políticas de escalonamento adotados pelo ambiente podem ser configuradas durante a execução.

A fila de prioridades utilizada pelo LoadBalancer possui 256 níveis. Usuários podem alterar (até um determinado valor especificado pelo administrador) seu nível de prioridade e também especificar uma determinada prioridade para sua aplicação.

A capacidade de suspender tarefas em execução é contemplada sob qualquer uma das seguintes condições: a carga da máquina ultrapassa um determinado valor limite, um usuário interativo começa a utilizar a máquina, a máquina será desligada ou utilizada para uma outra atividade dedicada ou mesmo quando o administrador do sistema decide suspender a tarefa. Uma vez suspensa, há também a possibilidade de migrar a tarefa para uma máquina diferente. 


\subsection{AMIGO - Conceitos e Características}

O Ambiente de Escalonamento Flexível e Dinâmico (dynAMical flexIble schedulinG envirOnment - AMIGO) é um software que tem a finalidade de gerenciar o escalonamento de aplicações em plataformas distribuídas de maneira flexível e dinâmica [Souza et al., 1999a]; [Souza, 2000]. Para tanto, esse ambiente agrupa diferentes algoritmos de escalonamento, permitindo que o usuário possa escolher qual deles é mais adequado para uma determinada aplicação. A parte flexível do AMIGO diz respeito à possibilidade de se alterar configurações (por exemplo, inserir ou remover políticas de escalonamento) de acordo com as necessidades do usuário. A parte dinâmica refere-se à adequação do ambiente com relação a novas situações/configurações (por exemplo, a mudança de uma política de escalonamento) em tempo de execução [Araújo, 1999]; [Souza et al., 1999b].

Inicialmente, o AMIGO foi projetado visando abranger aplicações paralelas desenvolvidas para redes de estações de trabalho com o sistema operacional LINUX, gerenciadas por um ambiente de passagem de mensagens como PVM ou o MPI. Entretanto, a sua utilização não está restrita a essas plataformas, podendo ser usado sobre um sistema distribuído, executando aplicações seqüenciais, ou então para máquinas com arquitetura paralela [Araújo, 1999]; [Souza, 2000].

$O$ ambiente AMIGO foi desenvolvido utilizando-se de interfaces claras e bem definidas, pelo fato de que em muitas situações, deve ser acoplado a outros softwares como os ambientes de passagem de mensagens e políticas de escalonamento. Além disso, o desenvolvimento através de interfaces bem definidas facilita a posterior manutenção do software.

$\mathrm{Na}$ tentativa de melhor separar as funcionalidades do ambiente e, assim, facilitar o projeto e desenvolvimento, o AMIGO foi organizado em duas camadas principais, conforme mostra a Figura 3.1 .

\subsubsection{A Camada Superior do AMIGO}

A camada superior é composta por uma interface gráfica, onde o usuário tem acesso a diversas opções de configuração do ambiente, dentre as quais: seleção de políticas de escalonamento, cadastro de classes de software, inserção de informações sobre o hardware utilizado, definição de métricas para o monitoramento da política de escalonamento, entre outros. 


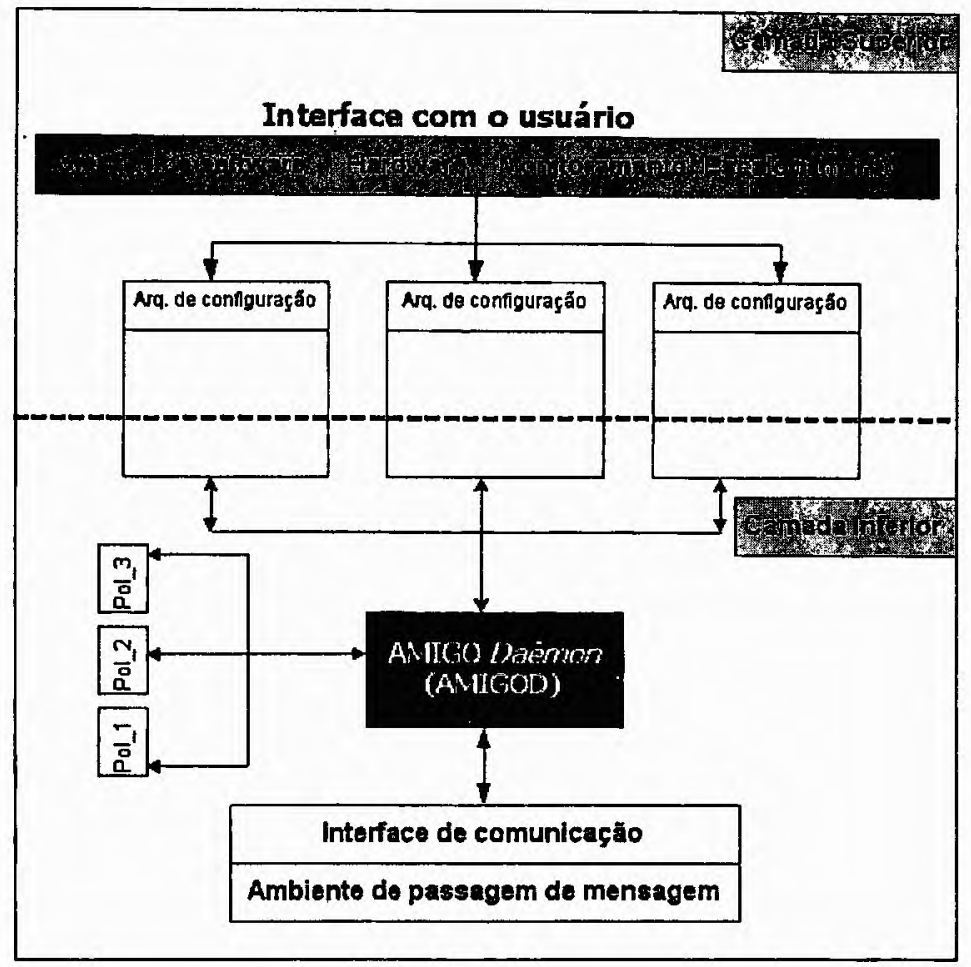

Figura 3.1: Estrutura do Ambiente AMIGO

Todas as informações referentes à configuração realizada na camada superior são armazenadas em arquivos de configuração, que por sua vez são utilizados pela camada inferior para a definição de qual opção deve ser utilizada. Assim, os arquivos de configuração são utilizados como um elo de ligação entre as camadas. Nesse sentido, é válido ressaltar também que, embora a camada inferior verifique arquivos modificados pela camada superior, a execução de uma, não depende necessariamente que a outra esteja sendo executada. Com isso, ambas possuem execução independente.

A implementação da interface gráfica assim como a organização dos arquivos de configuração que podem ser lidos pela camada inferior foram realizadas no trabalho de mestrado de Campos [Campos, 2001].

\subsubsection{A Camada Inferior do AMIGO}

A camada inferior oferece o suporte para a realização do escalonamento dinâmico e flexível através de três módulos: o ambiente de passagem de mensagens, o AMIGO Daemon (AMIGOD) e as políticas de escalonamento. A Figura 3.2 apresenta a disposição desses 
três módulos detalhando, inclusive, a biblioteca de mecanismos que fornece os recursos básicos para as que políticas possam desempenhar suas funcionalidades, a interface de comunicação que deve ser implementada para que um ambiente de passagem de mensagens utilize os serviços do AMIGO e os módulos (em tracejado) que são implementados de maneira independente ao ambiente de escalonamento.

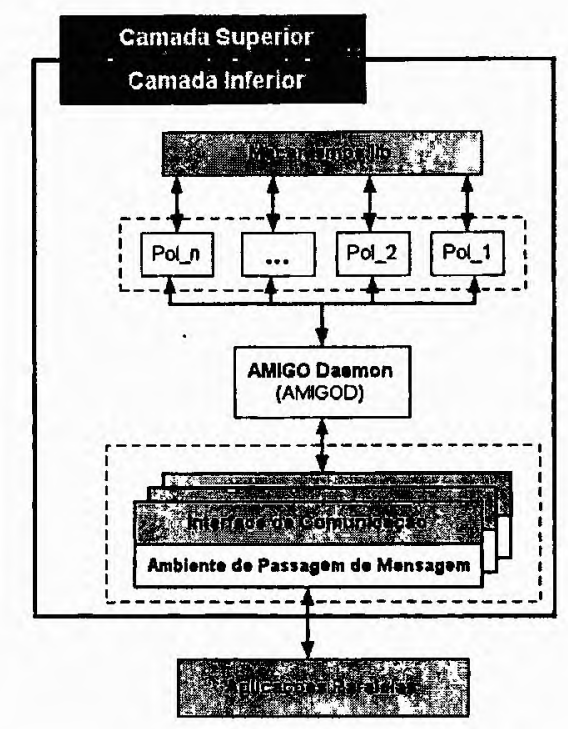

Figura 3.2: Módulos pertencentes à camada inferior do ambiente AMIGO

$\mathrm{O}$ ambiente de passagem de mensagens atua (no contexto do AMIGO) requìsitando elementos de processamento onde as aplicações paralelas devem ser executadas. O AMIGO não implementa ou utiliza um ambiente de passagem de mensagens específico; ao invés disso pode ser acoplado a qualquer ambiente desde que uma interface de comunicação tenha sido previamente construída. De maneira geral, para realizar a construção dessa interface as seguintes modificações devem ser realizadas no código-fonte do(s) ambiente(s) de passagem de mensagem(s) [Souza et al., 1999a]:

- Iniciar ou remover AMIGODs ao iniciar ou terminar a execução do ambiente de passagem de mensagens em novos elementos de processamento;

- As requisições das aplicações paralelas (através do ambiente de passagem de mensagens), com relação a quais elementos de processamento utilizar, devem ser repassadas ao AMIGOD; 
- Quando ocorrer uma redistribuição automática de serviços (processos, jobs, tarefas) por meio de migração, o AMIGOD deve avisar esse acontecimento ao ambiente de passagem de mensagem.

As alterações necessárias para que o AMIGO realize e gerencie o escalonamento de uma aplicação, dizem respeito às modificaçōes introduzidas no ambiente de passagem de mensagens. Assim, a aplicação paralela desenvolvida por um usuário não necessita ser modificada para utilizar o AMIGO e, com isso, as características desse ambiente podem ser totalmente transparentes para esses usuários.

Além da interface para CORBA (discutida no Capítulo 5), o AMIGO também possui interfaces para utilização dos ambientes de passagem de mensagens PVM e MPI-LAM. O desenvolvimento dessas duas interfaces ocorreram respectivamente nos trabalhos de Araújo [Araújo, 1999] e Figueiredo [Figueiredo, 2000], e serão abordados com mais detalhes nas próximas seções.

O AMIGO Daemon (AMIGOD) é um processo servidor distribuído (executado em todos os elementos de processamento ou máquinas participantes do escalonamento), que funciona como um elo entre a política de escalonamento e o ambiente de passagem de mensagens utilizado. Esse processo servidor não realiza o escalonamento propriamente dito, ao contrário, sua responsabilidade se resume a rotear e gerenciar as mensagens trocadas entre os módulos da camada inferior, iniciar e terminar a execução de políticas de escalonamento e manter informações sobre a execução de outros AMIGODs atualmente em execução. Não há uma hierarquia (por exemplo, mestre/escravo) entre os AMIGODs e, além disso, mesmo com a possibilidade de aumento na complexidade e sobrecarga de comunicação, a utilização de AMIGODs completamente distribuídos possibilita melhor tolerância a falhas e evita gargalos no sistema [Araújo, 1999]; [Souza et al., 1999a]; [Souza, 2000].

As políticas de escalonamento são as responsáveis por verificar e repassar (quando forem requisitadas) ao AMIGOD, quais são os elementos de processamento mais adequados para a execução das aplicaçōes. Essas políticas foram implementadas como um módulo independente do AMIGO com o intuito de permitir sua mudança (característica dinâmica do AMIGO) enquanto as aplicações estão executando [Souza et al., 1999b]. As principais características dessas políticas de escalonamento são:

- A independência com relação ao ambiente de passagem de mensagem adotado, uma vez que as políticas têm acesso apenas ao AMIGOD; 
- A utilização de métricas específicas para uma determinada classe de aplicações, pois o objetivo é utilizar políticas concisas e eficientes.

Uma das principais características da camada inferior do AMIGO é a troca de mensagens entre os módulos. Assim, a Figura 3.3 apresenta a comunicação realizada entre as políticas de escalonamento, o AMIGOD e o ambiente de passagem de mensagem na camada inferior.

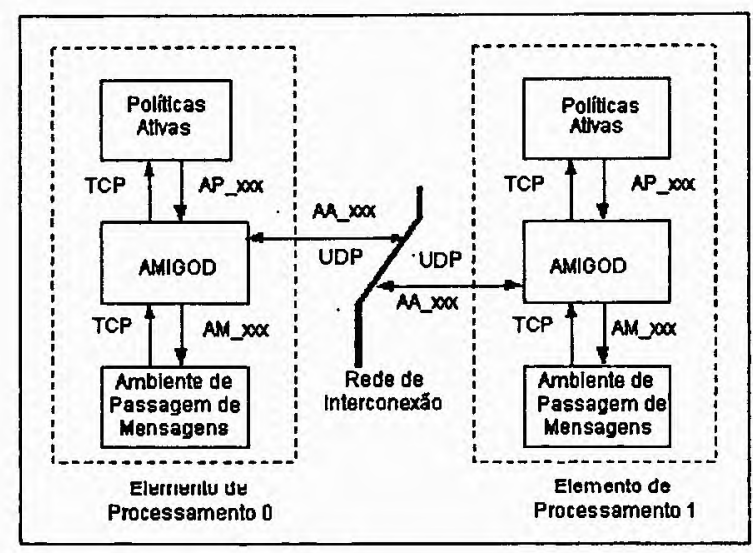

Figura 3.3: Comunicação entre os módulos da camada inferior do ambiente AMIGO

O mecanismo de comunicação entre processos na camada inferior do AMIGO é realizado por meio da interface sockets usando o protocolo TCP/IP [Souza, 2000]. A comunicação do ambiente de passagem de mensagem com o AMIGOD é desenvolvida através do protocolo TCP e as mensagens ${ }^{3}$ utilizam o código AM_xxx (onde $x x x$ representa um código específico da mensagem). A comunicação AMIGOD com as políticas de escalonamento é também efetivada através de mensagens TCP com o código AP_xxx. A comunicação AMIGOD-AMIGOD utiliza o protocolo UDP e as mensagens possuem o código AA_xxx. Segundo Souza [Souza et al., 1999a], a escolha do protocolo TCP para a comunicação entre os módulos em um mesmo elemento de processamento foi motivada pela confiabilidade (inerente ao protocolo TCP) e pelo número reduzido de módulos, o que, conseqüentemente ocasiona poucas conexões. De outra forma, a escolha pelo protocolo UDP entre AMIGODs teve como principal motivação a escalabilidade. Um sistema de comunicação entre módulos similar ao utilizado pelo AMIGO é também adotado no projeto do PVM.

\footnotetext{
${ }^{3}$ Uma descrição de todas as mensagens trocadas com o ambiente AMIGO é apresentada no Apêndice A.
} 


\subsubsection{Comparação entre o ambiente AMIGO e outros softwares de escalonamento}

A partir dos comentários sobre alguns softwares para escalonamento de aplicações e das discussões envolvendo os conceitos, objetivos e funcionalidades do AMIGO, podem-se agora destacar as diversas características em comum entre esses softwares. De antemão, percebe-se que tais características residem principalmente na configuração dinâmica das políticas de escalonamento e na capacidade de gerenciar as máquinas pertencentes ao sistema distribuído e que estão sendo utilizadas no escalonamento.

Contudo, uma característica que merece ser destacada com relação ao ambiente AMIGO refere-se à flexibilidade que esse ambiente provê, permitindo que diferentes ambientes de desenvolvimento/gerenciamento de aplicações possam ser agregados. Essa flexibilidade é decorrência da especificação e do projeto desse ambiente, uma vez que, através de suas interfaces, diferentes políticas de escalonamento podem ser acrescentadas, assim como diferentes tipos de aplicações.

Uma outra característica observada apenas no ambiente AMIGO diz respeito à transparência ${ }^{4}$ fornecida para os usuários da aplicação, sem, no entanto, causar detrimento à flexibilidade exigida por esses mesmos usuários e administradores de sistema. Essa característica é de especial importância, pois, em diversas situações, os usuários/desenvolvedores das aplicações não têm uma visão total do ambiente distribuído. Com isso, pode ser desejável que esses usuários não se preocupem ou mesmo implementem o escalonamento que, de outra forma, deve ser uma atividade realizada de maneira mais automatizada quanto possível.

Para resumir, a Tabela 3.1 apresenta algumas características do AMIGO e dos softwares para escalonamento de aplicaçōes apresentados nas Seções 3.2.1 a 3.2.5.

A característica de configuração dinâmica refere-se aos recursos que o ambiente de escalonamento disponibiliza para que mudanças (por exemplo, troca de políticas de escalonamento) possam ser realizadas em tempo de execução. O suporte para diferentes aplicações apresenta a abrangência do software de escalonamento, no sentido de prover sua funcionalidade para diferentes aplicações. A migração de tarefas é a característica que indica se o software de escalonamento, sob determinadas situações, pode transportar uma aplicação para outra máquina. Por serem consideradas características "comuns", tanto a migração de tarefas como a existência de interface gráfica são contempladas por todos os softwares apresentados na tabela. No caso do ambiente AMIGO, deve-se ressaltar que a migração de tarefas não é uma característica fornecida diretamente por esse ambiente, ao

\footnotetext{
${ }^{4}$ Com relação à atividade de escalonamento.
} 
Tabela 3.1: Comparação das características do AMIGO com outros softwares de escalonamento

\begin{tabular}{||c||c|c|c|c|c|c||}
\hline Características & AMIGO & CODINE & Condor & LoadBal. & LoadLevel. & LSF \\
\hline $\begin{array}{c}\text { Configuração } \\
\text { Dinâmica }\end{array}$ & $\operatorname{Sim}$ & $\operatorname{Sim}$ & Sim & Sim & Sim & Sim \\
\hline $\begin{array}{c}\text { Suporte para } \\
\text { diferentes } \\
\text { aplicações }\end{array}$ & $\begin{array}{c}\text { PVM, MPI } \\
\text { e CORBA }\end{array}$ & $\begin{array}{c}\text { PVM e } \\
\text { Express }\end{array}$ & $\begin{array}{c}\text { Apenas } \\
\text { PVM }\end{array}$ & $\begin{array}{c}\text { PVM, P4 } \\
\text { e P5 }\end{array}$ & $\begin{array}{c}\text { PVMe e AIX } \\
\text { Par. Env. }\end{array}$ & $\begin{array}{c}\text { PVM, P4, } \\
\text { DSM, HPF } \\
\text { e Linda }\end{array}$ \\
\hline $\begin{array}{c}\text { Migração de } \\
\text { Tarefas }\end{array}$ & $\operatorname{Sim}$ & $\operatorname{Sim}$ & $\operatorname{Sim}$ & $\operatorname{Sim}$ & $\operatorname{Sim}$ & Sim \\
\hline $\begin{array}{c}\text { Interface } \\
\text { Gráfica }\end{array}$ & $\operatorname{Sim}$ & $\operatorname{Sim}$ & $\operatorname{Sim}$ & $\operatorname{Sim}$ & $\operatorname{Sim}$ & Sim \\
\hline $\begin{array}{c}\text { Usuários } \\
\text { específicos }\end{array}$ & Não. & $\operatorname{Sim}$. & Não. & Sim. & Sim. & Sim. \\
\hline $\begin{array}{c}\text { Uso exclusivo } \\
\text { do processador } \\
\text { pela tarefa }\end{array}$ & Não. & $\operatorname{Sim.~}$ & Não. & Não. & Sim. & Sim. \\
\hline
\end{tabular}

contrário, deve ser implementada em uma das políticas de escalonamento. Alguns ambientes de escalonamento, visando acrescentar mais segurança em sua utilização, exigem a criação de usuários específicos. De maneira diferente, softwares como Condor e AMIGO permitem sua utilização por parte de qualquer usuário do sistema operacional. A última característica diz respeito à possibilidade de uma tarefa ser escalonada para um processador que já está sendo utilizado. Nesse sentido, os ambientes CODINE, LoadLeveler e LSF necessitam que o processador destino esteja ocioso, ou que pelo menos seja considerado como tal, para que o escalonamento possa ser realizado.

Pela Tabela 3.1 pode-se verificar que, de maneira geral, os softwares analisados contemplam a maioria das características que em muitas situações são suficientes para usuários de aplicações paralelas e/ou distribuídas. Dentre as características apresentadas destacam-se o suporte para diferentes tipos de aplicações (contemplado pela ferramenta LSF), como também a flexibilidade quanto aos usuários por parte dos ambientes AMIGO e Condor. O uso exclusivo do processador foi uma outra característica em que houve diferenciação por parte dos softwares analisados. Nesse caso, constata-se novamente uma maior flexibilidade dos ambientes AMIGO, Condor e LoadBalancer em razão de que esses ambientes não exigem que a aplicação escalonada execute de maneira exclusiva em um processador.

Apesar da similaridade de características, é adequado enfatizar que a adoção por um ou outro software deve ser baseada na verificação de funcionalidades suficientes para que 
os resultados desejados com a utilização do escalonamento sejam alcançados. Com isso, questões como facilidade de uso, disponibilidade de documentação e suporte para o usuário, que muitas vezes são esquecidas podem influenciar significativamente a adoção por parte de um ou outro ambiente de escalonamento.

\subsection{Interface AMIGO-PVM}

A construção da interface AMIGO-PVM foi realizada no trabalho de mestrado de Araújo [Araújo, 1999] e envolveu algumas mudanças no código do ambiente de passagem de mensagem, visando possibilitar sua atuação como um cliente do AMIGO. De forma geral, as mudanças necessárias foram:

- Na inclusão e remoção de novos processadores na máquina paralela virtual, onde novos AMIGODs devem ser iniciados e finalizados;

- No escalonamento de novos processos nos processadores;

- Na migração de processos que já estão em execução.

Para iniciar novos AMIGODs, foi adotada a idéia de inicializar esse processo através da rotina main() do PVMD (PVM Daemon), pelo fato de que o PVMD também deve ser executado em toda máquina onde há uma aplicação PVM. Para isso, foi incluída no código do PVMD uma chamada à rotina StartAMIGOD(), que cria os mecanismos de comunicação entre processos, executa o AMIGOD através das primitivas fork()/exec() e estabelece uma conexão TCP específica com o mesmo.

Depois de iniciado, o AMIGOD envia para o PVMD o port UDP utilizado na comunicação AMIGOD-AMIGOD. O port UDP, em conjunto com o endereço IP da máquina, será enviado posteriormente de um PVMD a um novo PVMD. Essa abordagem permite que o futuro AMIGOD iniciado no novo processador, receba um endereço para a comunicação com um AMIGOD já existente. Uma vez recebido o port UDP do AMIGOD local, o PVMD segue a sua execução normal de maneira independente, garantindo a ambos (PVMD e AMIGOD) autonomia nas suas atividades.

A finalização de um AMÍGOD deve ocorrer quando o PVMD que está na mesma máquina estiver para ser finalizado. A alteração necessária para a finalização do AMIGOD junto com o PVMD, foi a inclusão de uma chamada à função RemoveAMIGOD() no código do PVMD. Essa função envia para o AMIGOD a mensagem AM_REM para que a conexão 
TCP PVMD-AMIGOD seja cancelada e, além disso, indica ao AMIGOD que o mesmo deve ser finalizado de maneira apropriada, informando aos outros AMIGODs a sua exclusão, finalizando as suas políticas e cancelando os mecanismos de comunicação.

Sobre o escalonamento de novos processos, o PVM (em sua forma natural) utiliza a função pvm_spawn() (da biblioteca LIBPVM), que tem a finalidade de preparar e enviar uma mensagem ao PVMD local. Essa mensagem é recebida pela função tm_spawn() que determina quais processadores farão parte do escalonamento e, posteriormente, chama a rotina assign_tasks(). Essa rotina, por sua vez, verifica o número de processos a escalonar e encontra o mínimo entre o número de processos e o número de processadores determinados

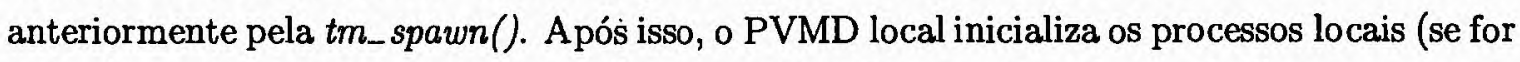
o caso) e envia mensagens $d m_{-}$exec() para os PVMDs remotos solicitando-lhes que iniciem os processos que faltam. Essa sequiência pode ser observada na Figura 3.4.

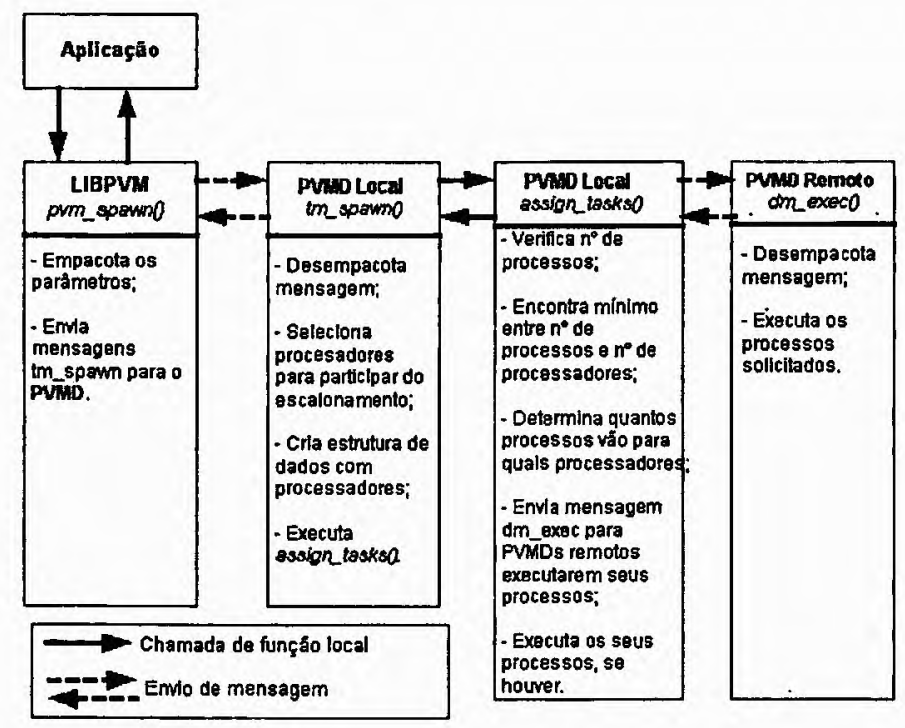

Figura 3.4: Seqüência para realização do escalonamento no PVM

As alterações necessárias para que o AMIGO indique quais são os processadores mais adequados, ocorrem na função $t m_{-}$spawn(), como pode ser observado através da Figura 3.5. A alteração é uma chamada à função GetHostsFromAMIGOD(), que determina quais processadores farão parte do escalonamento, em substituição à parte do código da tm_spawn() responsável anteriormente por isso. Basicamente, a função GetHostsFromAMIGOD() envia a mensagem AM_SCHED para o AMIGOD contendo o nome do processo a ser escalonado, o número de instâncias desse processo a serem criadas e a arquitetura desejada. O AMIGOD ao 
receber essa mensagem repassa-a para a política ativa. As mensagens retornadas da política de escalonamento e do AMIGOD contêm a relação dos processadores receptores de novos processos, exatamente na ordem em que os mesmos devem ser utilizados no escalonamento.

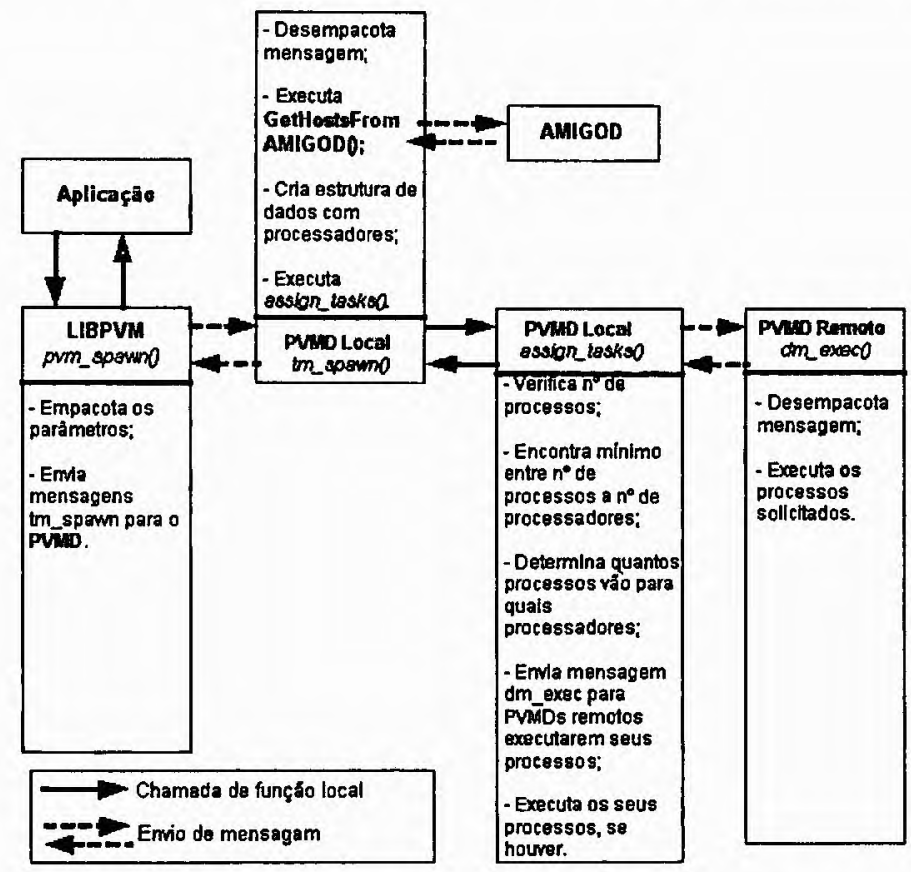

Figura 3.5: Alteração realizada para que o escalonamento do PVM fosse realizado com o auxílio do AMIGO

A migração de tarefas é, sem dúvida, uma das estratégias de escalonamento mais complexas, pois envolve mais detalhes para controlar, tais como, o Task Identifier (TID) da tarefa dependente do TID original e dos descritores de arquivos (sockets, arquivos, etc.).

A migração de tarefas especificada pelo AMIGO ainda não foi implementada, uma vez que tal trabalho ficaria a cargo de uma política de escalonamento utilizada, e a política atualmente em uso (DPWP - Dynamic Policy Without Preemption) pelo AMIGO, não contempla a migração de processos [Araújo, 1999]; [Souza, 2000].

\subsection{Interface AMIGO-MPI}

Para o desenvolvimento da interface AMIGO-MPI foi escolhida a implementação LAM (Local Area Multicomputer) devido aos seguintes fatores [Figueiredo, 2000]: 
- Por se tratar de uma implementação de domínio público;

- Ser uma implementação para plataforma Unix;

- Possuir semelhanças aparentes com o ambiente PVM;

- Apresentar melhor desempenho, segundo pôde ser constatado no trabalho de Souza [Souza, 1996a].

Assim como na interface AMIGO-PVM discutida na Seção anterior, a construção desta nova interface com o MPI, ocorre através de três passos básicos [Figueiredo, 2000]:

- Fazer com que o LAM inicie o daemon do AMIGO em todas as máquinas que receberão as aplicações paralelas do MPI;

- No caso do escalonamento, faz-se necessário desviar o fluxo normal do LAM, para que os processos sejam escalonados pèlo AMIGO através de sua política;

- Finalmente, o shutdown em uma.sessão LAM deve também finalizar o daemon referente ao AMIGO.

O LAM é iniciado através da ferramenta lamboot que recebe como parâmetro um arquivo contendo os nomes das máquinas que devem ser utilizadas para formação do multicomputador (ou máquina paralela virtual). O lamboot efetua uma chamada ao lambootagent, que é o agente de boot responsável por invocar o hboot, o qual inicia o LAM daemon em todas as máquinas.

A partir dessa configuração, alterações foram feitas no código do LAM daemon através da inclusão de uma chamada à função StartAMIGOD(), com o intuito de que o AMIGOD também fosse iniciado assim que o LAM daemon iniciasse sua execução. Além da inclusão da chamada à função StartAMIGOD(), os arquivos de makefile originais do LAM foram alterados para incluir os códigos de configuração do AMIGO.

Com relação ao escalonamento, verifica-se que tal tarefa varia, no LAM, de acordo com as opções passadas na linha de comando para o mpirun (ferramenta responsável por executar aplicações no LAM). Essas opções podem ser: especificando os nós onde os processos serão escalonados ou considerar todos os nós pertencentes ao multicomputador. Se a segunda opção for escolhida, o ambiente LAM adota a política round-robin para realizar o escalonamento. 
Em razão de utilizar no escalonamento uma ferramenta (mpirun) diferente da utilizada para iniciar (lamboot) o daemon do LAM (LAM daemon), o socket TCP criado quando - AMIGOD é iniciado não pode ser utilizado pela ferramenta mpirun, em razão de serem códigos distintos e compilados separadamente. Dessa forma, é necessária a criação de um segundo socket TCP que possibilite a comunicação AMIGOD-MPIRUN, visto que toda a modificação necessária ao escalonamento é feita no código do mpirun. A criação do socket AMIGOD-MPIRUN é feita pelo AMIGOD, que fica aguardando por uma conexão do mpirun. Uma vez que a comunicação AMIGOD-MPIRUN fica disponível, as mensagens referentes ao escalonamento são trocadas utilizando-se esse novo canal de comunicação.

Para que o escalonamento seja feito pela política definida pelo AMIGO, a lista de nós que são transmitidos ao LAM daemon deve ser alțerada. Para isso, foi incluída uma chamada à função GetHostsFromAMIGOD() no código do mpirun. A razão para incluir essa função no código do mpirun tem a intenção de que o AMIGOD informe ao mpirun quais são as máquinas que devem receber os processos a serem escalonados. Após ter recebido a lista com as máquinas que devem ser utilizadas para o escalonamento, o LAM continua sua execução normalmente criando e executando os processos da aplicação nos elementos de processamento indicados pelo AMIGO.

Quanto à finalização dos processos, o LAM utiliza a ferramenta wipe, cuja função é executar a ferramenta tkill em todas as máquinas (via Shell remoto) encerrando os processos relacionados à sessão LAM iniciada. A ferramenta tkill, para finalizar os processos, faz uso de um arquivo criado no diretório / tmp (lam-user@host) de cada máquina, cujo conteúdo é composto pelos identificadores dos processos (PID - Process IDentifier) da sessão LAM. Em razão de que o PID do AMIGOD também é gravado nesse arquivo, a finalização do AMIGO utiliza a estrutura do LAM, ou seja, ao terminar um processo do LAM em uma determinada máquina, o AMIGOD que está sendo executado nessa máquina também será finalizado.

\subsection{Considerações finais}

Neste Capítulo foram apresentados os conceitos, características e algumas definições de projeto relacionadas a seis softwares que realizam o escalonamento de aplicações em plataformas paralelas e distribuídas. Dentre esses softwares, o AMIGO foi abordado com maiores detalhes em razão de sua influência no presente trabalho. Visando comparar as funcionalidades disponibilizadas pelos softwares discutidos neste Capítulo, organizou-se uma Seção (Seção 3.3.3) para comparação dessas diversas funcionalidades. 
Como um dos objetivos do AMIGO reside na possibilidade de melhorar o desempenho de aplicações paralelas que utilizam ambientes de passagem de mensagens, foram apresentadas em duas seções, a construção das interfaces entre esse ambiente e o PVM, assim como, a interface com o LAM-MPI. A construção dessas interfaces se faz necessária, pois é a partir delas que as aplicações podem realmente usufruir das características do AMIGO.

Analisando as características do ambiente AMIGO, pode ser notado que suas funcionalidades não são restritas para aplicações de determinados ambientes ou paradigmas de programação. Ao contrário, um de seus principais objetivos reside na possibilidade de contemplar diferentes domínios de aplicaçōes e arquiteturas de software. A partir do exposto, há uma motivação especial em propiciar a integração do AMIGO com arquiteturas de software tais como CORBA, visto que essa arquitetura, em particular, é amplamente disseminada e oferece recursos para variados tipos de aplicações. 


4

\section{A Arquitetura CORBA}

\subsection{Considerações iniciais}

O desenvolvimento de aplicações distribuídas tem, ao longo dos anos, passado por uma considerável evolução nả tentativa de que questões como desempenho, interoperabilidade e facilidade de uso, antes consideradas complexas e de difícil obtenção, possam agora ser solucionadas com o uso das tecnologias disponíveis.

É justamente nesse contexto que arquiteturas para o desenvolvimento de aplicaçōes distribuídas como CORBA se enquadram. Em particular, CORBA tem sido adotada como um padrão para o desenvolvimento de aplicações distribuídas para diferentes domínios de aplicação, uma vez que alia abrangência e interoperabilidade, sem desconsiderar desempenho, confiabilidade e facilidade de uso para os usuários.

A partir do exposto e pelo fato do objetivo deste Capítulo ser o de discutir aspectos relevantes para o desenvolvimento de aplicações utilizando a arquitetura CORBA, as seções a seguir apresentam os conceitos e principais características dessa arquitetura. Visando explorar a possibilidade de construir aplicações paralelas distribuídas, abordam-se aspectos relacionados ao escalonamento, mecanismos de comunicação assíncrona e o desenvolvimento de aplicações paralelas utilizando essa arquitetura. Por fim, na Seção 4.7 discute-se o uso de implementações CORBA e a necessidade de ponderar adequadamente os fatores que devem ser levados em consideração para que a escolha entre uma ou outra implementação seja a mais acertada possível. 


\subsection{CORBA - Conceitos e Características}

A Common Object Request Broker Architecture (CORBA) é uma especificação padrão, definida pelo Object Management Group (OMG), para o desenvolvimento de aplicações em ambientes distribuídos heterogêneos usando o paradigma orientado a objetos [Vinoski, 1997]; [OMG, 1999a]. Uma das principais motivações para o emprego da orientação a objetos nesse ambiente de aplicações distribuídas é a possibilidade de desenvolver aplicações extensas e complexas sem, no entanto, causar detrimentos quanto ao suporte e reuso de componentes [Mowbray \& Malveau, 1997]; [Mowbray \& Ruh, 1997].

De maneira geral, CORBA define uma estratégia para que um desenvolvedor tenha condições de fácil e rapidamente integrar aplicações de rede e módulos de software, de forma a criar aplicações distribuídas mais robustas. Essas novas aplicações combinam a tecnologia de objetos e o modelo cliente/servidor, com o intuito de fornecer ao usuário uma visão uniforme (através de objetos) independente de sua localização real.

Em CORBA, as aplicações são nomeadas de acordo com a função que desempenham, ou seja, uma aplicação que requisita uma operação é denominada cliente, enquanto uma aplicação que executa as operações requisitadas ou invocadas é nomeada como um servidor. Contudo, uma mesma aplicação pode, em momentos distintos, funcionar tanto como cliente quanto como servidor.

Em se tratando de características, verifica-se que a interoperabilidade de aplicações é um dos tópicos mais visados. Essa interoperabilidade concerne a aplicações implementadas em linguagens, máquinas ou sistemas operacionais diferentes, que podem trocar mensagens exatamente da mesma forma como se fossem implementadas em uma mesma linguagem. Parte dessa interoperabilidade deve-se à utilização de uma notação para definição de interfaces de software denominada Interface Definition Language (IDL).

O objetivo da IDL é fornecer uma interface de software através de uma notação própria que pode ser mapeada para diferentes linguagens de programação [Mowbray \& Ruh, 1997]. O conceito de interface é atribuído à IDL em razão de apresentar aos objetos clientes, os métodos e operações que estes podem utilizar (invocar) em objetos servidores sem, no entanto, detalhar como essas operações foram realmente implementadas. Aplicações clientes e servidores são implementadas em uma linguagem de programação como C, C++ ou Java, ou qualquer outra linguagem que possua um mapeamento para a IDL. 
Para que as requisições efetivadas por clientes, sejam encaminhadas até os servidores, faz-se necessário um componente central na arquitetura CORBA conhecido como Object Request Broker (ORB) [Mowbray \& Malveau, 1997]; [Vinoski, 1997]. A função do ORB é possibilitar a comunicação de forma transparente entre objetos, através do atendimento das requisições dos clientes e do repasse dessas requisições a objetos servidores. Nessa tarefa de comunicação, a requisição passa pelo ORB, que por sua vez fica responsável em encontrar um objeto que a implemente e, conseqüentemente, repassar a invocação propriamente dita. No caminho inverso, o ORB também recebe os resultados de um objeto servidor (na forma de valores de retorno ou de exceções geradas) e repasșa a resposta para o objeto cliente.

Conforme a complexidade do problema a ser tratado, faz-se necessária a comunicação entre objetos que podem estar separados por longas distâncias, possivelmente por várias redes, fazendo com que a invocação de um método passe por diversos ORBs até chegar ao objeto que execute a requisição. Com isso, um ORB deve comunicar-se com outro ORB para que a mensagem possa ser enviada de um para outro. Essa característica é facilitada pelo protocolo IIOP (Internet Inter Orb Protocol), que funciona basicamente como uma especificação padrão para comunicação entre diferentes ORBs sobre o protocolo TCP/IP [Orfali, 1996]; [Vinoski, 1997]; [OMG, 1999a].

\subsection{Organização dos componentes na arquitetura CORBA}

De forma mais detalhada, os componentes definidos na arquitetura CORBA estão organizados conforme apresenta a Figura 4.1 .

A linha tracejada indica uma chamada a um método do objeto servidor na perspectiva do objeto cliente. O objeto cliente invoca o método no servidor exatamente da mesma forma (isto é, com a mesma sintaxe) como faria se fosse uma chamada local, no entanto, o processo "real" ocorre no sentido: Cliente $\longrightarrow$ Interface de Invocação (Dinâmica ou Estática) $\longrightarrow$ $\mathrm{ORB} \longrightarrow$ Adaptador de Objetos $\longrightarrow$ Skeleton (Dinâmico ou Estático) $\longrightarrow$ Servidor. Os elementos que compõe a arquitetura CORBA são definidos a seguir [Orfali, 1996]:

Servidor: É uma aplicação que atende as requisições dos clientes. Esta aplicação implementa a interface IDL previamente definida na forma de objeto(s) servidor(es) utilizando uma linguagem de programação como $\mathrm{C}, \mathrm{C}++$ ou Java. 


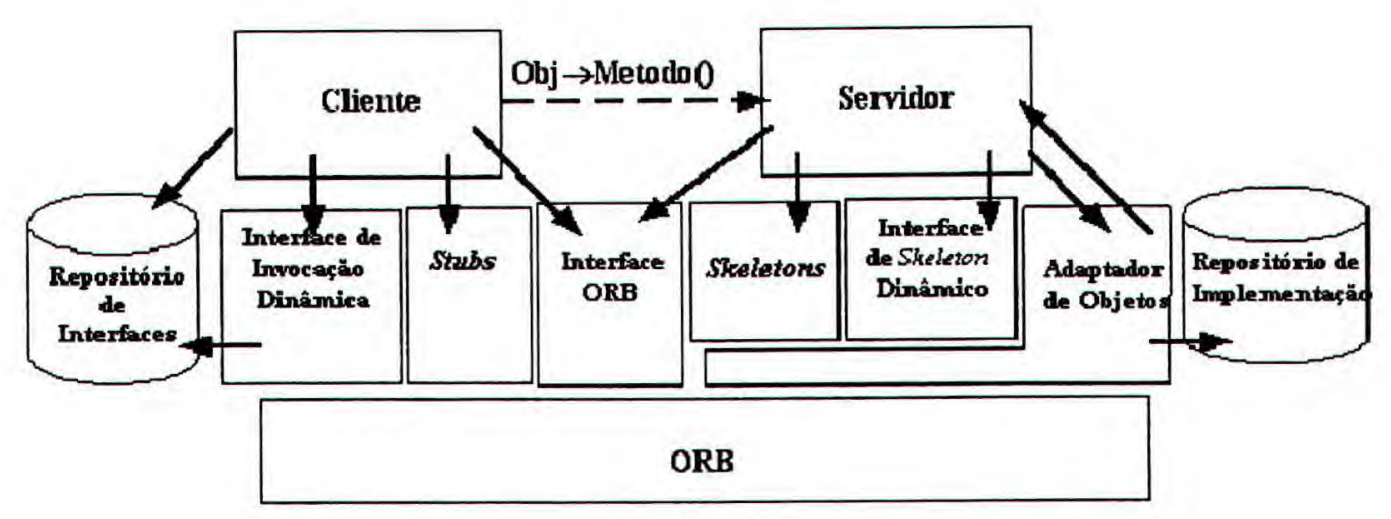

Figura 4.1: Arquitetura CORBA

Cliente: É uma aplicação que invoca operações em um objeto. O acesso aos serviços fornecidos por um objeto remoto é transparente, pois a invocação dessas operações é realizada através de uma chamada simples a um método, como se o mesmo fosse local.

Object Request Broker (ORB): Possibilita a comunicação transparente entre requisições de clientes e implementações de objetos. O ORB simplifica a programação distribuída pelo fato de separar o cliente de detalhes de comunicação pela rede. Isto faz com que as requisições dos clientes fiquem parecidas com chamadas a procedimentos locais.

Interface ORB: Constitui-se em um conjunto de funções que tanto objetos clientes, quanto servidores podem invocar diretamente ao ORB, sem a necessidade do intermédio por parte de outro componente.

Stubs: São os responsáveis por tratar dos detalhes de implementação na comunicação entre cliente e servidor, funcionando, de forma geral, como proxies para a aplicação cliente. Quando uma requisição é feita, esta é (geralmente) enviada para o stub local, que faz a serialização (marshaling) dos dados, para posteriormente enviá-los para um objeto servidor. Após o envio da requisição o stub bloqueia aguardando pela resposta.

Skeletons: Os skeletons têm basicamente o mesmo funcionamento dos stubs, só que atuam no lado servidor. Ao chegar uma solicitação, o skeleton obtém a identificação do método invocado e retira os seus parâmetros da mensagem recebida (unmarshaling), fazendo uma chamada local ao objeto servidor. Ao ser completada a solicitação, recebe os valores de retorno e realiza a serialização (marshaling) dos dados, posteriormente envia esses valores ao cliente. Em razão de que tanto skeletons quanto stubs são traduzidos (em 
tempo de compilação) diretamente de especificações OMG IDL e de serem específicos de uma interface, eles são chamados de mecanismos de invocação estática.

Interface de Invocação Dinâmica (DII): Objetos clientes utilizam a DII para fazer requisições dinâmicas para objetos servidores, permitindo assim, que o cliente requisite operações de um servidor sem a necessidade de stubs compilados por meio de interfaces OMG-IDL, para efetuar a operação de marshaling. Dessa forma, o objeto cliente pode especificar o objeto a ser invocado, a operação a ser executada e um conjunto de parâmetros para a operação através de uma chamada ou sequiência de chamadas. Em aplicações onde é importante obter flexibilidade quanto à invocação de chamadas, utilizar DII pode ser uma das soluções possíveis.

Interface de Skeleton Dinâmico (DSI): A DSI é o equivalente DII do lado servidor, ou seja, da mesma forma que é possível realizar invocações de chamadas sem conhecer os detalhes da invocação em tempo de compilação, também é possível aceitar e distribuir as requisições para um objeto servidor, sem conhecê-lo previamente (sem ter os skeletoris compilados baseados em IDL). Diferente de outros componentes da arquitetura CORBA, a DSI foi incorporada ao padrão a partir da especificação 2.0. A principal razão para sua introdução foi dar suporte à implementação de aplicações que funcionavam como gateways entre ORBs, utilizando diferentes protocolos de comunicação.

Repositório de Interfaces: $O$ repositório de interfaces na arquitetura CORBA possibilita que uma aplicação, em tempo de execução, possa descobrir informações sobre outros objetos com os quais deseja obter algum serviço. Esse repositório armazena as informações definidas nas interfaces IDL, de forma que as aplicações possam consultá-lo para descobrir quais métodos, parâmetros ou objetos devem ser especificados.

Repositório de Implementação: O repositório de implementação armazena informações sobre a identificação de objetos, as classes que um servidor suporta e os objetos que são instanciados. Essas informações podem ser utilizadas para instanciar objetos que devem atender as requisições das aplicações clientes. O Adaptador de objetos comumente utiliza os serviços do repositório de implementação.

Adaptador de Objetos: O Adaptador de objetos é o elemento responsável pela interconexão do ORB com a implementação dos objetos servidores. As principais funções do Adaptador de objetos são:

- Registrar as classes servidoras no Repositório de Implementação; 
- Ativar (instanciar) os objetos chamados, em tempo de execução, segundo a demanda dos clientes;

- Receber as chamadas para os objetos e repassá-las aos mesmos (invocação de métodos);

- Gerar e gerenciar os identificadores de referências de objetos.

Pelo exposto, pode-se observar que de maneira geral CORBA é baseada na arquitetura cliente/servidor onde a comunicação é similar ao modelo RPC de invocação de chamadas. Não obstante, e apesar desse modelo ser viável para uma grande quantidade de aplicaçōes, verifica-se que para algumas situações é desejável lançar mão de outros estilos de invocação de chamadas. Assim, CORBA suporta comunicação síncrona (baseada em RPC) e um número limitado de modelos para comunicação assíncrona [Schmidt \& Vinoski, 1998]; [Schmidt \& Vinoski, 1999]. A comunicação síncrona permite que um cliente, ao fazer uma requisição a um servidor, fique aguardando a resposta para continuar a execução. No modelo assíncrono de comunicação, o cliente faz uma requisição e pode contịuar sua execução enquanto a resposta do servidor ainda não foi retornada. Uma descrição dos modelos de chamadas assíncronas suportados na arquitetura CORBA é apresentado na Seção 4.5.

\subsection{Escalonamento na arquitetura CORBA}

Como já discutido no Capítulo 3, o escalonamento de aplicações é uma atividade de considerável importância em plataformas distribuídas e paralelas, em razão de possibilitar o atendimento de requisitos como melhor utilização dos recursos e o aumento dò desempenho na execução de aplicações. Nesse contexto, variadas ferramentas e arquiteturas de software para o desenvolvimento de aplicações distribuídas também têm utilizado técnicas de escalonamento, visando cumprir seus objetivos e ainda atender aos diferentes requisitos dos usuários.

Tomando como base as características apresentadas nas Seções 4.2 e 4.3, pode ser notado que CORBA enquadra-se no perfil dessas arquiteturas de software, uma vez que procura definir características para domínios de aplicações que variam desde aplicaçōes distribuídas [OMG, 1999b] a aplicações paralelas distribuídas [OMG, 2001b], sem causar detrimento às características e requisitos especificados diretamente pelo usuário.

Apesar de ser considerada abrangente quanto à diversidade de requisitos que contempla, algumas características da arquitetura CORBA têm sido especificadas de maneira restrita para utilização em domínios específicos. Um exemplo dessa restrição refere-se à 
especificação do serviço de escalonamento definido apenas na especificação CORBA RealTime [OMG, 2001d].

A especificação CORBA Real-Time tem por objetivo definir os serviços necessários para o desenvolvimento de aplicações CORBA para sistemas distribuídos de tempo real, levando em consideração os requisitos de tempo, inerentes a esse tipo de sistema. De maneira geral, essa especificação estende as funcionalidades e serviços definidos no padrão CORBA, acrescentando características de suporte a prioridades, escalonamento e flexibilidade. Dentre essas, destaca-se aqui o escalonamento em razão de sua importância para alcançar os requisitos exigidos pelas aplicações de tempo real.

Em se tratando do escalonamento, a especificação CORBA Real-Time define a possibilidade de escalonar threads distribuídos (entidades de escalonamento) com base em parâmetros (por exemplo, prioridade, limitações de tempo, entre outros) repassados para disciplinas de escalonamento. No contexto de CORBA, o termo disciplinas de escalonamento equivale às políticas de escalonamento ${ }^{1}$ [OMG, 2001d].

De forma geral, threads distribuídos são abstrações de modelos de programação que, basicamente, realizam operaçōes em objetos servidores locais ou remotos. Diferente da abordagem adotada pelos softwares de escalonamento discutidos no Capítulo 3, que procuram escalonar processos entre as máquinas do sistema distribuído, CORBA leva em consideração o escalonamento dos threads que serão responsáveis pela execução de uma determinada funcionalidade em um objeto. Assim, uma questão que deve ser verificada nesse tipo de escalonamento diz respeito a quais são os objetos servidores aptos (tendo como base os parâmetros de escalonamento especificados) para receber os threads distribuídos. As disciplinas de escalonamento (ou políticas de escalonamento) constituem-se no conjunto de mecanismos que permitem as entidades de escalonamento terem recursos alocados para sua execução [OMG, 1999a].

$\mathrm{O}$ uso de threads distribuídos como entidade de escalonamento ocorreu após a incorporação de características dinâmicas na especificação CORBA Real-Time versão 2.0 [OMG, 2001d]. Na versão 1.0, o escalonamento era baseado em parâmetros estáticos (política de prioridades fixas) e realizado apenas quando uma operação remota fosse invocada. $O$ crescente desenvolvimento, complexidade e quantidade de variáveis não-determinísticas dos sistemas de tempo real motivou a definição e acréscimo de características dinâmicas para o serviço de escalonamento.

\footnotetext{
${ }^{1}$ Percebe-se nesse sentido, a existência de um problema amplamente encontrado na literatura sobre escalonamento de processos: a divergência quanto a nomenclatura de termos. Uma discussão sobre os problemas de divergência quanto a nomenclatura utilizada em escalonamento de processos pode ser visto em [Souza et al., 2000].
} 
Apesar de atualmente possuir a limitação com relação ao uso de escalonamento para domínios específicos, algumas implementações CORBA, como ORBIX [IONA, 2000] e Visibroker [INPRISE, 1999], têm desenvolvido suas próprias soluções de escalonamento na tentativa de disponibilizar essa funcionalidade para outros domínios. No entanto, devido ao fato de serem alternativas proprietárias, essas soluções dificilmente aliam características como desempenho e interoperabilidade entre diferentes implementações.

Ainda com relação ao escalonamento, diversos esforços têm sido feitos para que essa funcionalidade seja estendida para todos os domínios de aplicações especificados pelo padrão CORBA. Uma dessas propostas, diz respeito à utilização de serviços de balanceamento de carga e monitoramento de requisições [Schnekenburger, 1999]. Basicamente, essa proposta possibilita através de técnicas de monitoramento, o balanceamento das requisições de aplicações clientes para objetos servidores utilizando o particionamento de objetos e atribuindo requisições de clientes para objetos (servants) que estejam mais ociosos. Com isso, a pretensão é atribuir para cada objeto servidor uma carga adequada a sua capacidade.

Por ser uma proposta relativamente recente, os serviços de balanceamento de carga e monitoramento não foram acrescentados na última versão (2.4.2) da especificação CORBA. No entanto, a implementação TAO [Schmidt \& Vinoski, 1995] já possui um serviço de balanceamento de carga adaptativo, em que diversas características da proposta de șerviços de balanceamento de carga e monitoramento são utilizadas. Uma descrição detalhada desse serviço pode ser observada em [Othman et al., 2001].

\subsection{Comunicação assíncrona na arquitetura CORBA}

Para uma diversidade de aplicações, maximizar o desempenho de execução é uma tarefa desejável, visto que tais aplicações exigem considerável quantidade de processamento e, muitas vezes, são de missão crítica para uma determinada área ou ramo de negócio. Além disso, no caso das aplicações distribuídas, pode também ser interessante melhorar o desempenho com o uso mais efetivo dos recursos disponíveis no sistema distribuído. Assim, e pelo fato de ser uma arquitetura que procura abranger o maior número possível de situações no tocante a aplicações distribuídas, CORBA disponibiliza alguns modelos de comunicação assíncrona, objetivando oferecer um certo nível de paralelismo para as aplicações, de forma a aumentar a quantidade de tarefas realizadas em uma unidade de tempo.

As invocações assíncronas em CORBA não se constituem em uma característica recente. Ao contrário, desde as primeiras versões da especificação já era possível a utilização de chamadas unidirecionais (oneway) e retardo síncrono (deferred synchronous) [Schmidt \& 
Vinoski, 1998], visando oferecer uma maneira mais flexível de invocação para métodos de objetos remotos.

O mecanismo de chamadas unidirecionais, apesar de ser relativamente simples (as chamadas são semelhantes às chamadas síncronas), não contempla o caso de chamadas que devem ter valor de retorno. Quando uma requisição ocorre, a aplicação continua seu processamento normal sem, no entanto, ter a possibilidade (fornecida pelo mecanismo) de consultar ou recuperar valores de retorno.

O mecanismo de retardo síncrono, apesar de mais flexível (no que concerne à criação das chamadas e recuperação de valores de retorno) que o mecanismo de chamadas unidirecionais, possui uma certa complexidade na criação/efetivação de chamadas, em razão de serem realizadas utilizando DII [Vinoski, 1997]; [Schmidt \& Vinoski, 1999]. Devido a isso, uma única chamada pode envolver uma sequiência de passos, que podem não parecer muito intuitivos para desenvolvedores iniciantes e/ou acostumados com o modelo de comunicação síncrona.

Os mecanismos de chamadas unidirecionais e de retardo síncrono, apesar de serem suficientes e adequados para algumas aplicações distribuídas, deixam em aberto algumas lacunas que poderiam ser preenchidas com outros mecanismos. Para tratar dessas questões, foi definida a especificação de mensagens CORBA (CORBA Messaging ${ }^{2}$ ) [OMG, 2000] para invocação de métodos assíncronos (Asynchronous Method Invocation - AMI). Essa especificação apresenta os detalhes necessários para a implementação de dois modelos de invocação assincrona: Polling e Callback [Schmidt \& Vinoski, 1996]; [Schmidt \& Vinoski, 1998]; [Schmidt \& Vinoski, 1999]. Esses modelos são discutidos com maiores detalhes nas seçōes a seguir.

\subsubsection{Modelo Polling}

Nesse modelo, uma invocação assíncrona retorna um tipo de dado denominado Poller, que é um novo tipo IDL definido pela especificação Object-by-Value [OMG, 2000]. Esse tipo de dado Poller é muito parecido com uma classe $\mathrm{C}++$ ou Java, pois pode possuir métodos e atributos.

O cliente pode utilizar métodos Poller, que são chamadas a funções locais, para obter o status da requisição e o valor da resposta do servidor. Se a resposta ainda não tiver

\footnotetext{
${ }^{2}$ Apesar de ter sido especificada em 1998, foi incorporada na especificação CORBA 2.4 em Outubro de 2000.
} 
retornado do servidor, o cliente pode optar por bloquear a execução e esperar pela chegada de uma resposta, ou pode simplesmente retornar para a execução imediatamente e verificar posteriormente o Poller.

Em termos gerais, a seqüência de chamadas utilizando o modelo polling ocorre conforme apresentado pela Figura 4.2 [Arulanthu et al., 2000].

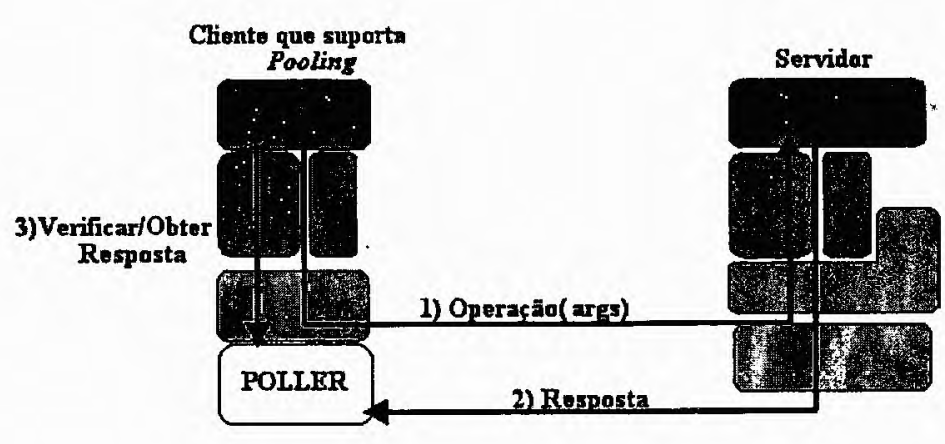

Figura 4.2: Invocação de chamadas no modelo polling

A verificação da resposta não necessita obrigatoriamente ser realizada após o passo 2, pois, ao executar uma chamada no servidor (passo 1) o cliente fica disponível para realizar outras operaçōes e, assim, verificar também se a resposta já está disponível.

\subsubsection{Modelo Callback}

Nesse modelo, quando uma aplicação cliente realiza uma chamada assíncrona para um servidor, é passado como parâmetro, além dos parâmetros comuns da chamada, um objeto ReplyHandler, o qual está implementado no cliente e é o responsável por manipular as respostas. O ORB responsável pela comunicação entre cliente e servidor, toma para si essa referência de objeto, de forma que quando o servidor responde, o ORB recebe e envia essa resposta através de uma invocação a um método apropriado no objeto ReplyHandler.

Apesar de ser um dos modelos mais discutidos, poucos ORBs têm implementado o modelo callback. A Figura 4.3 apresenta a seqüência de chamadas do modelo callback na implementação TAO [Arulanthu et al., 2000].

Uma conseqüência desses modelos é que nenhum thread adicional é necessário para o cliente. Assim, uma aplicação pode gerenciar múltiplas chamadas assíncronas simultane- 
amente, usando o mesmo thread de controle para sobrepor requisições remotas em um ou mais objetos.

Em geral, o modelo callback é mais eficiente que o modelo polling, pois o cliente não necessita consultar os resultados. No entanto, isto força os clientes a se comportarem como servidores (no passo 3, para que receba as chamadas callback) o que aumenta a complexidade de certas aplicações, em particular os chamados clientes "puros" [Schmidt \& Vinoski, 1999]. A adição de métodos assíncronos no lado cliente geralmente não requer qualquer modificação no servidor em razão de que a especificação CORBA Messaging trata invocações assíncronas como uma questão de mapeamento de linguagem no lado cliente.

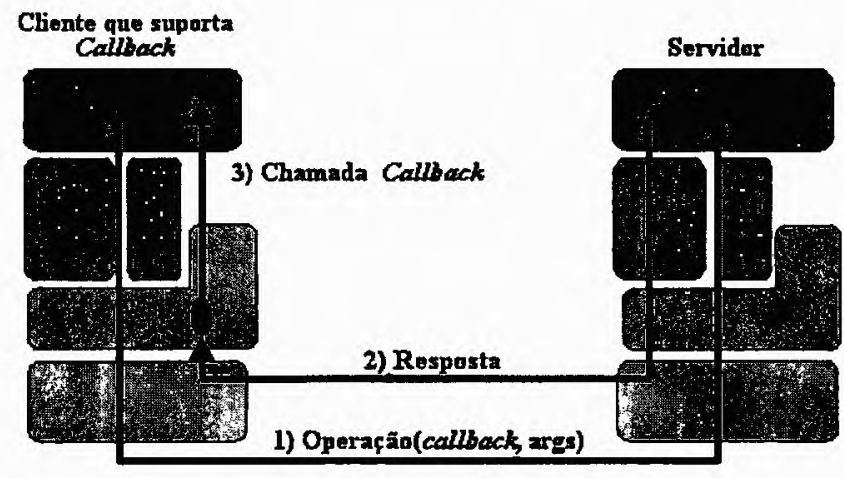

Figura 4.3: Invocação de chamadas no modelo callback

\subsection{Aplicações paralelas na arquitetura CORBA}

Em razão de ser um padrão para o desenvolvimento de aplicações distribuídas e, por abranger diversos domínios onde desempenho é um dos fatores preponderantes, observa-se que há uma tendência inerente à arquitetura CORBA em propiciar os recursos necessários para o provimento de aplicações paralelas.

A utilização de chamadas de retardo síncrono e unidirecionais (oneway), definidas desde as primeiras versões da especificação, podem ser consideradas como um início em direção ao desenvolvimento de aplicações paralelas distribuídas sobre a arquitetura CORBA. No entanto, essas chamadas tratam apenas do aspecto "não-bloqueante" das invocações e, isso, acaba por deixar uma lacuna a ser preenchida, uma vez que a disponibilidade de recursos para gerenciamento e tolerância a falhas fica sob a responsabilidade do usuário da aplicação. Ainda com relação às chamadas não-bloqueantes, um passo visando garantias de melhor 
desempenho foi dado com a definição de chamadas assíncronas através dos modelos callback e polling [Arulanthu et al., 2000]. Apesar do fator desempenho ser de extrema importância em computação paralela, verifica-se que a arquitetura ainda necessita contemplar outras características, visto que essas, podem equiparar CORBA com ferramentas amplamente utilizadas no desenvolvimento de aplicações paralelas distribuídas.

Os esforços visando adequar CORBA para o uso em computação paralela têm sido constantes. A literatura da área possui diversos trabalhos relatando esses esforços e, comumente, novos resultados de pesquisas são acrescentados. Em particular, destacam-se os trabalhos de Keahey [Keahey, 1997]; [Keahey \& Gannon, 1997], Beaugendre [Beaugendre et al., 1998] e Xu [Xu \& He, 2000] em razão de apresentarem idéias que, além de serem factíveis de implementação, possuem semelhanças com as definições da especificação Data Parallel CORBA [OMG, 2001b].

O trabalho de Keahey [Keahey, 1997] apresenta as idéias que nortearam o desenvolvimento do sistema PARDIS (PARallel DIStributed), cujo objetivo é o provimento de recursos para a implementação de aplicações paralelas distribuídas, através de uma extensão do modelo de objetos da arquitetura CORBA. Na extensão do modelo, destacam-se a introdução do conceito de objetos SPMD (Single Program Multiple Data) e de seqüências distribuídas.

Objetos SPMD são, em linhas gerais, objetos CORBA compostos por threads de computação que são capazes de atender serviços requisitados por aplicações clientes [Keahey, 1997]. A principal motivação para o uso de objetos SPMD é aproveitar a transparência inerente à aplicações CORBA e processar em paralelo uma requisição efetivada por uma aplicação cliente. A idéia embutida nesse conceito é a mesma de aplicações SPMD, uma vez que há um mesmo código (o serviço que resolve a requisição) operando com dados diferentes (partes dos parâmetros enviados pelos clientes). Em particular, apenas a camada ORB (discutida na Seção 4.3) interage diretamente com esses objetos e, portanto, sabe de sua existência. Nesse sentido, pode-se argumentar que o responsável pela ativação do paralelismo é o próprio $\mathrm{ORB}$, em razão de ser o responsável por distribuir a requisição do cliente para os objetos SPMD.

As seqüências distribuídas podem ser entendidas como o complemento necessário para a definição dos objetos SPMD, uma vez que constituem os argumentos repassados por aplicações clientes para esses objetos. De forma geral, seqüências distribuídas são generalizações do tipo de dado seqüência definido pela especificação CORBA [Keahey \& Gannon, 1997] e são utilizadas em parâmetros cujo tamanho não pode ser definido em tempo de compilação. A utilização de sequiências distribuídas como parâmetros para requisições em objetos SPMD é um fator primordial para a realização do processamento paralelo, 
pois, caso outro parâmetro seja utilizado, o ORB não "saberá" como distribuí-lo. Apesar de ser uma solução bastante diferente, em comparação com outras soluções amplamente encontradas em ferramentas para o desenvolvimento de aplicaçōes paralelas distribuídas, o projeto PARDIS traz importantes contribuiçōes para o avanço da arquitetura CORBA rumo ao processamento paralelo. Além de introduzir os conceitos de objetos SPMD e sequiências distribuídas, o trabalho apresenta uma alternativa viável para o provimento de recursos visando o paralelismo, sem afetar outras características já existentes como interoperabilidade, portabilidade e transparência.

Um outro trabalho que deve ser destacado no tocante ao uso de computação paralela em CORBA, refere-se ào projeto e implementação do ambiente COBRA [Beaugendre et al., 1998]. Uma das principais motivações para o desenvolvimento desse trabalho reside no fato que, as soluções comumente utilizadas em computação paralela distribuída não atendem aos requisitos de uma considerável gama de aplicações, em especial, aplicações que manipulam componentes e, dessa forma, necessitam de recursos como reuso de código e definição de interfaces. Além disso, os ambientes para o desenvolvimento de aplicações distribuídas também falham, em razão de fornecerem poucos serviços que possibilitem a execução de um componente de software dentro de uma aplicação paralela. Dessa forma, a solução discutida nesse trabalho consiste na junção de características dos ambientes que propiciam o desenvolvimento de aplicaçōes paralelas com aqueles que tratam de aplicaçōes distribuídas.

Semelhantemente à solução adotada no sistema PARDIS, esse ambiente também estende a arquitetura CORBA na tentativa de oferecer o suporte necessário para utilização de um novo tipo de objeto (denominado objeto paralelo CORBA ou apenas objeto paralelo) e ainda propiciar a integração de padrōes como MPI com esses objetos paralelos. De forma geral, um objeto paralelo desempenha a mesma função de um objeto SPMD no sistema PARDIS, além de ambos serem especificados através de uma linguagem de definição de interfaces (IDL) estendida. No entanto, COBRA não requer obrigatoriamente o uso de tipos de dados específicos como no caso das seqüências distribuídas do PARDIS, apesar de oferecer recursos na IDL que permitem ao desenvolvedor informar como a distribuição dos dados deverá ser feita.

É importante salientar que o sistema COBRA foi inicialmente desenvolvido para a arquitetura de multiprocessadores PACHA [Beaugendre et al., 1998] e, portanto, está centrado no provimento de recursos de computação paralela para algumas classes de aplicaçōes que executam sobre essa plataforma de hardware. Além disso, COBRA também implementa o conceito de máquina paralela virtual, associada com a execução de objetos paralelos. Essa 
máquina paralela virtual é alocada a partir da escolha de nós de rede (processadores PACHA) onde objetos paralelos serão mapeados para a execução.

Como pôde ser observado, PARDIS e COBRA possibilitam a utilização de computação paralela na arquitetura CORBA, através de uma extensão dos serviços fornecidos e acrescentando paralelismo através do paradigma SPMD. A partir dos conceitos introduzidos por esses ambientes e verificando a necessidade de adicionar outras características como suporte ao paradigma MPMD (Multiple Program Multiple Data), gerenciamento e controle de máquinas e aplicações, $\mathrm{Xu}[\mathrm{Xu} \& \mathrm{He}, 2000]$ apresenta o sistema PCB (Parallel Component $B u s)$. Esse sistema permite o desenvolvimento de aplicações baseando-se na arquitetura CORBA e na tecnologia Java. De maneira geral, esse novo trabalho utiliza o modelo de comunicação CORBA e adiciona uma camada intermediária (camada PCB) entre a aplicação do usuário e o componente ORB. A adição dessa camada propicia ao sistema $\mathrm{PCB}$, o fornecimento de características como suporte para SPMD e MPMD, ativação automática de aplicações e adição ou remoção de máquinas utilizadas no processamento. A Figura 4.4 apresenta a arquitetura do sistema PCB dividida em três camadas principais.

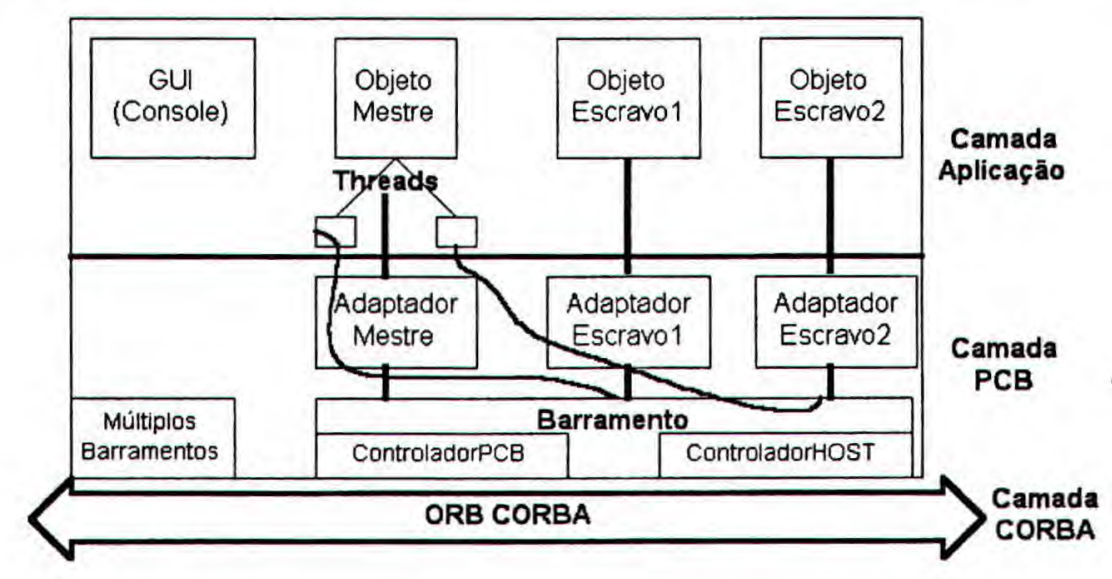

Figura 4.4: Arquitetura do sistema PCB

Uma análise mais detalhada do sistema $\mathrm{PCB}$ revela que diversos conceitos e decisões de projeto tiveram como base ambientes para troca de mensagens bem conhecidos, tais como PVM, P4 e padrões de interface para troca de mensagens como MPI. Verifica-se, nesse sentido, uma tentativa de unir características de ambientes orientados a procedimentos, orientados a objetos e orientados a componentes, com o intuito de disponibilizar um sistema para o desenvolvimento de aplicações paralelas distribuídas que, além de funcional, contemple aplicações com diferentes requisitos. 
Os trabalhos mencionados nas seções anteriores confirmam a possibilidade de utilizar a arquitetura CORBA para o desenvolvimento de aplicações paralelas distribuídas. Não obstante, as soluções mencionadas não garantem a interoperabilidade entre aplicaçōes desenvolvidas sob diferentes ferramentas. Com relação a isso, pode-se ainda argumentar que a definição de uma especificação para aplicações paralelas em CORBA seria uma forma adequada de contemplar, não apenas a interoperabilidade mas também a portabilidade de código e, ainda, oferecer algum nível de flexibilidade. Assim, visando propiciar o paralelismo para aplicaçōes e ainda abranger essas características, o OMG propôs a discussāo de uma especificação que contemple o desenvolvimento de aplicações paralelas na arquitetura CORBA [OMG, 2001b].

Apesar de ainda não ser uma especificação formalizada, as discussões em torno da disponibilidade de aplicações paralelas na arquitetura CORBA já definiram conceitos como objetos paralelos, particionamento de dados, ORBs paralelos e invocações coletivas, que devem ser adotados por essa nova especificação. Esses conceitos foram inicialmente introduzidos tanto nos ambientes comentados anteriormente como também em outras especificações tais como CORBA Real-Time [OMG, 2001d], Modelo de Mensagens Assíncronas [OMG, 2001a] e Balanceamento de Carga [OMG, 2001c]; agora estão sendo incorporados a uma especificação exclusiva para aplicações paralelas em CORBA. Em especial, destacase a utilização da especificação de invocações coletivas através do modelo de mensagens assíncronas, em razão de não terem sido explicitamente explorados por nenhum dos trabalhos citados anteriormente, apesar do potencial oferecido para aplicações que necessitem de melhor desempenho de execução.

\subsection{Implementações CORBA}

Como já mencionado, CORBA é uma especificação de uma arquitetura para o desenvolvimento de aplicações distribuídas, que trata da interoperabilidade e transparência, sem deixar de lado questões como desempenho e flexibilidade. No entanto, para utilização das características disponibilizadas por essa especificação, faz-se necessária a adoção de uma ferramenta que a implemente, uma vez que o Object Management Group não fornece uma implementação CORBA, mas, apenas especifica e define o que deve conter na arquitetura. Nesse contexto, existem diversas implementaçōes disponíveis, onde podem ser encontrados desde produtos comerciais até implementações (com ou sem o código fonte) disponibilizadas gratuitamente. 
Um aspecto importante nesta dissertação é a escolha de uma ferramenta que possibilite o desenvolvimento de aplicações CORBA, visando uma nova interface com o ambiente AMIGO. Assim, há necessidade de se analisar as diversas opções de ferramentas disponíveis, procurando-se uma opção que seja a mais acertada possivel. Tendo em vista a integração com o AMIGO, foram definidos alguns requisitos que devem ser satisfeitos pela ferramenta CORBA adotada, servindo como base para a escolha. Os requisitos definidos são:

- Ter código aberto e ser uma ferramenta freeware;

- Ser implementada em $\mathrm{C} / \mathrm{C}++$;

- Possuir documentação que possa atender às necessidades do projeto;

- Estar de acordo com as últimas versões da especificação CORBA;

- Implementar algum modelo de invocação assíncrona.

A partir desses requisitos e da análise de outras ferramentas tais como MiCO [Puder et al., 2000], ORBit [Birney et al., 2000], ORBacus [OOC, 2000], OmniORB [Lo et al., 2000], Electra [Maffeis \& Landis, 1997] e Arachne [Deibel \& Ehresman, 1997], optou-se pela utilização da ferramenta TAO (The $A C E O R B$ ), desenvolvida pelo DOC Group na Universidade de Washington. Essa escolha foi motivada pelo fato da ferramenta TAO contemplar os quatro primeiros requisitos e ainda possuir o mecanismo callback de invocação assíncrona [Schmidt \& Vinoski, 1996]; [Schmidt \& Vinoski, 1998]; [Schmidt \& Vinoski, 1999]; [Arulanthu et al., 2000]. Além disso, essa ferramenta apresentou melhor desempenho através de benchmarks realizados com outras ferramentas similares como MiCO e Visibroker [Amar \& Bensoussan, 2000], como também em testes desenvolvidos no Laboratório de Sistemas Distribuídos e Programação Concorrente do ICMC-USP.

\subsection{Considerações finais}

Neste Capítulo foram apresentados os conceitos, motivações e principais características a respeito da arquitetura CORBA, com o intuito de destacar as diversas possibilidades que essa arquitetura fornece para o desenvolvimento de diferentes tipos de aplicações.

Apesar de suas diversas características para o desenvolvimento de aplicações distribuídas e paralelas distribuídas, verificou-se que, para uma integração adequada com 0 ambiente AMIGO, há a necessidade de se desenvolver previamente uma estrutura de software 
visando adequar essa arquitetura para contemplar funcionalidades tais como escalonamento e gerenciamento de aplicações remotas.

Com isso, o próximo Capítulo descreve os aspectos envolvidos na implementação de uma estrutura de software visando o escalonamento de aplicações e, posteriormente, no desenvolvimento da interface AMIGO-CORBA. 


\begin{tabular}{l|c|}
\hline & Capítulo \\
\hline 5 \\
\hline
\end{tabular}

\section{Interface AMIGO-CORBA}

\subsection{Considerações iniciais}

Como pôde ser observado na Seção 4.4, a especificação CORBA não define um mecanismo para escalonamento de aplicações. Embora algumas iniciativas já estão sendo direcionadas visando abranger essa característica, os esforços de especificação e implementação têm-se concentrado na possibilidade de escalonar requisições [OMG, 1999b]; [Othman et al., 2001]. A ausência de uma padronização para o escalonamento de aplicações faz com que diferentes soluções sejam empregadas e, com isso, questões como desempenho, portabilidade e interoperabilidade dificilmente são alcançadas.

Uma proposta para oferecer os serviços de escalonamento ao padrão CORBA sem afetar a portabilidade e interoperabilidade das aplicações e ainda, possibilitar ganhos de desempenho, consiste em utilizar esses serviços através da integração de aplicações CORBA com um ambiente de escalonamento. Essa proposta apresenta uma maneira atrativa de oferecer serviços de escalonamento, pois, não são necessárias alterações nos componentes disponibilizados por uma determinada implementação e poucos acréscimos devem ser feitos para que esse novo serviço seja oferecido.

Diante do exposto, este Capítulo apresenta o projeto e desenvolvimento de uma interface entre o ambiente de escalonamento AMIGO e a implementação TAO, com o intuito de oferecer serviços de escalonamento às aplicações desenvolvidas com essa implementação. Durante o projeto, verificou-se a necessidade de desenvolver uma estrutura de software sobre $\mathrm{TAO}$, visando fornecer o suporte necessário para posteriormente implementar a interface com 
o AMIGO. Assim, as seções a seguir apresentam, a arquitetura e características principais da ferramenta TAO, o projeto e desenvolvimento dessa estrutura de suporte e, por fim, os detalhes envolvidos na implementação da interface AMIGO-CORBA.

\subsection{TAO (The ACE ORB)}

TAO (The ACE Orb) é uma implementação CORBA desenvolvida pelo DOC (Distributed Object Computing) Group da Universidade de Washington. O desenvolvimento dessa implementação CORBA é baseada no framework orientado a objetos ACE (Adaptive Communication Environment) que, basicamente, implementa os recursos de comunicação necessários para o desenvolvimento de aplicaçōes concorrentes. De maneira geral, ACE provê os recursos de comunicação que podem ser adaptados para diferentes Sistemas Operacionais e arquiteturas de hardware. Para alcançar esse objetivo, suas funcionalidades foram organizadas em classes e divididas em camadas possibilitando, assim, que extensões possam ser efetivadas sem causar detrimento às características já existentes.

A arquitetura do framework ACE é apresentada na Figura 5.1 e a estrutura da implementação TAO utilizando ACE pode ser vista na Figura 6.3.

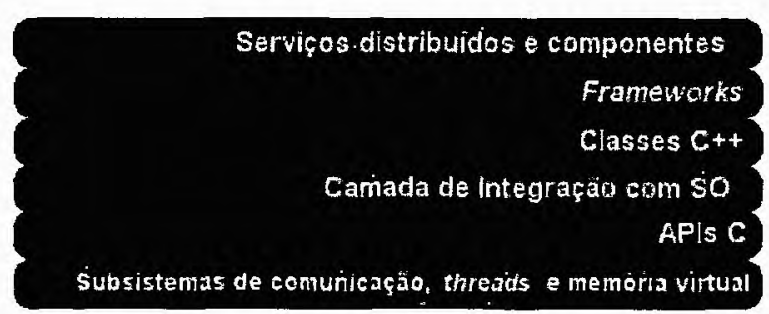

Figura 5.1: Arquitetura do framework ACE

Conforme pode ser observado na Figura 6.3, além de utilizar o framework ACE, TAO implementa o modelo de programação definido pela especificação CORBA através de stubs e skeletons, além de acrescentar novas funcionalidades visando unir questões como melhor desempenho e qualidade de serviço para aplicações distribuídas. Alguns dos fatores que nortearam o desenvolvimento dessa ferramenta compreendem:

- Fornecer uma implementação gratuita, com código aberto, que possa ser usada por pesquisadores e desenvolvedores; 


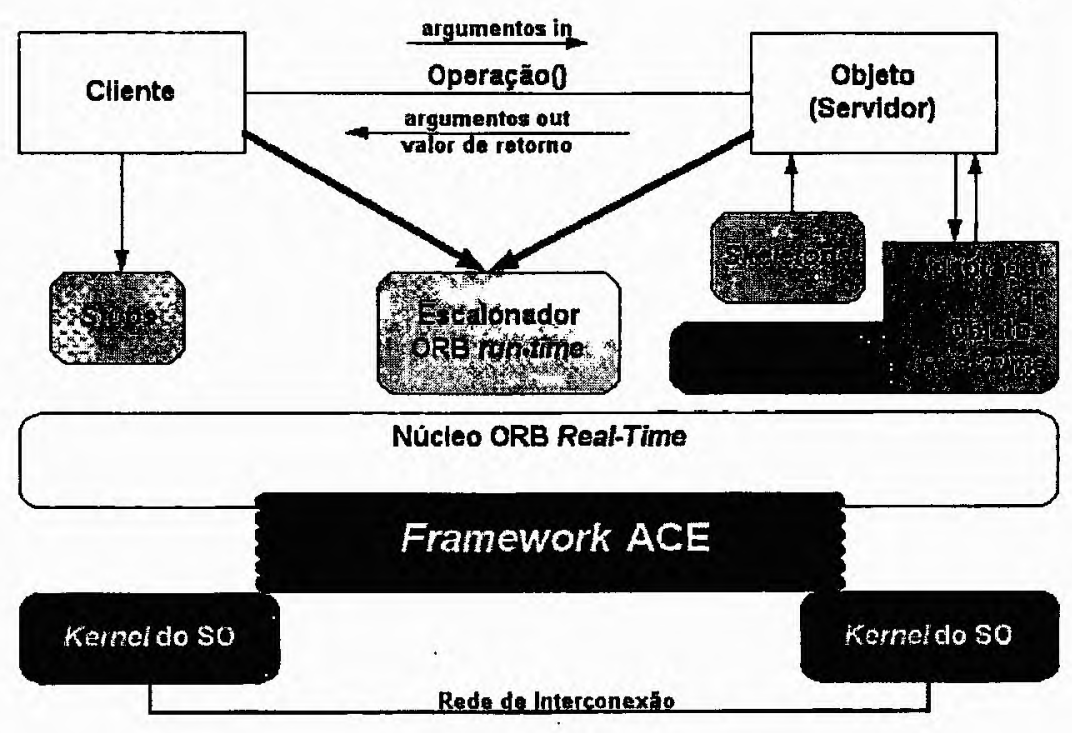

Figura 5.2: Estrutura básica da implementação TAO

- Determinar empiricamente as características necessárias para permitir que implementações CORBA tenham suporte para o desenvolvimento de aplicações de missão crítica com qualidade de serviços determinísticos e estatísticos;

- Utilizar modelos de projeto para desenvolver implementações que sejam portáteis, extensíveis, e com garantias de qualidade de serviço;

- Auxiliar na especificação do padrão Real-Time CORBA.

Por ser direcionada principalmente para aplicações de tempo real, em que desempenho e confiabilidade são dois fatores de extrema importância, a implementação TAO tem lançado mão de diversas técnicas e mecanismos na tentativa de melhorar o desempenho das aplicações sem perder a confiabilidade. Um desses mecanismos refere-se às invocações assíncronas através dos modelos polling e callback da especificação CORBA Messaging [OMG, 2001a]. Embora não tenha ainda implementado o modelo polling, TAO já possui suporte para o modelo callback, além dos mecanismos de chamadas unidirecionais (oneway) e retardo síncrono (deferred synchronous).

Além dessas características, TAO atualmente implementa totalmente a especificação 2.3 e diversas características da especificação CORBA 2.4 .

Apesar de todas as suas características e vantagens em comparação com outras opções para desenvolvimento de aplicações CORBA, verifica-se que, no tocante à integração 
com o ambiente AMIGO, há uma lacuna a ser preenchida para que a interface entre a implementação TAO e esse ambiente de escalonamento possa ser realizada. Essa lacuna refere-se principalmente aos requisitos impostos pelo AMIGO com relação às características de escalonamento que uma ferramenta ou ambiente para desenvolvimento de aplicações deve fornecer. De forma mais detalhada, esses requisitos compreendem a necessidade de existir um processo daemon que seja executado nas máquinas que podem fazer parte do escalonamento, algum nível de gerenciamento ${ }^{1}$ dessas máquinas e a realização do escalonamento.

Com isso, antes de iniciar o desenvolvimento da interface AMIGO-CORBA, deve-se prover uma estrutura de software que contemple esses requisitos visando possibilitar que a interface seja posteriormente implementada.

Um outro aspecto que merece atenção especial neste trabalho diz respeito à verificação da adequabilidade de um dos componentes da arquitetura CORBA para o desenvolvimento da estrutura que forneça o suporte necessário para a interface AMIGO-CORBA.

Analisando-se os diversos componentes que formam a arquitetura CORBA e a idéia de desenvolver um novo componente para contemplar os requisitos mencionados, decidiuse utilizar o Repositório de Implementação (RI) como elemento base para desenvolvimento dessa estrutura e, posteriormente, da interface com o ambiente AMIGO. Uma descrição mais detalhada sobre o. RI da ferramenta TAO, assim como as idéias que nortearam o desenvolvimento da estrutura de suporte à interface AMIGO-CORBA são apresentadas nas seções a seguir.

\subsubsection{Repositório de Implementação da ferramenta TAO}

A decisão de utilizar o RI para o desenvolvimento da estrutura de suporte à interface AMIGO-CORBA foi embásada na análise das características que abrangem o gerenciamento de aplicações locais ou remotas e os aspectos envolvidos no projeto e implementação desse componente. Os aspectos envolvidos no projeto e implementação devem ser destacados em razão de ser através dos mesmos que a possibilidade de acrescentar novas características, sem causar detrimento às funcionalidades existentes, pode ser alcançada.

Em linhas gerais, o Repositório de Implementação da ferramenta TAO é um componente que oferece serviços para iniciar, terminar e verificar o estado de execução de aplicações locais ou remotas [Brunsch, 1999].

O RI em TAO é implementado da mesma forma que aplicações CORBA. Por isso, qualquer aplicação pode utilizar seus serviços desde que saiba qual interface deve ser em-

\footnotetext{
${ }^{1}$ Agrupa as operações de adicionar, visualizar e remover hosts remotos.
} 
pregada. De acordo com a organização do RI, as funcionalidades que podem ser invocadas por aplicações clientes são definidas em um arquivo de interfaces denominado ImplRepo.pidl. A implementação dessas e outras funcionalidades é realizada nos arquivos ImplRepo_i.cpp, ImplRepo.cpp e Repository.cpp. Caso o usuário não queira utilizar sua aplicação para fazer invocações diretamente ao Repositório de Implementação, pode-se lançar mão do utilitário tao_imr que, basicamente, oferece uma interface mais simples para utilização dos recursos providos pelo RI.

A Figura 5.3 apresenta graficamente a organização dos arquivos que constituem o Repositório de Implementação.

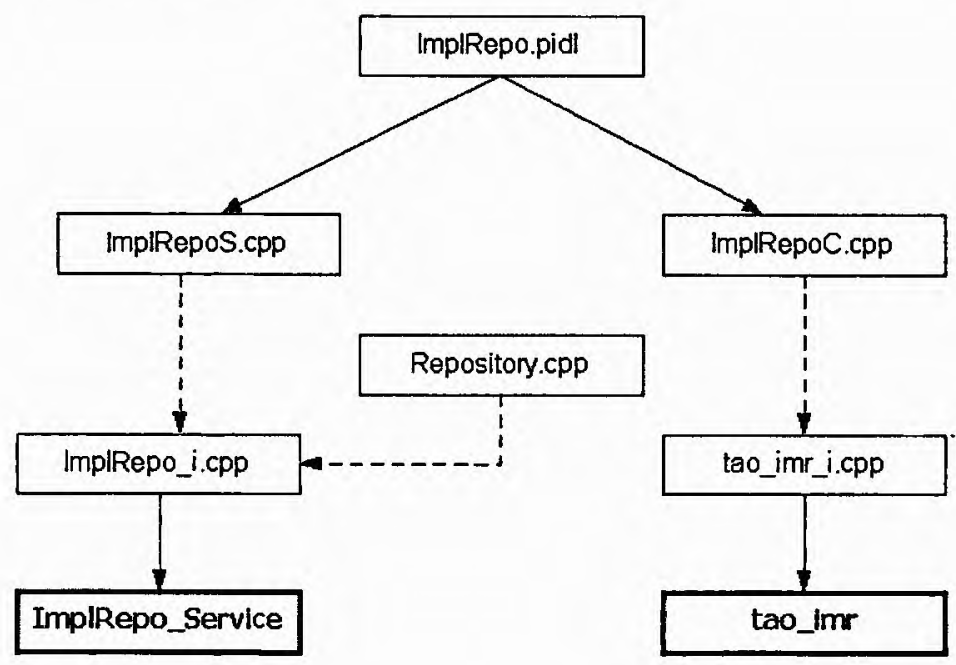

Figura 5.3: Organização dos arquivos que compõem o Repositório de Implementação

Na Figura 5.3, os arquivos ImplRepoS.cpp e ImplRepoC.cpp são respectivamente stubs e skeletons gerados a partir do arquivo de definição de interfaces ImplRepo.pidl. A seta tracejada indica apenas que o arquivo apontado utiliza classes e/ou métodos do arquivo que encontra-se na base. Os dois últimos arquivos (ImplRepo_Service e tao_imr) são responsáveis pelas funcionalidades do repositório (ImplRepo_Service) e por permitir ao usuário a utilização dessas funcionalidades (tao_imr).

Apesar de possuir diversas características que abordam o gerenciamento de aplicações, originalmente, o RI da ferramenta TAO não estava adequado para a integração com o ambiente AMIGO, devido aos seguintes fatores:

- Permitia apenas o gerenciamento de aplicações do usuário que fossem previamente cadastradas; 
- Funcionava de maneira centralizada para todos os clientes (tao_imr);

- Não implementava uma forma padrão para comunicação entre diferentes repositórios;

- Não possuía nenhum mecanismo de escalonamento de aplicações.

O gerenciamento apenas de aplicações do usuário é uma característica atrativa mas não suficiente para dar suporte ao escalonamento, pois, nesse caso, faz-se necessário gerenciar também outras instâncias do RI que estejam distribuídas pelas máquinas do șistema distribuído. O funcionamento centralizado pode ser adequado para simplificar a comunicação entre aplicação cliente e RI, mas não propicia a integração com o ambiente AMIGO, em razão de que esse deve ser iniciado e finalizado pelo ambiente ao qual está integrado e, principalmente, por funcionar absolutamente distribuído a fim de contemplar políticas que também são estruturadas dessa forma.

Devido ao fato de funcionar originalmente de maneira centralizada, a comunicação entre diferentes instâncias de repositórios não estava implementada. No entanto, com a distribuição, essa comunicação deve existir uma vez que características como tolerância a falhas e balanceamento de carga necessitam desse tipo de funcionalidade. Por fim, uma forma de escalonar aplicações deve ser fornecida e, preferivelmente, implementada de maneira flexível, pois, quando houver uma política que realize essa atividade, esse mecanismo pode ser desabilitado sem prejudicar o funcionamento normal do Repositório de Implementação.

A ausência desses fatores ocasiona uma deficiência significativa na utilização dos recursos necessários para escalonamento de aplicações e, com isso, impossibilita a implementação de uma interface com o AMIGO. Após uma análise detalhada das características do RI e de suas limitações no tocante à atividade de escalonamento, constatou-se a necessidade de implementar uma camada de software na tentativa de eliminar essas deficiências e fornecer os recursos necessários para realização do escalonamento de aplicações e a integração com o ambiente AMIGO.

\subsection{Desenvolvimento da estrutura de suporte à inter- face AMIGO-CORBA}

Visando atender as limitações do RI constatadas na Seção 5.2.1, o projeto e desenvolvimento da estrutura de suporte à interface AMIGO-CORBA foi baseada em dois fatores principais:

- Necessidade de iniciar e gerenciar Repositórios de Implementação distribuídos; 
- Desenvolvimento de funcionalidades para realização do escalonamento de aplicações a partir das diretrizes de uma política de escalonamento.

A necessidade de gerenciar e iniciar RIs distribuídos é um requisito básico para a posterior integração com o ambiente AMIGO, visto que esse ambiente funciona de maneira distribuída, além de ser iniciado pela ferramenta a qual está integrado. O desenvolvimento de características responsáveis pelo escalonamento de aplicações é também necessário pois o AMIGO não realiza o escalonamento propriamente dito, ao contrário, atua na gerência dessa atividade. Apesar da possibilidade de ser realizado por uma política, a atividade de escalonamento não é atualmente contemplada por nenhuma das políticas em uso pelo AMIGO. Com isso, os softwares integrados a esse ambiente devem implementar um "escalonador" de aplicações.

As seções a seguir apresentam, as decisões de projeto e os detalhes de implementação envolvidos no gerenciamento de RIs distribuídos e no desenvolvimento de mecanismos para escalonamento de aplicações na ferramenta TAO.

\subsubsection{Implementação do gerenciamento distribuído no Repositório de Implementação}

O gerenciamento de RIs distribuídos deve abranger operações que possibilitem a inicialização e exclusão de RIs em diferentes máquinas, além do gerenciamento da execução desses RIs para que a tolerância a falhas também seja contemplada. De forma geral, foram definidos três métodos que implementam as operações mencionadas 'e que podem ser invocados diretamente por aplicações clientes ou mesmo pela linha de comando através do utilitário tao_imr. Nesse contexto, os métodos implementados diretamente no arquivo de definição de interfaces, como foi o caso dos métodos para gerenciamento de RIs, podem ser invocados por qualquer aplicação cliente desse repositório. De maneira mais específica, a definição desses métodos foi feito no arquivo ImplRepo.pidl e a implementação foi realizada no arquivo ImplRepo_i.cpp

No tocante à implementação, inicialmente foi definida uma estrutura de dados do tipo lista para armazenar informações sobre as máquinas onde existem RIs sendo executados. Essa lista é um item de importância fundamental para alcançar o gerenciamento distribuído, pois, através dela pode-se obter informações sobre as máquinas que estão sendo utilizadas no escalonamento. Para tanto, os métodos que realizam a inserção e remoção de RIs devem manipular essa lista de máquinas a fim de mantê-la tão atualizada quanto possível. 
O método addh() é responsável por iniciar os $\mathrm{RIs}$ nas máquinas indicadas pelo usuário. Para cumprir seus objetivos, esse método cria uma nova entrada ${ }^{2}$ na lista de máquinas e, posteriormente, envia as informações dessa nova entrada para os outros RIs que já estavam em execução a fim de que eles também atualizem suas listas.

A operação de remoção é realizada pelo método deleteh() aproveitando-se de uma funcionalidade disponibilizada pela biblioteca ORB para finalização de aplicações. O funcionamento desse método consiste em remover da lista local a entrada referente à máquina indicada pelo usuário e invocar o método shutdown() no RI dessa mesma máquina. A implementação do método shutdown() realiza três operações: (1) liberar todo o espaço ocupado pela lista de máquinas e variáveis que foram alocadas, (2) cancelar todas as conexões com outros clientes e (3) retirar de execução o RI local. As duas últimas operações foram contempladas através de outro método shutdown implementado na biblioteca ORB (libtao.so). Após esses passos, a informação indicando a remoção de uma máquina deve ser enviada para todos os RIs que ainda estão em execução para que esses também retirem de suas listas a entrada referente a essa máquina.

Além de métodos para iniciar e finalizar, também foi implementado o método printht() que exibe informações sobre as máquinas que constam na lista do RI local. Apesar de sua relativa simplicidade de implementação, esse método assume um papel importante, pois é através dele que pode-se determinar quais as máquinas possíveis de receberem aplicações escalonadas.

Uma característica importante refere-se à estratégia adotada para localizar RIs distribuídos. Em particular, o problema dessa característica está em determinar um serviço de nomes "padrão" para que um RI tenha condições de "descobrir" outro(s). Pelo fato de serem concebidos como aplicações CORBA, esses componentes podem usufruir dos mesmos serviços de nomes dessas aplicações, com o objetivo de alcançar maior flexibilidade e também contemplar aplicações de diferentes ambientes e recursos. Assim, optou-se por fornecer dois mecanismos diferentes para comunicação entre RIs. O primeiro utiliza os recursos da biblioteca ORB para armazenar em arquivo a identificação (IOR-Interoperable Object Reference) de cada RI. Esse arquivo pode, posteriormente, ser aberto por qualquer outra aplicação que deseje utilizar a identificação ali armazenada para iniciar uma comunicação. O segundo mecanismo faz uso do utilitário Naming_Service onde qualquer RI pode registrarse ou mesmo buscar a identificação de outro(s). A Figura 5.4 apresenta os passos utilizados para que um RI registre-se e localize outros através do serviço de nomes fornecido pelo utilitário Naming_Service.

\footnotetext{
${ }^{2}$ Cada entrada armazena o nome e o endereço IP da máquina onde o RI remoto está sendo executado e o Port TCP utilizado por esse RI.
} 


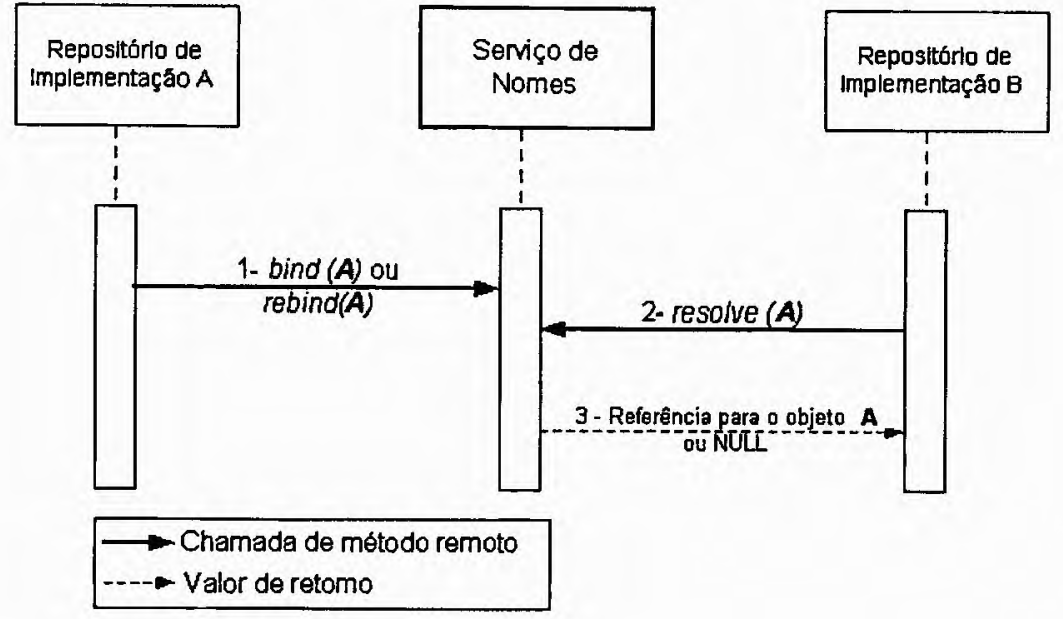

Figura 5.4: Iteração do Repositório de Implementação com o Serviço de Nomes

A motivação para implementar duas formas de localização de RIs está relacionada com a possibilidade de contemplar plataformas distribuídas com diferentes recursos e, com isso, permitir maior flexibilidade para os usuários de aplicações. É importante, nesse sentido, que um usuário pondere os recursos disponíveis e as necessidades de suas aplicações para que a escolha por uma ou outra forma possa ser a mais acertada possível.

\subsubsection{Implementação do escalonamento}

A implementação do escalonamento de aplicações foi dividida em duas etapas: a implementação de um método escalonador que, a partir de informações recebidas de um cliente, realize o escalonamento dessa referida aplicação nas máquinas indicadas por uma política ativa e a implementação de uma política genérica (round-robin), com a finalidade de escolher as máquinas que devem participar do escalonamento tendo como base a sua ordem de inserção na lista mantida pelo RI local.

O funcionamento básico do mecanismo de escalonamento implementado, consiste em uma invocação realizada pela aplicação cliente ao método sched_app() no RI local. Esse método deve receber informações (nome e localização da aplicação e o número de cópias) sobre a aplicação que deve ser escalonada e repassar a informação do número de cópias como um parâmetro para a política ativa que, de forma geral, deverá retornar as máquinas aptas a receberem essa aplicação. Após receber o(s) resultado(s) da política, devem ser feitas invocações para o método spawn_app() nos RIs que residem nessas máquinas indicadas. $\mathrm{O}$ 
método spawn_app() executa a aplicação requisitada pelo usuário, através de parâmetros fornecidos pelo RI origem.

A política de escalonamento round-robin foi implementada no método sched_app_i() $\mathrm{e}$ é invocada apenas pelo método sched_app(). Essa política pesquisa as máquinas que devem ser utilizadas no escalonamento tendo como base a ordem das entradas na lista do RI local. Caso o número de máquinas requisitado pelo usuário seja maior que o número de entradas nessa lista, a política provavelmente retornará uma mesma máquina mais de uma vez.

A Figura 5.5 apresenta os passos utilizados para a realização do escalonamento utilizando a política round-robin implementada.

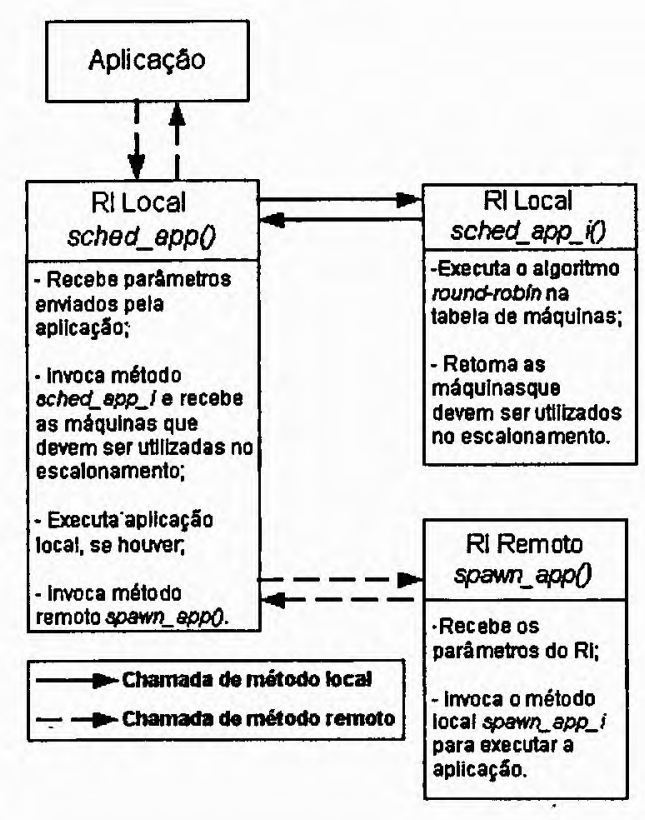

Figura 5.5: Escalonamento na ferramenta TAO utilizando uma política round-robin

\subsection{Desenvolvimento da interface AMIGO-CORBA}

Após a implementação e testes visando a validação dos mecanismos de gerenciamento e escalonamento do RI, iniciou-se o desenvolvimento da interface AMIGO-CORBA com o intuito de integrar a ferramenta TAO com o ambiente AMIGO.

Embora a inicialização dessa interface seja realizada apenas com a chamada da função StartAMIGOD(), nota-se a existência de três situações básicas em que o RI deve interagir com o ambiente AMIGO: 
- Durante a inicialização de RIs;

- Quando ocorrer o escalonamento de aplicações;

- Na finalização de um RI através do método shutdown().

Após um RI ter sido iniciado, deve-se também iniciar o AMIGO, possibilitando assim que seus serviços de escalonamento sejam posteriormente requisitados. Essa característica é contemplada através da função StartAMIGOD() que executa o Daemon do AMIGO (AMIGOD) e estabelece a comunicação entre os dois extremos (AMIGO e TAO) através de um socket TCP. No tocante aos detalhes de implementação, a chamada à função StartAMIGOD() foi colocada no método init() do arquivo ImplRepo_i.cpp. O método init() foi adotado em razão de já atuar na ativação de outros serviços necessários para o funcionamento do RI e também por ser usado para iniciar a lista local de máquinas e diversas variáveis de ambiente globais. A despeito do AMIGOD, é importante salientar que há uma diferença entre iniciar o primeiro Daemon e os demais, pois, caso existam outros AMIGODs executando no sistema, o ambiente que iniciou o último deve repassar-lhe o endereço do socket UDP do primeiro AMIGOD criado, a fim de que possam trocar informações sobre suas configurações.

Quando o usuário requisitar um escalonamento de aplicações, o RI, através do método sched_app (), deve invocar o método GetHostsFromAMIGOD() que, por sua vez, envia para o AMIGOD local uma mensagem com o código AM_SCHED, contendo o número de máquinas para o escalonamento, a aplicação que deseja-se escalonar e a arquitetura da plataforma distribuída utilizada. Esse código indica ao AMIGOD que trata-se de umá operação de escalonamento e, portanto, a política ativa deve ser consultada. A política ativa, por sua vez, deverá encontrar quais são as máquinas mais adequadas para atender aquela requisição e retornar uma lista dessas máquinas para o AMIGOD. O AMIGOD retorna essa mesma lista para o RI que, somente então, poderá escalonar a aplicação indicada pelo usuário. No caso de uma política implementar um escalonador e com isso realizar o escalonamento, o ambiente que controla a aplicação (neste caso, o RI) deve ser informado, para que não tente realizar um outro escalonamento. A Figura 5.6 ilustra os passos utilizados no escalonamento de uma aplicação TAO utilizando o AMIGO e sua política ativa.

$\mathrm{Na}$ finalização de RIs, o AMIGOD local e, conseqüentemente, a política de escalonamento ativa, também podem ser retirados de execução. Para tanto, faz-se uma chamada ao método removeamigod() do RI local que envia uma mensagem com o código AM_REM para - AMIGOD que reside nessa mesma máquina. Ao receber essa mensagem, esse AMIGOD envia outras duas mensagens: a primeira possui o código AA_REM e é destinada aos outros 


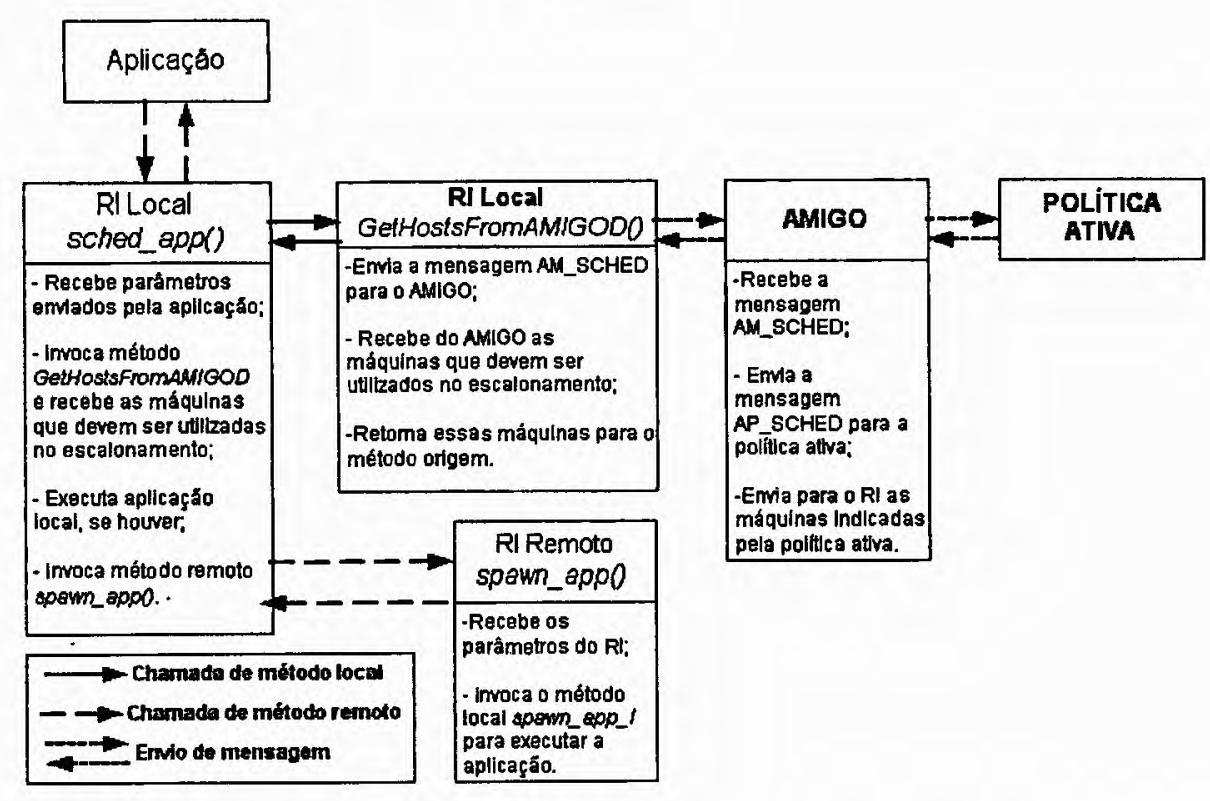

Figura 5.6: Escalonamento na ferramenta TAO utilizando o AMIGO

AMIGODs ainda em execução, com o intuito de que esses sejam informados sobre sua saída; a segunda possui o código AP_REMPOL e é enviada para a política ativa local para que essa também seja finalizada. Após enviar essas mensagens o AMIGOD fecha os sockets de comunicação ainda abertos e termina sua execução. A saída de um AMIGOD não implica na remoção de todos os outros que ainda estão em execução. Enquanto houver um RI ativo haverá também um AMIGOD e, conseqüentemente, uma política de escalonamento utilizada por esse AMIGOD.

\subsection{Considerações finais}

O escalonamento é uma atividade de considerável importância para diferentes tipos de aplicações, em especial, para aplicações paralelas e distribuídas, principalmente quando um dos objetivos desejados é o aumento no desempenho de execução.

$\mathrm{Na}$ tentativa de alcançar esse objetivo, diversos ambientes para desenvolvimento/gerenciamento de aplicações paralelas e distribuídas têm oferecido algum tipo de escalonamento para suas aplicações. Exemplos desses ambientes são PVM, P4, Linda, HPF, entre outros, uma vez que contemplam o escalonamento através de mecanismos já embutidos em seu código ou mesmo por meio de ambientes que gerenciam e/ou escalonam aplicações. A arquitetura CORBA também pode ser colocada nesse contexto, em razão de possibilitar o 
desenvolvimento de aplicações distribuídas e mesmo aplicações paralelas distribuídas, apesar de não especificar como o escalonamento de aplicações deve ser implementado.

Tendo como base essa limitação, este Capítulo abordou como o escalonamento pode ser contemplado pelo padrão CORBA sem causar detrimento às características já existentes. A disponibilidade dos serviços de escalonamento foi conseguida através da implementação de uma interface entre o ambiente AMIGO e a ferramenta TAO. Com essa interface, torna-se possível escalonar aplicações CORBA, desenvolvidas com a ferramenta TAO, sob a gerência do ambiente AMIGO e de suas políticas de escalonamento.

Mesmo possuindo diversas características semelhantes aos ambientes para desenvolvimento de aplicações paralelas distribuídas e já integrados com o AMIGO, como é o caso do PVM e LAM-MPI, houve a necessidade de implementar alguns recursos adicionais à ferramenta TAO, para que a interface com o ambiente de escalonamento pudesse ser implementada.

Tendo a interface com o AMIGO já implementada, é necessário validar essa implementação e verificar o desempenho obtido pelas aplicações escalonadas. Assim, o próximo Capítulo apresenta os resultados obtidos com a avaliação de desempenho de aplicações CORBA com o escalonamento fornecido pelo AMIGO. Também são apresentados os resultados obtidos com aplicações PVM e LAM-MPI, a fim de comparar possíveis diferenças de desempenho entre aplicações desses ambientes e aquelas implementadas com a ferramenta TAO. 


\section{Avaliação de Desempenho e Resultados}

\subsection{Considerações iniciais}

Como discutido no Capítulo 2 desta dissertação, um dos principais objetivos almejados quando opta-se por computação paralela consiste na melhoria do desempenho das aplicações. Com isso, em trabalhos que utilizam computação paralela, comumente encontrase uma etapa de avaliação de desempenho, na tentativa de determinar se essa melhoria foi realmente alcançada. Além disso, essa etapa merece atenção especial em razão de também ser utilizada para validar as implementações desenvolvidas.

Tendo em vista a importância da avaliação de desempenho em trabalhos que utilizam computação paralela, o presente Capítulo discorre sobre os resultados obtidos com a avaliação de desempenho de aplicações TAO utilizando o escalonamento round-robin (utiliza a política de escalonamento round-robin) e o definido pelo ambiente AMIGO (utiliza a política DPWP ${ }^{1}$ ). Nos diversos experimentos realizados e apresentados a seguir, procurou-se verificar não apenas as diferenças de desempenho quando adota-se uma ou outra estratégia de escalonamento mas, também, quando o sistema encontra-se em diferentes situações de carga.

Os experimentos realizados com aplicações TAO foram extrapolados para contemplar aplicações PVM e LAM-MPI, uma vez que para esses dois ambientes têm-se também um

\footnotetext{
${ }^{1}$ A política DPWP distribui as aplicaçōes para as máquinas com menor valor de índice de carga. Esse índice leva em consideração a potência computacional e o número de processos na fila de "prontos" do processador.
} 
escalonamento round-robin e uma interface para o ambiente AMIGO. A principal motivação para realização de experimentos com PVM e LAM-MPI foi comparar com os resultados obtidos por aplicações TAO e ratificar as avaliações já realizadas nos trabalhos de Araújo [Araújo, 1999], Souza [Souza, 2000] e Figueiredo [Figueiredo, 2000], com relação aos ganhos que a adoção de um escalonamento mais aprimorado pode propiciar.

\subsection{Plataforma utilizada para realização dos experi- mentos}

A implementação da interface AMIGO-CORBA e os experimentos apresentados neste Capítulo, foram realizados em uma rede de computadores pessoais, em que todos utilizavam o sistema operacional Linux (kernel 2.2.16) e o sistema de arquivos de rede NFS. Essa organização de máquinas possibilita a formação de uma arquitetura MIMD com memória distribuída, tornando factível a execução de aplicações paralelas desenvolvidas sobre ambientes que aceitam esse tipo de plataforma de hardware.

A Tabela 6.1 apresenta mais informações sobre a configuração das máquinas utilizadas.

Tabela 6.1: Configuração do ambiente computacional utilizado na avaliação de desempenho

\begin{tabular}{||l||l|r|r||}
\hline Máquina & Processador & Memória & Disco Rígido \\
\hline Lasdix & Pentium MMX 200MHz & $32 \mathrm{Mb}$ & $13 \mathrm{~Gb}$ \\
\hline Lasdpc04 & Pentium II 233MHz & $64 \mathrm{Mb}$ & $3 \mathrm{~Gb}$ \\
\hline Lasdpc05 & Pentium II 266MHz & $120 \mathrm{Mb}$ & $6 \mathrm{~Gb}$ \\
\hline Lasdpc07 & Pentium II 400MHz & $64 \mathrm{Mb}$ & $13 \mathrm{~Gb}$ \\
\hline Lasdpc08 & Pentium MMX 200MHz & $64 \mathrm{Mb}$ & $4 \mathrm{~Gb}$ \\
\hline Lasdpc09 & Pentium II 233MHz & $64 \mathrm{Mb}$ & $12 \mathrm{~Gb}$ \\
\hline Lasdpc10 & Pentium MMX 200MHz & $32 \mathrm{Mb}$ & $3 \mathrm{~Gb}$ \\
\hline
\end{tabular}

Com relação aos softwares utilizados nos experimentos, ọptou-se por verificar o desempenho de aplicações PVM (versão 3.3.10), LAM-MPI (versão 6.3) e TAO (versão 1.1), uma vez que a integração de TAO com o AMIGO foi o principal objeto de estudo deste trabalho e as duas primeiras ferramentas já possuíam interfaces para o ambiente AMIGO. Além disso, os trabalhos de Araújo [Araújo, 1999] e Figueiredo [Figueiredo, 2000], que implementaram (nessa ordem) a interface AMIGO-PVM e AMIGO-MPI, não discutiram o desempenho de aplicações nesses diferentes softwares e também utilizando o escalonamento em diferentes situações de carga. 


\subsection{Experimentos realizados}

Devido ao considerável número de fatores envolvidos na avaliação de desempenho aqui discutida, houve a necessidade de serem definidos experimentos visando contemplar alguns objetivos. Nesses experimentos, verificou-se o desempenho das aplicações ${ }^{2}$ quando 0 escalonamento utiliza a política round-robin ou quando adota-se o AMIGO com a política DPWP. Também foi enfatizado o desempenho da aplicação (sob cada uma dessas políticas) com o sistema em diferentes situações de carga, isto é, com o sistema ocioso (nenhuma outra aplicação no sistema além daquelas utilizadas no experimento) e carregado com alguns processos ${ }^{3}$ que ocupavam a fila do processador.

A idéia de utilizar um sistema "carregado" possibilitou analisar o desempenho da aplicação quando já existem outros processos executando no sistema. Essa idéia trouxe a necessidade de se definirem perfis de carga visando sistematizar a maneira como os experimentỏs eram realizados e; com isso, repeti-los utilizando outras aplicações e ferramentas. Uma outra motivação para definição de perfis de carga é verificar se existem diferenças de desempenho entre a adoção do escalonamento round-robin e o AMIGO e, assim, apresentar situações onde um ou outro escalonamento pode ser melhor aproveitado.

Na Tabela 6.2 são descritos cada um dos perfis de carga. Também é apresentada a carga atribuída a cada máquinà quando foram alocadas 07 e 06 máquinas nos experimentos.

A decisão de se utilizarem 07 e 06 máquinas foi motivada pelos resultados alcançados em experimentos preliminares realizados no Laboratório de Sistemas Distribuídos e Programação Concorrente. Esses experimentos tinham por objetivo determinar a quantidade de máquinas que poderia ser utilizada para alcançar melhores desempenhos (melhor speedup), tendo como base as aplicações do caixeiro viajante e do método do trapézio composto. No caso da aplicaçāo do caixeiro viajante, foi possível alcançar speedup com até 07 máquinas levando-se em consideração uma configuração com 12 cidades. Na aplicação do trapézio composto foi possível alcançar speedup com até 06 máquinas e um número de 3500000 divisões. Dessa maneira, para os experimentos com a aplicação do caixeiro viajante foram utilizadas 07 máquinas, enquanto que no caso do trapézio composto foram alocadas 06 máquinas.

A determinação do número de processos atribuídos para as máquinas em cada um dos perfis de carga foi baseada nos valores utilizados pela política DPWP para definição de um sistema ocioso, moderado e carregado [Araújo et al., 1999]. A escolha de 05 processos

\footnotetext{
${ }^{2}$ Neste trabalho, considera-se o desempenho de uma aplicação como sendo o tempo de execuçāo.

${ }^{3}$ Esses processos ficam em um loop infinito e não realizam comunicação
} 
Tabela 6.2: Definição dos perfis de carga utilizados nos experimentos

\begin{tabular}{|c|c|c|c|}
\hline Perfil & Descrição & $\begin{array}{c}\text { Carga das } \\
07 \text { máquinas }\end{array}$ & $\begin{array}{c}\text { Carga das } \\
06 \text { máquinas }\end{array}$ \\
\hline 1 & $\begin{array}{l}\text { As máquinas com maior potência } \\
\text { computacional (de acordo com o resultado } \\
\text { do benchmark utilizado pela política de } \\
\text { escalonamento do AMIGO) ficam } \\
\text { carregadas com cinco processos } \\
\text { que ocupam a fila de processos prontos. } \\
\text { As demais máquinas ficam ociosas. }\end{array}$ & $\begin{array}{l}\text { lasdpc07 - } 05 \text { proc. } \\
\text { lasdpc05 - } 05 \text { proc. } \\
\text { lasdpc04 - } 05 \text { proc. } \\
\text { lasdpc09 - } 05 \text { proc. } \\
\text { lasdpc08, lasdix e } \\
\text { lasdpc10 - ociosos }\end{array}$ & $\begin{array}{l}\text { lasdpc07 - } 05 \text { proc. } \\
\text { lasdpc05 - } 05 \text { proc. } \\
\text { lasdpc04 - } 05 \text { proc. } \\
\text { lasdpc09, lasdpc08 } \\
\text { e lasdix - ociosos }\end{array}$ \\
\hline 2 & $\begin{array}{l}\text { As máquinas com menor potência } \\
\text { computacional ficam carregadas com cinco } \\
\text { processos seriais. Dessa forma, } \\
\text { as melhores máquinas ficam ociosas. }\end{array}$ & $\begin{array}{l}\text { lasdpc07, lasdpc05 } \\
\text { e lasdpc04- ociosos } \\
\text { lasdpc09, lasdpc08, } \\
\text { lasdix e } \\
\text { lasdpc10 - } 05 \text { proc. }\end{array}$ & $\begin{array}{l}\text { lasdpc07, lasdpc05 } \\
\text { e lasdpc04 - ociosos } \\
\text { lasdpc09, lasdpc08 } \\
\text { e lasdix - } 05 \text { proc. }\end{array}$ \\
\hline 3 & $\begin{array}{l}\text { Todas as máquinas do sistema são carregadas } \\
\text { de maneira proporcional à sua potência. } \\
\text { Assim, a máquina mais potente possui } \\
\text { mais processos e a menos potente a menor } \\
\text { quantidade de processos. }\end{array}$ & $\begin{array}{l}\text { lasdpc07 - } 05 \text { proc: } \\
\text { lasdpc05 - } 04 \text { proc. } \\
\text { lasdpc04 - } 03 \text { proc. } \\
\text { lasdpc09 - } 03 \text { proc. } \\
\text { lasdpc08, lasdix e } \\
\text { lasdpc10 - } 01 \text { proc. }\end{array}$ & $\begin{array}{l}\text { lasdpc07 - } 05 \text { proc. } \\
\text { lasdpc05 - } 04 \text { proc. } \\
\text { lasdpc04 - } 03 \text { proc. } \\
\text { lasdpc09 - } 03 \text { proc. } \\
\text { lasdpc08 e } \\
\text { lasdix - } 01 \text { proc. }\end{array}$ \\
\hline 4 & $\begin{array}{l}\text { Todas as máquinas do sistema são carregadas } \\
\text { de maneira inversamente proporcional à sua } \\
\text { potência. Com isso, a máquina mais potente } \\
\text { possui menos processos e a menos potente } \\
\text { fica com mais processos. }\end{array}$ & $\begin{array}{l}\text { lasdpc07 - } 01 \text { proc. } \\
\text { lasdpc05 - } 03 \text { proc. } \\
\text { lasdpc04 - } 03 \text { proc. } \\
\text { lasdpc09 - } 04 \text { proc. } \\
\text { lasdpc08, lasdix e } \\
\text { lasdpc10 - } 05 \text { proc. }\end{array}$ & $\begin{array}{c}\text { lasdpc07 - } 01 \text { proc. } \\
\text { lasdpc05 - } 02 \text { proc. } \\
\text { lasdpc04 - } 03 \text { proc. } \\
\text { lasdpc09 - } 03 \text { proc. } \\
\text { lasdpc08 e } \\
\text { làsdix - } 05 \text { proc. }\end{array}$ \\
\hline
\end{tabular}

como o valor de carga máxima atribuída a uma máquina foi considerada suficiente, uma vez que essa quantidade possibilitava a qualquer uma das máquinas do sistema passar (de acordo com os critérios adotados pela DPWP) do estado ocioso para carregado.

Um outro ponto que deve ser destacado sobre os experimentos, diz respeito à maneira como cada uma das diferentes aplicações (desenvolvidas nos ambientes TAO, PVM e LAMMPI) foram utilizadas. Quando diferentes aplicações são avaliadas, deve-se atentar para detalhes tais como: parâmetros de compilação, mecanismos de conversão de dados e organização dos programas, pois qualquer um desses fatores pode influenciar sobremaneira nos resultados. Com relação aos parâmetros de compilação foi possível definir uma padronização para que todas as aplicações não possuíssem diferenças, isto é, todas utilizaram o mesmo compilador e os mesmos parâmetros. No tocante à conversão de dados, apenas em PVM foi 
encontrada flexibilidade suficiente para permitir a escolha entre converter ou não os dados. LAM-MPI não define explicitamente um mecanismo de conversão de dados, enquanto TAO sempre utiliza o mecanismo CDR (Common Data Representation) [Vinoski \& Henning, 1999]. A organização dos programas também é uma questão difícil de ser contemplada de maneira homogênea entre as aplicações, pois, no caso da ferramenta TAO essa organização era restrita às invocações assíncronas através do modelo callback, o que diferencia consideravelmente das organizações adotadas por PVM e LAM-MPI. O código fonte das aplicações (TAO, PVM e LAM-MPI) utilizadas nos experimentos pode ser encontrado no Apêndice C.

\subsubsection{O problema do Caixeiro Viajante}

O problema do Caixeiro Viajante (Salesman Travelling) é comumente encontrado na literatura em razão de ser exemplificado para diversos domínios de aplicação e pertencer à classe de problemas NP-completo. De maneira geral, esse problema consiste em determinar a melhor rota (levando-se em consideração algum critério, por exemplo, tempo ou distância) que um viajante deve percorrer de maneira que visite todas as cidades de sua rota e ainda consiga retornar à cidade de onde partiu inicialmente. Levando-se em consideração os conceitos envolvidos com teoria dos grafos e programação dinâmica, Terada [Terada, 1991] apresenta a seguinte formulação para esse problema:

Seja $G=(V G, a G)$ um grafo orientado com custos $c_{i j}$ positivos associados às arestas $(i, j)$. Caso uma aresta $c_{i j}$ não exista convenciona-se que $c_{i j}$ seja infinito. Uma viagem em $G$ é um circuito (orientado) que contém cada vértice em $V G$ uma e uma só vez. A soma dos custos das arestas que foram utilizadas na viagem é chamada custo da viagem. Com isso, o problema do Caixeiro Viajante (PCV) consiste em encontrar uma viagem de custo mínimo, entre todas as viagens possíveis em $G$.

Uma abordagem para resolução do PCV consiste em utilizar a programação dinâmica [Terada, 1991], visto que essa técnica reduz significantemente o número de permutaçōes dos $n$ vértices e, com isso, pode propiciar um melhor desempenho para as aplicações. Assim, a resolução apresentada a seguir considera a programação dinâmica e supõe que uma viagem começa e termina no vértice 1 , após visitar cada um dos vértices $2,3, \ldots, n$ uma e uma só vez. Nesse sentido, qualquer viagem é constituída por uma aresta $(1, k), 2 \leq+k \leq n$, e um caminho $M$ de $k$ até 1 , sendo que o caminho $M$ visita cada um dos vértices em $V G-\{1, k\}$ uma e uma só vez. Se a viagem considerada é de custo mínimo, o caminho $M$ deve ser necessariamente de custo mínimo.

A Figura 6.1 apresenta um grafo orientado que será utilizado como base para o desenvolvimento de um exemplo a seguir: 


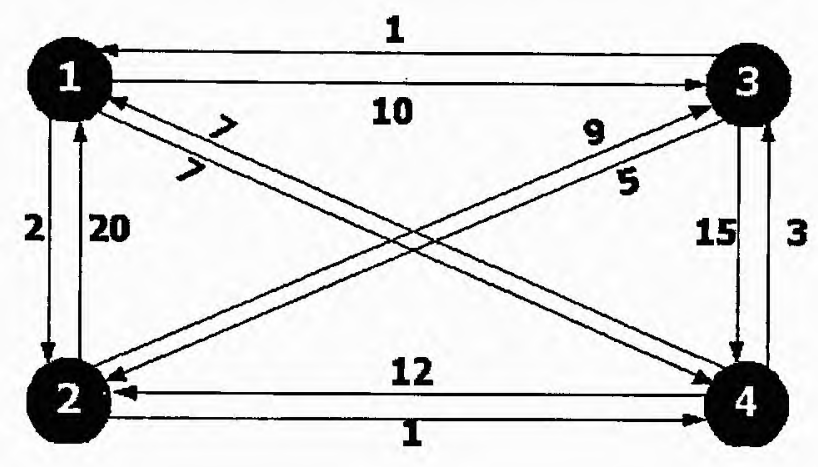

Figura 6.1: Grafo orientado com 04 nós (vértices) e 12 arcos (arestas)

Inicialmente, cria-se uma matriz contendo os pesos entre todas as cidades pertencentes ao grafo

1
1
2
3
4 $\left(\begin{array}{cccc}0 & 2 & 3 & 4 \\ 20 & 0 & 9 & 1 \\ 1 & 5 & 0 & 15 \\ 7 & 12 & 3 & 0\end{array}\right)$

A partir dessa matriz calcula-se todos todos os possíveis caminhos do grafo:

$$
\begin{aligned}
& f(2,\{3\})=C_{23}+C_{31}=9+1 \\
& f(2,\{4\})=C_{24}+C_{41}=1+7 \\
& f(3,\{2\})=C_{32}+C_{21}=5+20 \\
& f(3,\{4\})=C_{34}+C_{41}=15+7 \\
& f(4,\{2\})=C_{42}+C_{21}=12+20 \\
& f(4,\{3\})=C_{43}+C_{31}=3+1 \\
& f(2,\{3,4\})=\min \left\{C_{23}+f(3,4), C_{24}+f(4,\{3\})\right\}=5(j=4) \\
& f(3,\{2,4\})=\min \left\{C_{32}+f(2,4), C_{34}+f(4,\{2\})\right\}=13(j=2) \\
& f(4,\{2,3\})=\min \left\{C_{42}+f(2,3), C_{43}+f(3,\{2\})\right\}=28(j=3) \\
& f(1,\{2,3,4\})=\min \left\{C_{12}+f(2,3,4), C_{13}+f(3,\{2,4\}), C_{14}+f(4,\{2,3\})\right\}=7(j=2)
\end{aligned}
$$

Assim, como $j=2$ no cálculo de $f(1,\{2,3,4\})$ a primeira aresta do caminho mínimo é $(1,2)$. Prosseguindo, como $j=4$ no cálculo de $f(2,\{3,4\})$, a segunda aresta é $(2,4)$. A terceira aresta é $(4,3)$ pois $j=3$ no cálculo de $f(4,\{3\})$. Portanto, a viagem mínima nesse exemplo é $(1,2,4,3,1)$, com custo 7 .

Essa técnica de resolução para o PCV foi implementada, neste trabalho, em aplicações paralelas distribuídas utilizando os softwares PVM, LAM-MPI e TAO. Em cada uma dessas aplicações foi adotado um processo mestre e o número de escravos é proporcional ao número de cidades menos 1. O mestre envia a rota completa (uma matriz contendo todos os possíveis 
caminhos) e o ponto (cidade) onde o viajante deve ir a partir da origem. Para cada escravo é enviado um ponto diferente. Após enviar essas informações para todos os escravos, o mestre aguarda pela resposta (a rota percorrida) de cada um deles e determina qual foi a melhor rota.

\subsubsection{Método do trapézio composto}

$\mathrm{Na}$ aplicação que utiliza o método do trapézio composto para solucionar integrais definidas, o algoritmo utilizou-se de uma propriedade das integrais, onde dada uma função qualquer $f(x)$ que pode ser integrada nos pontos de $a$ até $b$, ela pode ser dividida no somatório de $n$ outras integrais. Assim, o cálculo das integrais é dividido entre os processos da aplicação [Cortés, 1999]. Para a execução dessa aplicação foram utilizadas seis máquinas e 7 processos (incluindo o processo mestre) com uma divisão total de três milhões e quinhentos mil trapézios e um intervalo de $a=0$ e $b=1.2$.

A paralelização dessa aplicação foi feita da seguinte maneira: o nó mestre calcula os intervalos (entre 0 e 1.2) para cada processo e os envia aos escravos. Os escravos recebem os seus intervalos, calculam a quantidade de divisōes e, após calcularem a integral, enviam o resultado ao mestre. O mestre, por sua vez, efetua o somatório dos resultados obtendo a solução final. A Figura 6.2 apresenta os passos necessários para a resolução desse método.

Uma descrição mais detalhada sobre o método do trapézio composto pode ser vista no trabalho de Cortés [Cortés, 1999].

\subsection{Análise estatística considerada}

O objetivo de realizar uma análise estatística neste trabalho é verificar se as diferenças de desempenho das aplicações, considerando os diversos fatores (diferentes ferramentas, políticas de escalonamento, situações de carga do sisțema, etc.), são estatisticamente significativas.

Assim, para os experimentos apresentados na Seção 6.5, considerou-se lançar mão da técnica estatística denominada Teste de Hipóteses [Francisco, 1995]; [Achcar \& Rodrigues, 1995] visando justamente notar a diferença entre os resultados obtidos. Essa técnica é desenvolvida a partir de duas hipóteses, $H_{0}$ ou hipótese nulidade e $H_{1}$ ou hipótese alternativa, formuladas sobre os valores que deseja-se comparar. O primeiro passo para utilização do Teste de Hipóteses consiste na definição dessas duas hipóteses que, após realizar o cálculo dos testes, uma delas será aceita e a outra rejeitada. A hipótese $H_{0}$ ou hipótese nulidade 


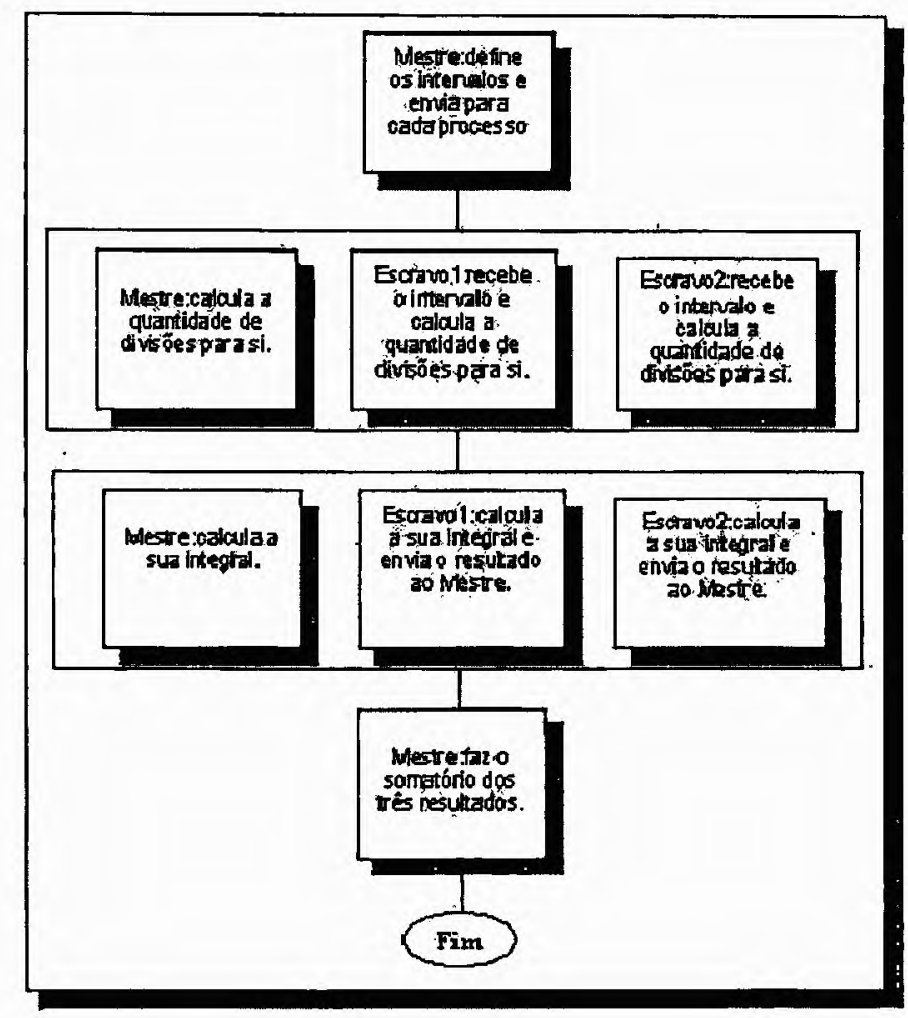

Figura 6.2: Passos utilizados para execução da aplicação do trapézio composto

é geralmente formulada procurando-se "discordar" dos valores obtidos com o experimento. A hipótese $H_{1}$ ou hipótese alternativa é aquela que geralmente "concorda" com os valores obtidos no experimento quando comparados "in-loco". Dessa forma, a hipótese $H_{0}$ é a negação da hipótese $H_{1}$.

Visando exemplicar o emprego dessas duas hipóteses tem-se o seguinte exemplo [Francisco, 1995]:

"Em uma classe de 40 alunos, as notas de Matemática distribuíram-se normalmente com média 7,25 e desvio-padrão 3,5. Em outra classe de 50 alunos as notas também distribuíram-se normalmente com média 6,8 e desvio-padrão 1,75. Testar a hipótese de que não há diferença significativa no aproveitamento dos alunos das duas classes em relação à Matemática." 
De acordo com o enunciado do problema, pode-se observar que as médias dos alunos são diferentes $(7,25$ e 6,8$)$. No entanto, é interessante comprovar se essa diferença é realmente significativa. Assim, a formulação das hipóteses $H_{0}$ e $H_{1}$ seria:

$$
\begin{aligned}
& H_{0}: \mu_{1}=\mu_{2} \\
& H_{1}: \mu_{1} \neq \mu_{2}
\end{aligned}
$$

Para determinar estatisticamente qual hipótese pode ser aceita tenta-se provar a hipótese nulidade. Caso não se consiga prová-la, a hipótese alternativa é adotada.

O teste de hipótese, propriamente dito, é desenvolvido a partir da seguinte equação:

$$
\mathrm{z}=\frac{\mu_{1}-\mu_{2}}{\sqrt{\frac{\mathbf{s}_{1}^{2}}{\mathbf{n}_{1}}+\frac{\mathbf{s}_{2}^{2}}{\mathbf{n}_{2}}}}
$$

onde:

$\mu_{1}$ e $\mu_{2}$ são as médias amostrais que deseja-se testar;

$s_{1}^{2}$ e $s_{2}^{2}$ representam o desvio padrão amostral;

$n_{1}$ e $n_{2}$ representam o tamanho das amostras.

Antes de resolver a Equação 6.1 deve-se escolher um nível de significância ( $\alpha$ ) para o teste. Esse nível indica a probabilidade de que o valor de $z$ esteja correto em $(100-\alpha) \%$ das vezes em que esse teste for realizado. Por exemplo, caso seja escolhido um nível de significância de $0,01(1 \%)$, isso significa que há uma probabilidade de que o valor de $z$ esteja correto em $99 \%$ das vezes em que a análise estatística for feita. De acordo com o nível de significância adotado, 0 valor de $z$ deve ser comparado com os valores fornecidos pela Tabela de Distribuição Normalizada [Achcar \& Rodrigues, 1995]. Se o valor de $z$ estiver dentro da faixa indicada nessa tabela, a hipótese $H_{0}$ é aceita. De outra forma, a hipótese $H_{1}$ deve ser considerada.

O tipo de teste de hipótese apresentado no exemplo acima, é denominado teste da diferença de duas médias [Francisco, 1995] em razão de comparar se os valores obtidos com as duas médias são significativos. No exemplo, a resolução desse teste é bilateral, uma vez que realizou-se apenas um cálculo da Equação $6.1 \mathrm{e}$, após isso, foi verificado se o valor obtido estava dentro de uma faixa de aceitação. Devido à adequação, esse mesmo teste foi adotado nos experimentos apresentados na Seção 6.5, considerando um nível de significância de 0,01 e também resolvido de maneira bilateral. As tabelas contendo os cálculos de média, variância, desvio padrão e teste de hipótese realizados neste trabalho encontram-se no Apêndice $B$. 


\subsection{Resultados obtidos}

Os gráficos apresentados em todas as figuras a seguir correspondem a valores médios obtidos após 30 execuções de cada uma das aplicações e sob cada uma das formas de escalonamento.

As Figuras 6.3 a 6.5 mostram os resultados obtidos com aplicações TAO, PVM e LAMMPI, utilizando o escalonamento round-robin e o escalonamento definido pelo AMIGO em um sistema ocioso. Na tentativa de melhor organizar as figuras de acordo com os objetivos considerados em cada experimento e, com isso, apresentar conclusões de maneira mais coesa, as Figuras 6.3, 6.4 e 6.5 foram organizadas como pertencentes ao experimento 1, enquanto que as Figuras 6.6, 6.7 e 6.8 estão relacionadas ao experimento 2. A discussão sobre cada um desses dois experimentos encontra-se na Tabela 6.3.

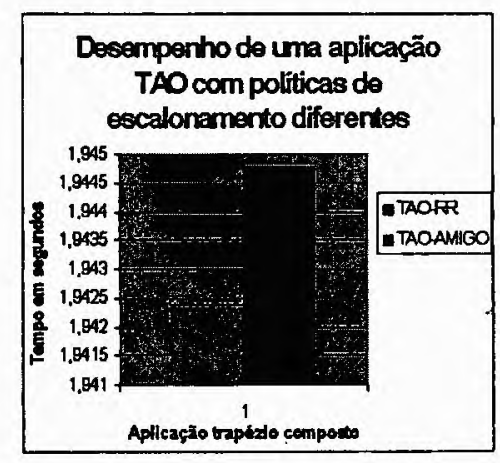

Figura 6.3: Desempenho da aplicação do trapézio composto utilizando a ferramenta-TAO com escalonamento round-robin e definido pelo AMIGO em um sistema ocioso

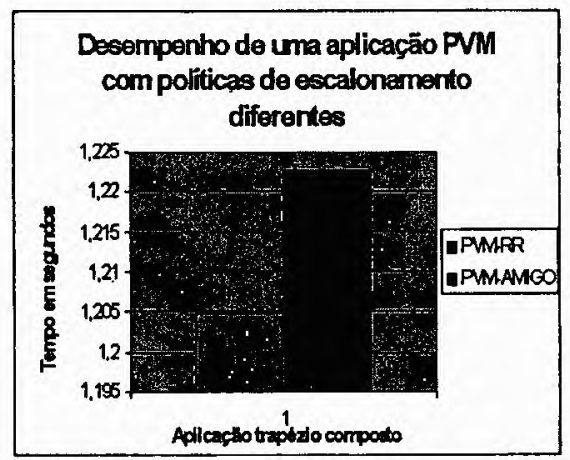

Figura 6.4: Desempenho da aplicação do trapézio composto utilizando a ferramenta PVM com escalonamento round-robin e definido pelo AMIGO em um sistema ocioso 


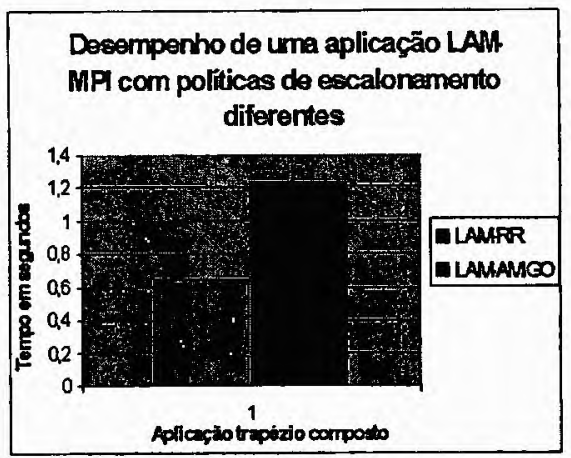

Figura 6.5: Desempenho da aplicação do trapézio composto utilizando a ferramenta LAM-MPI com escalonamento round-robin e definido pelo AMIGO em um sistema ocioso

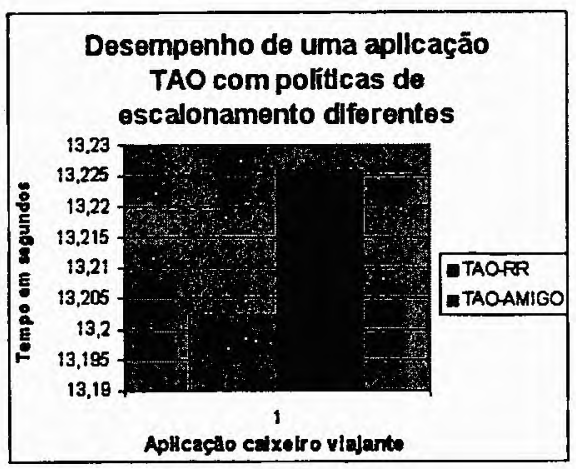

Figura 6.6: Desempenho da aplicação do caixeiro viajante utilizando a ferramenta TAO com escalonamento round-robin e definido pelo AMIGO em um sistema ocioso

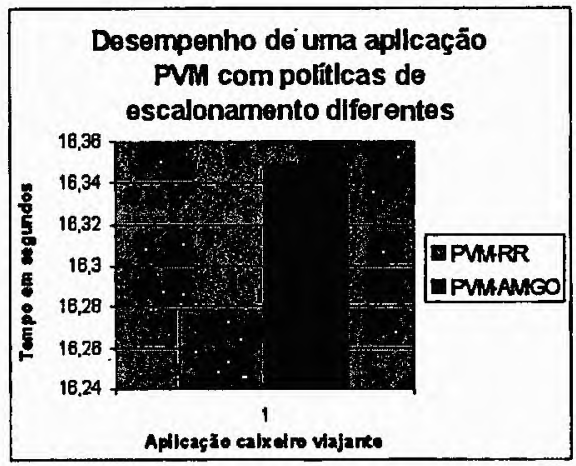

Figura 6.7: Desempenho da aplicação do caixeiro viajante utilizando a ferramenta PVM com escalonamento round-robin e definido pelo AMIGO em um sistema ocioso 


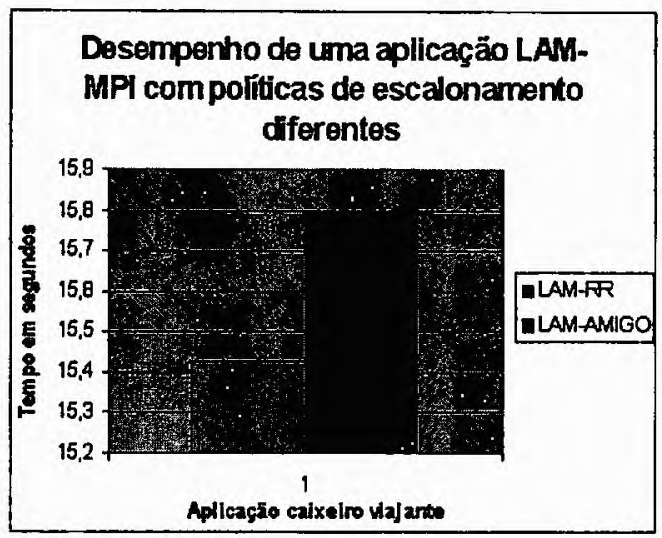

Figura 6.8: Desempenho da aplicação do caixeiro viajante utilizando a ferramenta LAM-MPI. com escalonamento round-robin e definido pelo AMIGO em um sistema ocioso

Tabela 6.3: Detalhamento e conclusões sobre os experimentos 1 e 2

\begin{tabular}{||c|c|l||}
\hline Experimento & $\begin{array}{c}\text { Situação do } \\
\text { sistema }\end{array}$ & Conclusões \\
\hline 1 e 2 & Ocioso & $\begin{array}{l}\text { Os resultados apresentados confirmam a idéia de que sob determi- } \\
\text { nadas condiçöes, utilizar técnicas aprimoradas de escalonamento } \\
\text { (diferente do escalonamento round-robin) pode não surtir efeitos } \\
\text { positivos no desempenho final da aplicação. Os valores obtidos } \\
\text { nesses 2 experimentos foram fortemente influenciados pelas ca- } \\
\text { racterísticas das aplicaçöes (ambas utilizavam todas as máquinas } \\
\text { ou hosts disponíveis no multicomputador ou máquina paralela } \\
\text { virtual) e pelo conhecimento prévio que o desenvolvedor possuía } \\
\text { sobre o desempenho das máquinas utilizadas. Em situações onde } \\
\text { nem todos os hosts da máquina paralela são utilizados e o de- } \\
\text { senvolvedor não possui conhecimento sobre a configuração desses } \\
\text { hosts, é possível qué a utilização de ambientes de escalonamento } \\
\text { e técnicas aprimoradas possam trazer melhorias de desempenho. } \\
\text { Apesar da diferença entre o escalonamento do AMIGO e o round- } \\
\text { robin ser notória, pôde-se constatar através de testes de hipóteses } \\
\text { que apenas os. resultados obtidos com aplicações LAM-MPI e } \\
\text { PVM (apenas na Figura 6.4) eram realmente significativos dentro } \\
\text { de um nível de significância de 0,01. }\end{array}$ \\
\hline
\end{tabular}

Um outro experimento (experimento 3) tem o objetivo de verificar as diferenças de desempenho de uma aplicação quando é adotado o escalonamento round-robin e o definido pelo AMIGO em um sistema com diferentes perfis de carga. As Figuras 6.9 a 6.11 apresentam os tempos de execução obtidos com a aplicação do trapézio composto, respectivamente, nos ambientes TAO, PVM e LAM-MPI. 


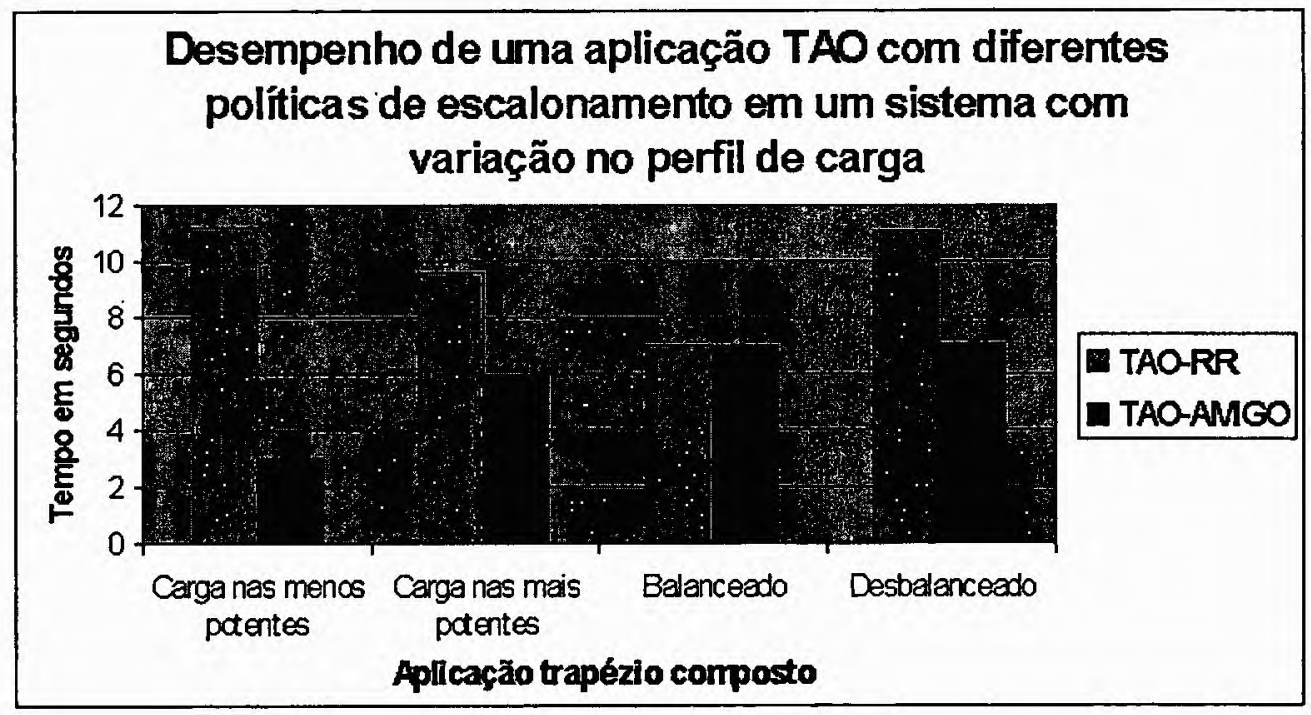

Figura 6.9: Desempenho da aplicação do trapézio composto utilizando a ferramenta TAO com escalonamento round-robin e definido pelo AMIGO em um sistema com perfis de carga diferentes

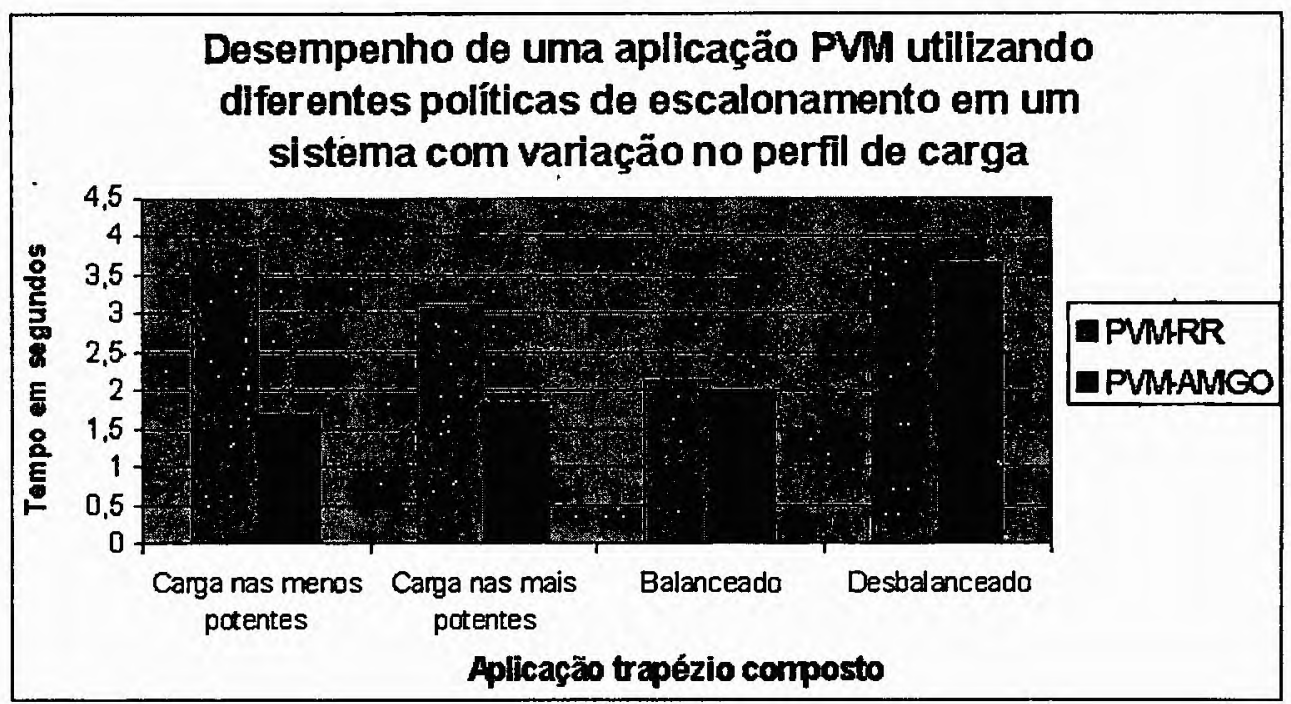

Figura 6.10: Desempenho da aplicação do trapézio composto utilizando a ferramenta PVM com escalonamento round-robin e definido pelo AMIGO em um sistema com perfis de carga diferentes

O experimento 4 tem os mesmos objetivos do experimento 3. No entanto, nesse novo experimento são apresentados, através das Figuras 6.12 a 6.14, os tempos de execução 


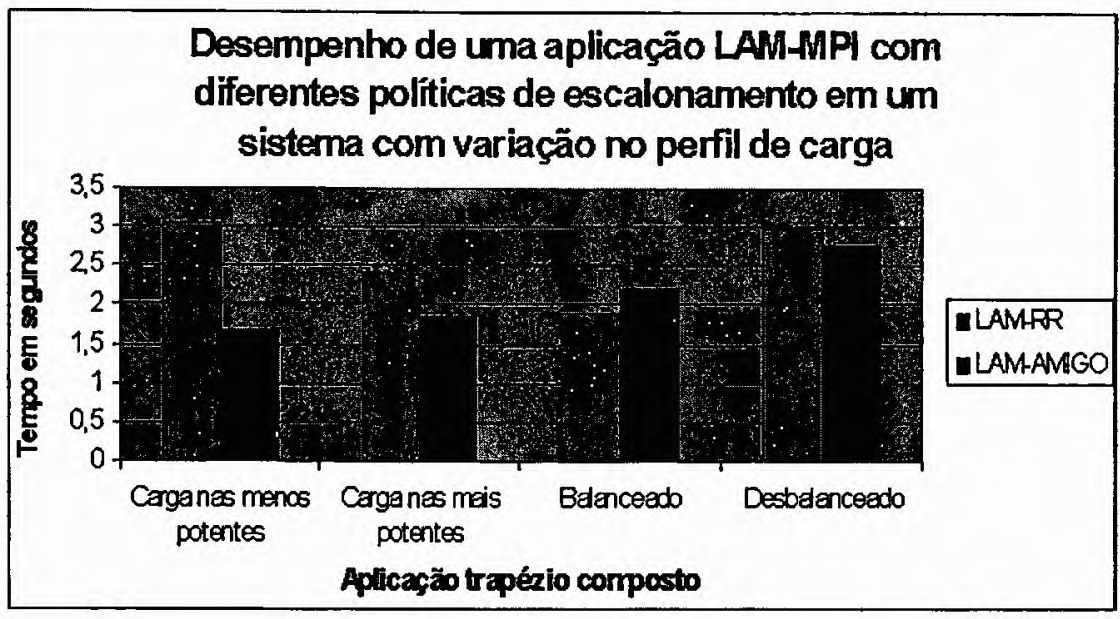

Figura 6.11: Desempenho da aplicação do trapézio composto utilizando a ferramenta LAMMPI com escalonamento round-robin e definido pelo AMIGO em um sistema com perfis de carga diferentes

da aplicação do caixeiro viajante nos ambientes TAO, PVM e LAM-MPI sob as diferentes condições de carga e com diferentes políticas de escalonamento.

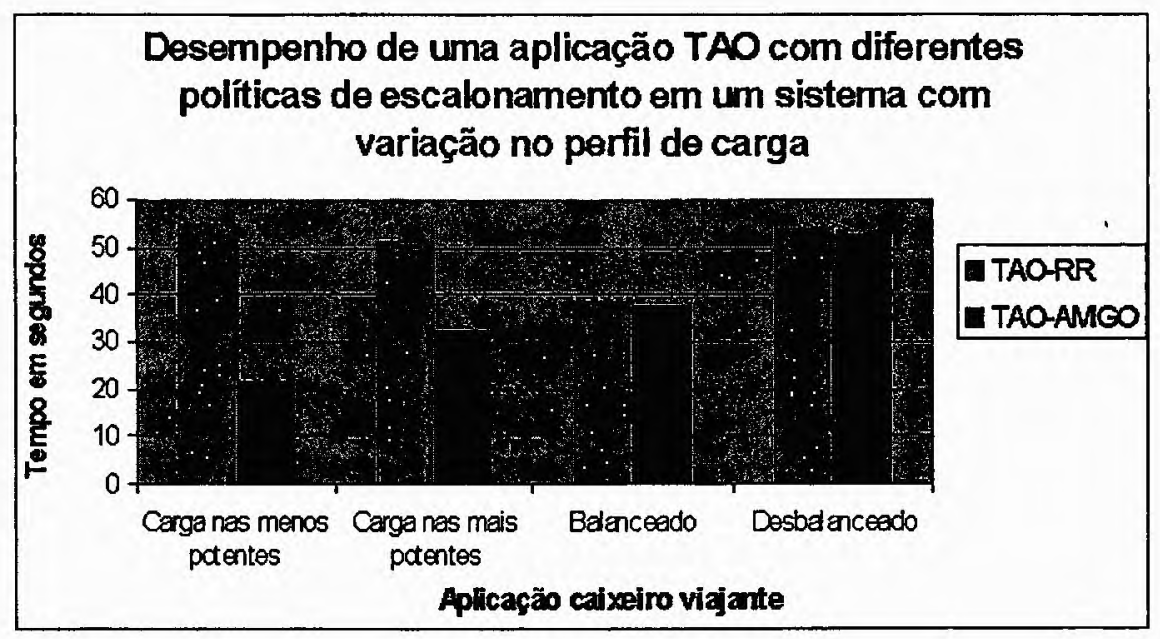

Figura 6.12: Desempenho da aplicação do caixeiro viajante utilizando a ferramenta TAO com escalonamento round-robin e definido pelo AMIGO em um sistema com perfis de carga diferentes

Nas Figuras 6.3 a 6.14 são observadas as diferenças de desempenho de uma aplicação que adota o escalonamento round-robin ou o AMIGO. Apesar de ser correto comparar 


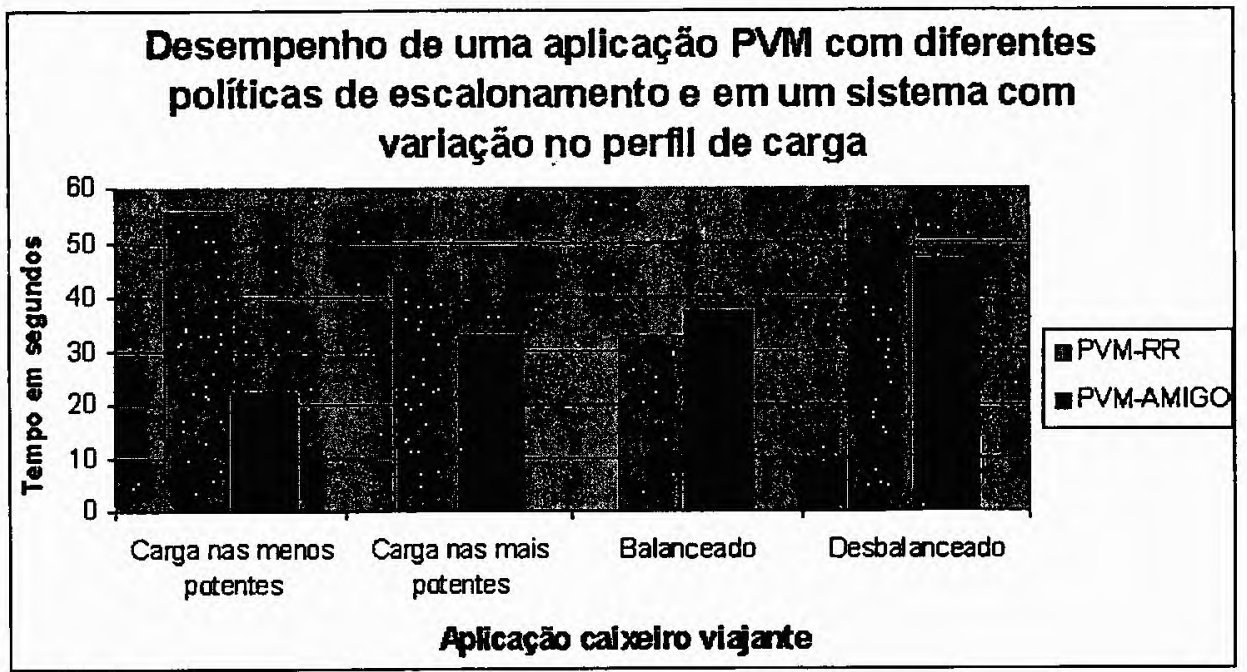

Figura 6.13: Desempenho da aplicação do caixeiro viajante utilizando a ferramenta PVM com escalonamento round-robin e definido pelo AMIGO em um sistema com perfis de carga diferentes

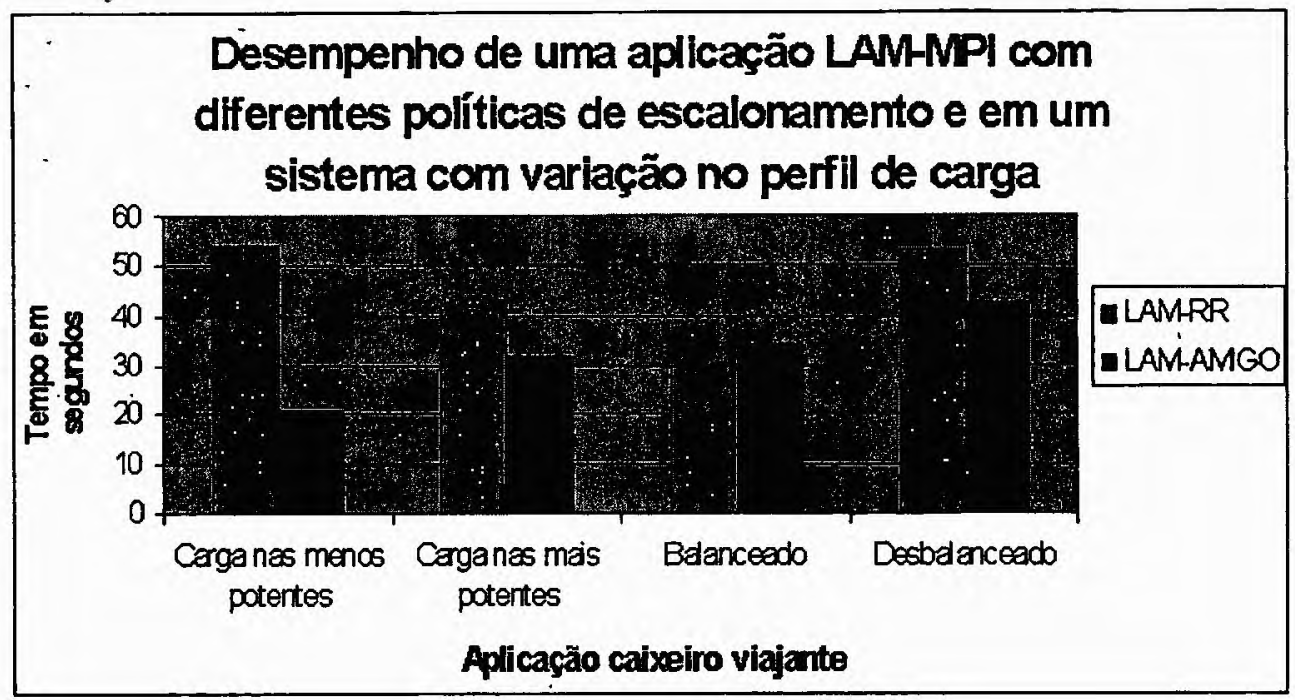

Figura 6.14: Desempenho da aplicação do caixeiro viajante utilizando a ferramenta LAMMPI com escalonamento round-robin e definido pelo AMIGO em um sistema com perfis de carga diferentes

essas duas formas de escalonamento, pode ser desejável também analisar o desempenho da aplicação sob o ponto de vista das diferentes ferramentas de desenvolvimento. 
Tabela 6.4: Detalhamento e conclusões sobre os experimentos 3 e 4

\begin{tabular}{||c|c|l||}
\hline Experimento & $\begin{array}{c}\text { Situação do } \\
\text { sistema }\end{array}$ & Conclusōes \\
\hline 3 & Carregado & $\begin{array}{l}\text { Nesse experimento podem ser notados os ganhos de desempenho } \\
\text { com a utilização do AMIGO em perfis de carga diferentes. No } \\
\text { caso do perfil "balanceado" não houve ganhos de desempenho } \\
\text { significativos (de acordo com os testes de hipóteses realizados) } \\
\text { pois, a política de escalonamento utilizada pelo AMIGO consi- } \\
\text { derava todas as máquinas como sendo carregadas e, com isso, o } \\
\text { escalonamento ocorria da mesma maneira que o round-robin. }\end{array}$ \\
\hline 4 & Carregado \\
& $\begin{array}{l}\text { As figuras que representam esse experimento apresentam um } \\
\text { comportamento parecido as do experimento anterior. A única } \\
\text { alteração está na aplicação, pois agora utiliza-se a aplicação que } \\
\text { resolve o problema do caixeiro viajante. Na situação onde o } \\
\text { sistema foi carregado com o perfil "balanceado" não há ganhos de } \\
\text { desempenho significativos (de acordo com os testes de hipóteses } \\
\text { realizados) entre adotar o escalonamento padrão (round-robin) e } \\
\text { o AMIGO. Em alguns casos, os tempos obtidos quando utiliza- } \\
\text { se o AMIGO são superiores em virtude dos atrasos (sobrecarga) } \\
\text { para distribuição e inicialização dos processos escravos. Um } \\
\text { fato importante a destacar é que o melhor desempenho obtido } \\
\text { com o AMIGO ocorreu na situação onde há o pior desempenho } \\
\text { com o round-robin (carga nas máquinas menos potentes). Nesse } \\
\text { caso, o AMIGO escalona os processos apenas para as melhores } \\
\text { máquinas uma -vez que essas estão ociosas enquanto o round- } \\
\text { robin continua distribuindo processos para todas as máquinas de } \\
\text { maneira igualitária. }\end{array}$ \\
\hline
\end{tabular}

Visando contemplar essa perspectiva, os gráficos das Figuras 6.15 a 6.18 indicam os tempos de execução obtidos com aplicações dos ambientes TAO, PVM e LAM-MPI sob situações de carga variadas. De forma mais detalhada, a Figura 6.15 apresenta os tempos de execução da aplicação do trapézio composto nos três ambientes utilizando o escalonamento round-robin em um sistema carregado. A Figura 6.16 utiliza os mesmos parâmetros de 6.15 modificando-se apenas a maneira de escalonamento, pois agora, o AMIGO é o responsável por gerenciar essa atividade. As Figuras 6.17 e 6.18 possuem os mesmos critérios adotados nas duas anteriores. A única mudança está na aplicação utilizada, pois, os tempos obtidos dizem respeito ao problema do caixeiro viajante. 


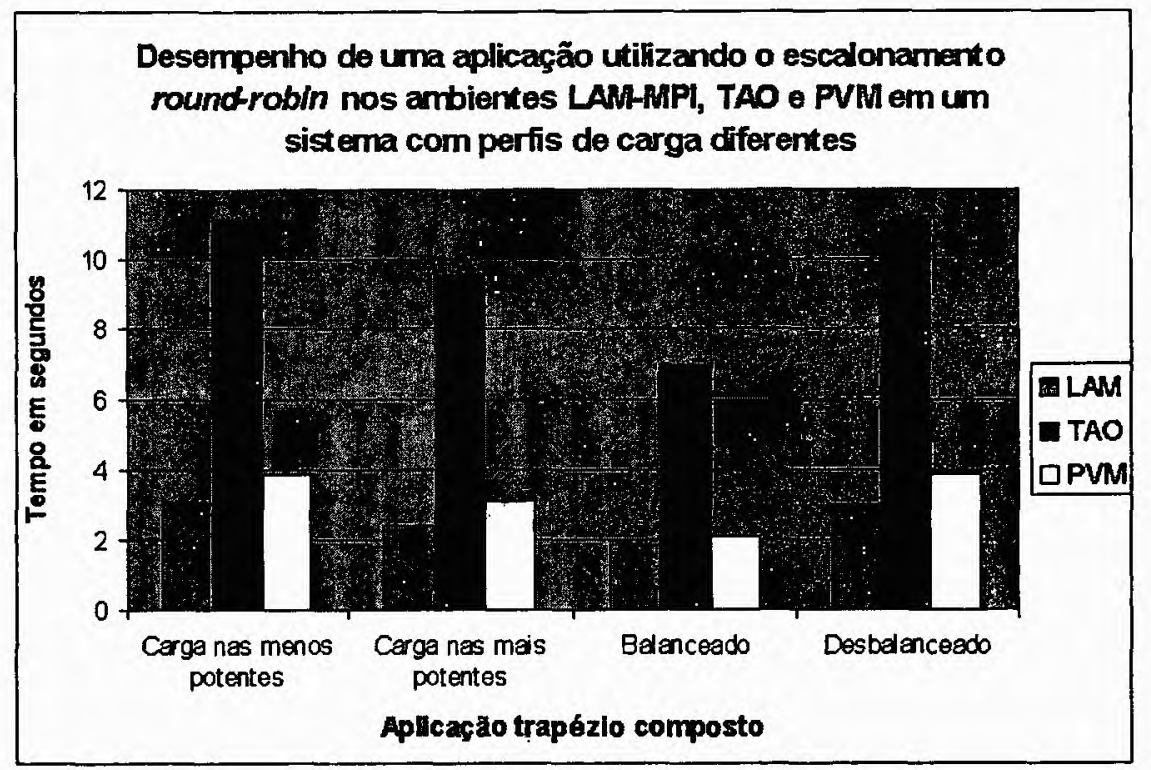

Figura.6.15: Desempenho da aplicação do trapézio composto utilizando as ferramentas LAMMPI, .TAO e PVM com escalonamento round-robin em um sistema com perfis de carga diferentes

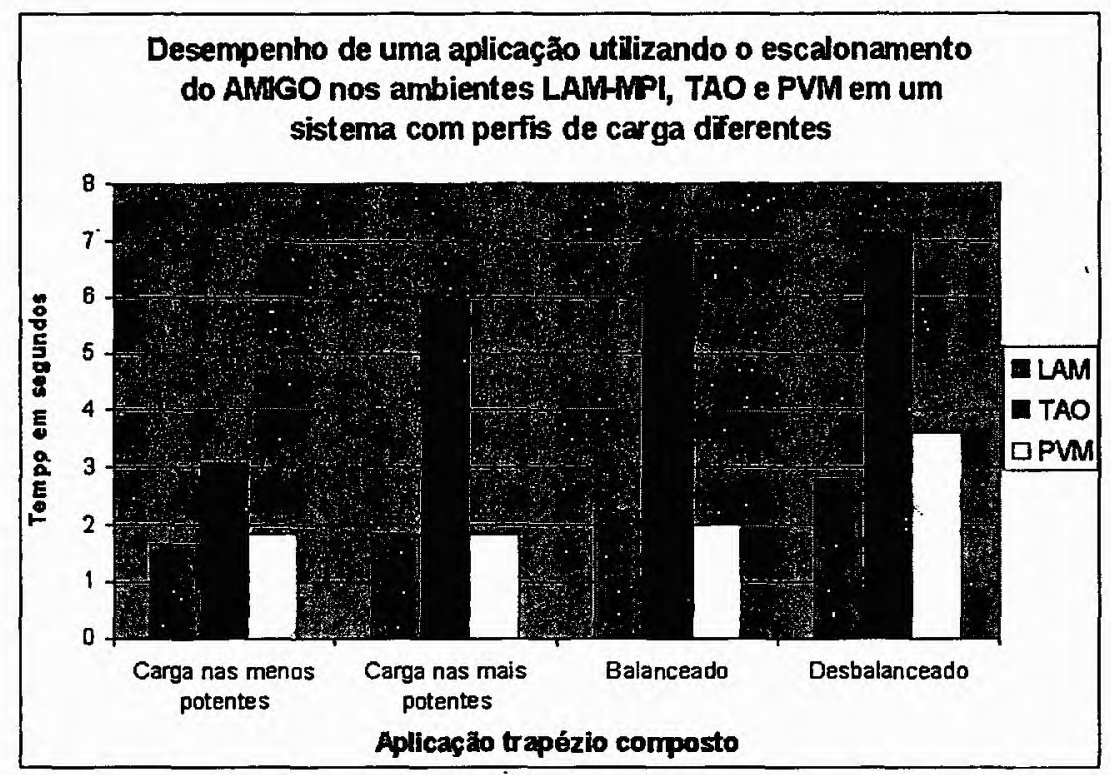

Figura 6.16: Desempenho da aplicação do trapézio composto utilizando as ferramentas LAMMPI, TAO e PVM com escalonamento definido pelo AMIGO em um sistema com perfis de carga diferentes 


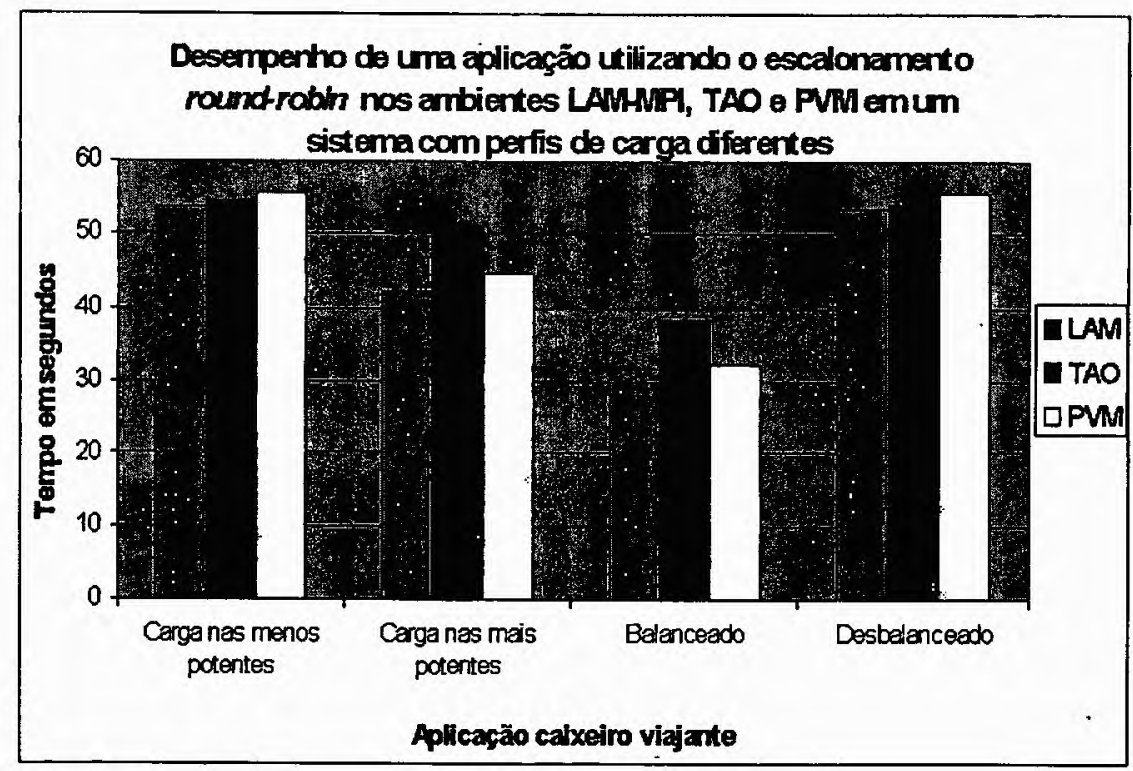

Figura 6.17: Desempenho da aplicação do caixeiro viajante utilizando as ferramentas LAMMPI, TAO e PVM com escalonamento round-robin em um sistema com perfis de carga diferentes

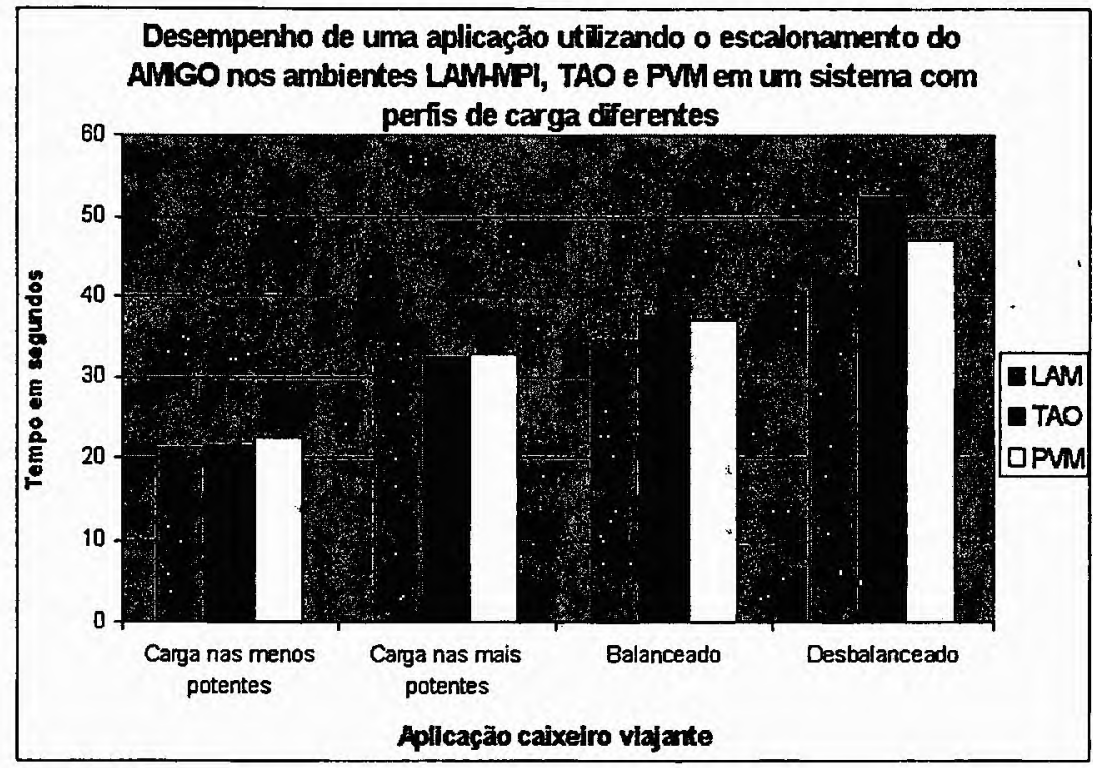

Figura 6.18: Desempenho da aplicação do caixeiro viajante utilizando as ferramentas LAMMPI, TAO e PVM com escalonamento definido pelo AMIGO em um sistema com perfis de carga diferentes 
Tabela 6.5: Detalhamento e conclusões sobre as Figuras 6.15 a 6.18

\begin{tabular}{|c|c|c|}
\hline Figuras & $\begin{array}{l}\text { Situação do } \\
\text { sistema }\end{array}$ & Conclusões \\
\hline 6.15 e 6.16 & Carregado & $\begin{array}{l}\text { Nas Figuras } 6.15 \text { e } 6.16 \text { a comunicação adotada na aplicação } \\
\text { do trapézio composto é realizada através do envio/recebimento } \\
\text { de tipos de dados básicos (inteiros). O processamento realizado } \\
\text { por cada um dos escravos é suficientemente pequeno para que } \\
\text { a sobrecarga imposta pela comunicação possa influenciar direta- } \\
\text { mente os resultados. Como pode ser observado, TAO apresenta } \\
\text { um desempenho inferior em razão de sua sobrecarga para en- } \\
\text { vio/recebimento desses tipos de dados. A ferramenta LAM-MPI } \\
\text { tem uma certa vantagem nesse aspecto, pois, possui uma biblioteca } \\
\text { de comunicação otimizada para esses tipos de dados e também por } \\
\text { utilizar protocolos de comunicação com menor sobrecarga, como o } \\
\text { UDP. TAO utiliza protocolos que levam em consideração fatores } \\
\text { como confiabilidade (TCP) e interoperabilidade (IIOP) e, devido } \\
\text { a isso, geram maior sobrecarga e menor desempenho. Além disso, } \\
\text { a ferramenta LAM-MPI não utiliza um mecanismo para conversão } \\
\text { de dados, enquanto TAO utiliza o CDR (Commom Data Repre- } \\
\text { sentation) e PVM utiliza o XDR (eXternal Data Representation). } \\
\text { Assim, no caso da aplicação do trapézio composto a eficiência da } \\
\text { camada de comunicação dessas ferramentas acaba influenciando o } \\
\text { desempenho final da aplicação. }\end{array}$ \\
\hline 6.17 e 6.18 & Carregado & $\begin{array}{l}\text { Nas Figuras } 6.17 \text { e } 6.18 \text { a comunicação entre o processo mestre } \\
\text { e os escravos é realizada através do envio/recebimento de vetores } \\
\text { e matrizes de inteiros. Apesar disso, pôde-se notar que a sobre- } \\
\text { carga de comunicação imposta por ferramentas como TAO não } \\
\text { influenciou consideravelmente no desempenho final da aplicação, } \\
\text { pois, no caso da aplicação do caixeiro viajante o tempo necessário } \\
\text { para a resolução do problema é alto. Com isso, os três ambientes } \\
\text { tiveram um desempenho bastante parecido. Em algumas situações, } \\
\text { a aplicação TAO obteve resultados melhores que a aplicação PVM. } \\
\text { Nos testes de hipóteses realizados para os valores obtidos da } \\
\text { Figura 6.18, verificou-se que a diferença existente na situação onde } \\
\text { há carga na máquina menos potentes e com o sistema "balanceado", } \\
\text { não é significativa. No caso da situação "carga nas mais potentes" } \\
\text { e "balanceado", TAO apresentou um desempenho inferior devido } \\
\text { à maneira como a política utilizada pelo AMIGO distribuiu os } \\
\text { processos. }\end{array}$ \\
\hline
\end{tabular}

\subsection{Considerações finais}

Neste capítulo foram apresentados os resultados de avaliações de desempenho realizadas com aplicações paralelas desenvolvidas com três ferramentas: LAM-MPI, TAO e PVM. 
Alguns dos experimentos aqui realizados tiveram o objetivo de verificar o desempenho dessas aplicaçōes quando submetidos ao escalonamento round-robin e o definido pelo AMIGO sob um sistema com diferentes situaçōes de carga.

Além de servirem como validação para a interface CORBA-AMIGO e sua estrutura de suporte, os resultados apresentados e discutidos ratificam as conclusões apresentadas nos trabalhos de Araújo [Araújo, 1999], Souza [Souza, 2000] e Figueiredo [Figueiredo, 2000], sobre os ganhos no desempenho da aplicação que a adoção de ambientes de escalonamento com políticas mais aprimoradas, pode propiciar. Além disso, as discussões em torno desses resultados confirmam a possibilidade de serem utilizadas ferramentas CORBA, tais como TAO, para o desenvolvimento de aplicaçōes paralelas podendo, em alguns casos, alcançar desempenho semelhante ao obtido com outras ferramentas concebidas especificamente para esse propósito.

Os resultados também demonstram que o uso de CORBA para a implementação de aplicações paralelas distribuídas é viável e atrativo sob diversos aspectos. Isso amplia a gama de possibilidades disponíveis para os desenvolvedores de aplicações paralelas distribuídas, bem como amplia o número de ambientes que utilizam os serviços do AMIGO.

Um outro aspecto que merece especial destaque refere-se à flexibilidade e independência do ambiente AMIGO com relação aos tipos de aplicações que utilizam seus serviços. Os esforços necessários para o desenvolvimento das interfaces entre o AMIGO e os softwares PVM, LAM-MPI e TAO foram diferentes, pois, cada um possui características que podem, ou não, ser mais adequadas para a construção dessa interface. No entanto, essas diferenças quanto ao número e tipo de características nāo inviabilizaram a utilização do AMIGO e, por conseguinte, os ganhos de desempenho com o uso de seus serviços. 


\section{Conclusões e Trabalhos Futuros}

\subsection{Considerações finais}

O trabalho discutido nesta dissertação abordou aspectos envolvendo a implementação de uma interface de comunicação entre a ferramenta TAO e o ambiente AMIGO, com o intuito de prover um escalonamento eficiente para aplicações desenvolvidas sob essa ferramenta. Para o desenvolvimento dessa interface houve a necessidade de realizar estudos e avaliações visando escolher uma ferramenta que fosse adequada aos requisitos (apresentados no Capítulo 4) do trabalho. Após um estudo minucioso, constatou-se a adequabilidade da implementação TAO, não apenas para a construção da interface com o AMIGO mas, também, no que diz respeito ao desenvolvimento de aplicações paralelas. Não obstante, verificou-se a necessidade de implementar uma estrutura de suporte (sobre a ferramenta TAO) para posteriormente construir a interface com o AMIGO. Os detalhes envolvendo a implementação da estrutura de suporte e da interface CORBA-AMIGO foram apresentados no Capítulo 5.

De acordo com os resultados apresentados e discutidos no Capítulo 6, pôde-se notar a possibilidade de serem obtidos ganhos de desempenho com a utilização do ambiente AMIGO sob diversas situações de um sistema computacional utilizado. Além dessas situações, há também a possibilidade de aumento no desempenho quando o usuário/desenvolvedor da aplicação não possui conhecimento detalhado sobre a plataforma de hardware utilizada.

Os resultados apresentados no Capítulo 6 também mostraram que ferramentas CORBA podem ser utilizadas como uma alternativa para o desenvolvimento de aplicações 
Alguns dos experimentos aqui realizados tiveram o objetivo de verificar o desempenho dessas aplicações quando submetidos ao escalonamento round-robin e o definido pelo AMIGO sob um sistema com diferentes situações de carga.

Além de servirem como validação para a interface CORBA-AMIGO e sua estrutura de suporte, os resultados apresentados e discutidos ratificam as conclusões apresentadas nos trabalhos de Araújo [Araújo, 1999], Souza [Souza, 2000] e Figueiredo [Figueiredo, 2000], sobre os ganhos no desempenho da aplicação que a adoção de ambientes de escalonamento com políticas mais aprimoradas, pode propiciar. Além disso, as discussōes em torno desses resultados confirmam a possibilidade de serem utilizadas ferramentas CORBA, tais como TAO, para o desenvolvimento de aplicações paralelas podendo, em alguns casos, alcançar desempenho semelhante ao obtido com outras ferramentas concebidas especificamente para esse propósito.

Os resultados também demonstram que o uso de CORBA para a implementação de aplicações paralelas distribuídas é viável e atrativo sob diversos aspectos. Isso amplia a gama de possibilidades disponíveis para os desenvolvedores de aplicações paralelas distribuídas, bem como amplia o número de ambientes que utilizam os serviços do AMIGO.

Um outro aspecto que merece especial destaque refere-se à flexibilidade e independência do ambiente AMIGO com relação aos tipos de aplicações que utilizam seus serviços. Os esforços necessários para o desenvolvimento das interfaces entre o AMIGO e os softwares PVM, LAM-MPI e TAO foram diferentes, pois, cada um possui características que podem, ou não, ser mais adequadas para a construção dessa interface. No entanto, essas diferenças quanto ao número e tipo de características não inviabilizaram a utilização do AMIGO e, por conseguinte, os ganhos de desempenho com o uso de seus serviços. 


\begin{tabular}{l|c|} 
Capítulo & . \\
\hline
\end{tabular}

\section{Conclusões e Trabalhos Futuros}

\subsection{Considerações finais}

O trabalho discutido nesta dissertação abordou aspectos envolvendo a implementação de uma interface de comunicação entre a ferramenta TAO e o ambiente AMIGO, com o intuito de prover um escalonamento eficiente para aplicações desenvolvidas sob essa ferramenta. Para o desenvolvimento dessa interface houve a necessidade de realizar estudos e avaliações visando escolher uma ferramenta que fosse adequada aos requisitos (apresentados no Capítulo 4) do trabalho. Após um estudo minucioso, constatou-se a adequabilidade da implementação TAO, não apenas para a construção da interface com o AMIGO mas, também, no que diz respeito ao desenvolvimento de aplicações paralelas. Não obstante, verificou-se a necessidade de implementar uma estrutura de suporte (sobre a ferramenta TAO) para posteriormente construir a interface com o AMIGO. Os detalhes envolvendo a implementação da estrutura de suporte e da interface CORBA-AMIGO foram apresentados no Capítulo 5.

De acordo com os resultados apresentados e discutidos no Capítulo 6, pôde-se notar a possibilidade de serem obtidos ganhos de desempenho com a utilização do ambiente AMIGO sob diversas situações de um sistema computacional utilizado. Além dessas situações, há também a possibilidade de aumento no desempenho quando o usuário/desenvolvedor da aplicação não possui conhecimento detalhado sobre a plataforma de hardware utilizada.

Os resultados apresentados no Capítulo 6 também mostraram que ferramentas CORBA podem ser utilizadas como uma alternativa para o desenvolvimento de aplicações 
paralelas, podendo, em algumas situações, ter-se um desempenho comparado ao obtido com outras ferramentas concebidas exclusivamente para esse propósito. Se o desempenho é considerado um agravante quando utiliza-se a arquitetura CORBA em alguns domínios de aplicações, a relativa facilidade na implementação de aplicações, juntamente com a gama de serviços disponiveis, podem ser citados como um fator favorável à adoção dessa arquitetura.

A partir do exposto, este Capítulo discorre sobre as principais contribuições geradas por este trabalho, assim como as dificuldades encontradas durante o período de desenvolvimento e, por fim, as sugestões para realização de trabalhos futuros.

\subsection{Contribuições deste trabalho}

O fato de se tratar CORBA como uma alternativa para desenvolvimento de aplicações paralelas, pode ser visto como uma das principais contribuições, uma vez que há poucos trabalhos encontrados na literatura que tratam dessa questão, principalmente no que concerne à disponibilidade de ferramentas. De forma geral, outras contribuições deste trabalho são elencadas a seguir:

- Adequação de uma ferramenta CORBA para o desenvolvimento e. gerenciamento de aplicações paralelas distribuídas, através da implementação de uma camada de software sobre o Repositório de Implementação. Essa camada acrescentou diversas características para gerenciamento de hosts remotos, tendo como base ferramentas como PVM e LAM-MPI;

- Constatação da "independência" e flexibilidade providas pelo AMIGO no que refere-se às ferramentas e/ou aplicações que utilizam seus serviços. Com mais essa interface, $o$ AMIGO está integrado atualmente com três ferramentas: PVM, LAM-MPI e TAO;

- Validação do mecanismo callback no que diz respeito a sua utilização para o desenvolvimento de aplicações, uma vez que os trabalhos encontrados na literatura enfocam mais os aspectos conceituais desse mecanismo ou, em outros casos, maneiras de implementálo em ferramentas CORBA;

- Realização de avaliações de desempenho utilizando aplicações paralelas desenvolvidas em diferentes ferramentas e sob situações de carga variadas;

- Ratificação das conclusões obtidas em outros trabalhos desenvolvidos no grupo de Sistemas Distribuídos e Programação Concorrente, que também enfatizaram a construção 
de interfaces para o ambiente AMIGO e a avaliação de desempenho comparando o escalonamento round-robin com o fornecido por esse ambiente.

\subsection{Dificuldades encontradas}

O fato de procurar unir aspectos de teoria (definições e especificações) e prática (implementação) pode ser encarado como uma dificuldade inerente a este trabalho. Em muitas situações é difícil conciliar esses dois fatores, principalmente quando é abordado sob diversas áreas como: arquiteturas de objetos distribuídos, escalonamento de processos, computação paralela e sistemas distribuídos.

De forma mais específica, durante a etapa de implementação existiram diversos fatores que acarretaram dificuldades para o desenvolvimento do trabalho. Alguns desses fatores foram:

- Escolha de uma implementação CORBA adequada para o desenvolvimento da interface. Essa dificuldade ocorreu devido à existência de diversas implementações disponíveis, mas que não contemplavam satisfatoriamente alguns dos requisitos necessários para a integração com o ambiente AMIGO;

- Estudo minucioso sobre a implementação e funcionamento da ferramenta TAO, visando encontrar características similares às existentes nos ambientes PVM e LAM-MPI. Esse estudo foi de extrema utilidade para o desenvolvimento da camada de suporte e para a realização das avaliaçõẹ de desempenho, uma vez que, era desejável implementar características semelhantes às existentes nesses ambientes e havia necessidade de equiparar todas as ferramentas (no que diz respeito aos parâmetros e recursos utilizados) para que a avaliação de desempenho realizada fosse tão justa quanto possível;

- Definição e implementação dos recursos necessários para a adequação da ferramenta TAO com o ambiente AMIGO. Após a escolha da ferramenta CORBA, foi necessário realizar um estudo detalhado (baseando-se nas características de ambientes como PVM e LAM-MPI) a fim de verificar o que deveria ser implementado para tornar essa ferramenta adequada para a integração com o AMIGO;

- Pouca documentação sobre a implementação e funcionamento do modelo callback de comunicação assíncrona, principalmente no que diz respeito a exemplos práticos. 


\subsection{Propostas para trabalhos futuros}

Tendo como base a utilização de arquiteturas de objetos distribuídos e escalonamento de processos, este trabalho pode ser considerado pioneiro dentro do grupo de Sistemas Distribuídos e Programação Concorrente, uma vez que outros trabalhos, anteriores a este, abordando o tema escalonamento de processos, visavam principalmente a integração com ferramentas específicas para computação paralela.

Essa inovação trouxe a possibilidade de gerar novas pesquisas que podem contribuir para a área de escalonamento de processos, objetos distribuídos, computação paralela e, por conseguinte, computação paralela distribuída. Dessa forma, algumas sugestões para realização de novos trabalhos são:

- Avaliar o desempenho dos tipos de invocação de chamadas em CORBA, procurando destacar classes de aplicações e/ou situações onde um mecanismo de invocação pode ser melhor empregado;

- Implementar o modelo polling de chamadas assíncronas e comparar o desempenho com o modelo callback;

- Estudar a literatura disponível sobre a possibilidade de paralelização de objetos CORBA, visando especificar e, posteriormente, implementar mecanismos para paralelização desses objetos;

- Desenvolver outras políticas de escalonamento para o ambiente AMIGO objetivando abranger outras classes de aplicações. Nesse sentido, obsrva-se que uma nova política pode utilizar toda a estrutura de comunicação já implementada na DPWP, o que possibilitará uma redução significativa no tempo de desenvolvimento;

- Verificar a adeqüabilidade do AMIGO no tocante ao escalonamento de requisições entre objetos servidores.Possivelmente, implementar mecanismos para que a ferramenta TAO utilize os serviços do AMIGO não somente para o escalonamento de processos, mas também quando houver necessidade de escalonar requisições;

- Implementar o modelo de organização para programas paralelos SPMD (Single Program Multiple Data) na ferramenta TAO e comparar essa nova abordagem com o modelo MPMD (Multiple Program Multiple Data);

- Estudar o uso do monitoramento embutido diretamente em aplicações CORBA e implementar essa característica na ferramenta TAO. 


\section{Referências Bibliográficas}

[Achcar \& Rodrigues, 1995] ACHCAR; J. A., RODRIGUES, J. (1995). Introdução à Estatística para Ciências e Tecnologia. ICMSC-USP, São Carlos. Apostila de consulta.

[Almasi \& Gottlieb, 1994] ALMASI, G. S., GOTTLIEB, A. (1994). Highly Parallel Computing. Benjamin Cummings Publishing, 2 edição.

[Amar \& Bensoussan, 2000] AMAR, V., BENSOUSSAN, P. (2000). Benchmarks Results. http://www.beust.com/virginie/Benchmarks/index.html. Visitado em Julho de 2000.

[Araújo, 1999] ARAÚJO, A. P. F. (1999). DPWP - Uma nova Abordagem ao Escalonamento Dinâmico em Computação Paralela Virtual. Dissertação de Mestrado, Instituto de Ciências Matemáticas e de Computação da Universidade de São Paulo, São Carlos-SP.

[Araújo et al., 1999] ARAÚJO, A. P. F., SOUZA, P. S. L., SANTANA, M. J., SANTANA, R. H. C. (1999). A New Dynamical Scheduling Algorithm. Proceedings of the Parallel Distributed Technics and Applications (PDPTA) Conference.

[Arulanthu et al., 2000] ARULANTHU, A. B., SCHMIDT, D. C., O'RYAN, C., KIRCHER, M., PARSONS, J. (2000). The Design and Performance of a Scalable ORB Architecture for CORBA Asynchronous Messaging. Proceedings of the IFIP/ACM Middleware 2000 Conference.

[Basney \& Livny, 1999] BASNEY, J., LIVNY, M. (1999). Deploying a High Throughput Computing Center, volume 1. Prentice Hall, Massachussets.

[Beaugendre et al., 1998] BEAUGENDRE, P., PRIOL, T., RENé, C. (1998). COBRA: A CORBA-Compliant Programming Environment for High Performance Computing. Relatório Técnico 1141, Institut de Recherche en Informatique et Systèmes Aléatoires, Rennes Cedex - France. 
[Beguelin et al., 1994] BEGUELIN, A., GEIST, A., DONGARRA, J., JIANG, W., MANCHEK, R., SUNDERAM, V. (1994). PVM: Parallel Virtual Machine. A User's Guide and Tutorial for Networked Parallel Computing. The MIT Press, Massachussets.

[Birney et al., 2000] BIRNEY, E., LAUSCH, M., LEWIS, T., GENAUD, S. (2000). ORBit Beginners Documentation. http://icps.u-strasbg.fr/ genaud/ORBIT/. Visitado em Junho de 2000.

[Brunsch, 1999] BRUNSCH, D. (1999). Overview of TAO's Implementation Repository. Relatório técnico, Washington University.

[Burns \& Daoud, 1995] BURNS, G., DAOUD, R. (1995). MPI Primer/Developing with LAM. Ohio Supercomputer Center-The Ohio State University.

[Butler \& Lusk, 1994] BUTLER, R. M., LUSK, E. L. (1994). Monitors, Messages and Clusters: The P4 Parallel Programming System. Parallel Computing, 20:547-564.

[Calkin et al., 1994] CALKIN, R., HEMPEL, R., HOPPE, H. C., WYPIOR, P. (1994). Portable Programming With the PARMACS Message-Passing Library. Parallel Computing, 20:615-632.

[Campos, 2001] CAMPOS, A. (2001). Desenvolvimento de uma interface gráfica para um ambiente de escalonamento. Dissertação de Mestrado, Instituto de Ciências Matemáticas e de Computação da Universidade de São Paulo, São Carlos-SP.

[Carriero et al., 1994] CARRIERO, N., GELERNTER, D., MATTSON, T.; SHERMAN, A. H. (1994). The LINDA Alternative to Message-Passing Systems. Parallel Computing, 20:633-655.

[Casas et al., 1994] CASAS, J., KONURU, R., OTTO, S. W. (1994). Adaptive Load Migration Systems for PVM. Proceedings of the Conference on Supercomputing'94, páginas 390-399.

[Cenapadne, 1999] CENAPADNE (1999). Centro Nacional de Processamento de Alto Desempenho do Nordeste-Curso de MPI. http://www.cenapadne.br. Visitado em Dezembro de 1999.

[Comer, 1995] COMER, D. E. (1995). Internetworking with TCP/IP - Volume I. Prentice Hall, New Jersey, 3 edição. 
[Cortés, 1999] CORTÉS, O. A. C. (1999). Desenvolvimento de Algoritmos Numéricos Paralelos. Dissertação de Mestrado, Instituto de Ciências Matemáticas e de Computação da Universidade de São Paulo, São Carlos-SP.

[Coulouris et al., 1994] COULOURIS, G., DOLLIMORE, J., KINDBERG, T. (1994). Distributed Systems - Concepts and Design. Addison-Wesley, Wokingham-England, 2 edição.

[Deibel.\& Ehresman, 1997] DEIBEL, S. R. A., EHRESMAN, J. P. (1997). Arachne Developer's Guide. ftp://ftp.arachne.org/pub/Arachne/arachne-book.ps. Visitado em Junho de 2000.

[Duncan, 1990] DUNCAN, R. (1990). A Survey of Parallel Computer Architectures. IEEE Computer, páginas 5-16.

[Fatoohi, 1997] FATOOHI, R. (1997). Performance Evaluation of Communication Software Systems for Distributed Computing. Distributed Systems Engineering Journal, 4(3):169175.

[Figueiredo, 2000] FIGUEIREDO, T. C. (2000). Interface AMIGO-MPI: Uma Abordagem Flexivel e Dinâmica para o Escalonamento de Processos. Dissertação de Mestrado, Instituto de Ciências Matemáticas e de Computação da Universidade de São Paulo, São Carlos-SP.

[Flower \& Kolawa, 1994] FLOWER, J., KOLAWA, A. (1994). Express is not just a Message Passing System. Current and Future Directions in Express. Parallel Computing, 20:597614.

[Flynn, 1972] FLYNN, M. J. (1972). Some Computer Organizations and Their Effectiveness. IEEE Transactions on Computers, 21:948-960.

[Flynn \& Rudd, 1996] FLYNN, M. J., RUDD, K. W. (1996). Parallel Architectures. ACM Computing Surveys, 28(1):67-70.

[Francisco, 1995] FRANCISCO, W. (1995). Estatística Básica. Unimep, Piracicaba, 2 edição.

[Geist et al., 1996] GEIST, G. A., KOHL, J. A., PAPADOPOULOS, P. M. (1996). PVM and MPI: A Comparison of Feature. U. S. Department of Energy.

[Hwang \& Briggs, 1984] HWANG, K., BRIGGS, F. A. (1984). Computer Architecture and Parallel Processing. McGraw-Hill. 
[IBM, 2000] IBM (2000). IBM LoadLeveler for AIX - Using and Administering. IBM Press, Pouhgkeepsie - NY. Version 2 Release 2.

[INPRISE, 1999] INPRISE (1999). Visibroker for Java 4.0: Programmer's Guide: Using the POA. http://www.inprise.com/techpubs/books/vbj/vbj40/programmersguide/poa.html. Visitado em Dezembro de 1999.

[IONA, 2000] IONA (2000). Orbix 2000. http://www.ionaiportal.com/suite/orbix2000.htm. Visitado em Setembro de 2000.

[Kaplan \& Nelson, 1994] KAPLAN, J. A., NELSON, M. L. (1994). A Comparison of Queueing, Cluster and Distributed Computing Systems. Relatório Técnico TM 109025, NASA Langley Research Center.

[Keahey, 1997] KEAHEY, K. (1997). PARDIS: A Parallel Approach to CORBA. Proceedings of the 6th IEEE Internation Symposium on High Performance Distributed Computing.

[Keahey \& Gannon, 1997] KEAHEY, K., GANNON, D. (1997). PARDIS: CORBA-Based Architecture for Application-Level Parallel Distributed Computation. Proceedings of SC97 (Supercomputing '97).

[Kirner, 1991] KIRNER, C. (1991). Arquiteturas de Sistemas Avançados de Computação. Anais da Jornada EPUSP/IEEE em Sistemas de Computação de Alto Desempenho, páginas 307-353.

[Lamport, 1994] LAMPORT, L. (1994). LaTEX: A Document Preparation System. AddisonWesley Publising Company.

[Lo et al., 2000] LO, S. L., RIDDOCH, D., GRISBY, D. (2000). The omniORB verison 3.0 User's Guide. ATT Laboratories, Cambridge.

[Macdonald et al., 1997] MACDONALD, N., MINTY, E., HARDING, T., BROWN, S. (1997). Writing Message-Passing Parallel Programs with MPI. Curse Notes - University of Edinburg-Germany.

[Maffeis, 1996] MAFFEIS, S. (1996). The Object Group Design Pattern. Proceedings of the 1996 USENIX Conference on Object-Oriented Technologies.

[Maffeis \& Landis, 1997] MAFFEIS, S., LANDIS, S. (1997). Building Reliable Distributed Systems with CORBA. Theory and Practice of Object Systems. 
[Maffeis et al., 1996] MAFFEIS, S., RENESSE, R. V., BIRMAN, K. P. (1996). Horus: A Flexible Group Communications System. Communications of the ACM, 39(4).

[McBryan, 1994] MCBRYAN, O. A. (1994). An Overview of Message Passing Environments. Parallel Computing, 20(4):417-444.

[Mowbray \& Malveau, 1997] MOWBRAY, T. J., MALVEAU, R. C. (1997). CORBA Design Patterns. John Wiley Sons, New York.

[Mowbray \& Ruh, 1997] MOWBRAY, T. J., RUH, W. A. (1997). Inside CORBA: Distributed Object Standards and Applications. Addison-Wesley.

[Mucci \& Dongarra, 1995] MUCCI; P. J., DONGARRA, J. (1995). Possibilities for Active Messaging in PVM. Relatório Técnico UT-CS-95-277, University of Tenessee.

[Mullender, 1993] MULLENDER, S. (1993). Distributed Systems. Addison-Wesley, New York, 2 edição.

[Navaux, 1989] NAVAUX, P. O. A. (1989). Introdução ao Processamento Paralelo. $R B C$ Revista Brasileira de Computą̧ão, 5(2):31-43.

[OMG, 1999a] OMG (1999a). The Common Object Request Broker: Architecture and Specification. Document formal/01-02-32, 2.3 edição.

[OMG, 1999b] OMG (1999b). Dynamic Scheduling - Request For Proposal. Document orbos/99-03-32.

[OMG, 2000] OMG (2000). The Common Object Request Broker: Architecture and Specification. Document formal/01-02-32, 2.4 edição.

[OMG, 2001a] OMG (2001a). The Common Object Request Broker: Architecture and Specification. Document formal/01-02-32.

[OMG, 2001b] OMG (2001b). Data Parallel CORBA. RFP - Document orbos/01-06-08.

[OMG, 2001c] OMG (2001c). Load Balancing and Performance Monitoring RFP. Document orbos/01-04-27.

[OMG, 2001d] OMG (2001d). Real-Time CORBA 2.0 - Joint Final Submission. Document orbos/01-06-09.

[OMG, 2001e] OMG (2001e). Survey of High Performance Computing Activities. Document orbos/99-07-23. 
[OOC, 2000] OOC (2000). ORBacus for C++ and Java User's Manual. http://www.ooc.com/ob/download4.html. Visitado em Agosto de 2000:

[Orfali, 1996] ORFALI, R. (1996). The Essential Distributed Objects Surival Guide. John Wiley Sons, New York.

[Othman et al., 2001] OTHMAN, O., O'RYAN, C., SCHMIDT, D. C. (2001). Obtimizing Distributed System Performance via Adaptive Middleware Load Balaticing. Proceedings of the ACM Sigplan Workshop on Optimization of Middleware and Distributed Systems.

[Puder et al., 2000] PUDER, A., RöMER, K., PILHOFER, F. (2000). MiCO: An Open Source CORBA 2.3 Implementation. http://www.mico.org/doc-book.ps. Visitado em Junho de 2000.

[Quinn, 1994] QUINN, M. J. (1994). Parallel Computing: theory and practice. McGraw-Hill, New York, 2 edição.

[Santos et al., 2001] SANTOS, R. R., SOUZA, P. S. L., SANTANA, M. J., SANTANA, R. H. C. (2001). Performance Evaluation of Distributed Applications Development Tools From The Interprocess Communication Point of View. Proceedings of the Parallel Distributed Technics and Applications (PDPTA) Conference.

[Schmidt \& Kuhns, 2000] SCHMIDT, D. C., KUHNS, F. (2000). An Overview of the Realtime CORBA Specification. IEEE Computer special issue on Object-Oriented Real-time Distributed Computing.

[Schmidt \& Vinoski, 1995] SCHMIDT, D. C., VINOSKI, S. (1995). Modeling Distributed Object Applications. $\mathrm{C}++$ Report Magazine, 2.

[Schmidt \& Vinoski, 1996] SCHMIDT, D. C., VINOSKI, S. (1996). Distributed Callbacks and Decoupled Communication in CORBA: $C++$ Report Magazine, 8.

[Schmidt \& Vinoski, 1998] SCHMIDT, D. C., VINOSKI, S. (1998). An Introduction to CORBA Messaging. $C++$ Report Magazine, 15.

[Schmidt \& Vinoski, 1999] SCHMIDT, D. C., VINOSKI, S. (1999). Programming Asynchronous Method Invocations with CORBA Messaging. $C++$ Report Magazine, 16.

[Schnekenburger, 1999] SCHNEKENBURGER, T. (1999). Load Balancing in CORBA: A Survey. Document orbos/99-07-19. 
[Shivaratri et al., 1992] SHIVARATRI, N. G., KREUGER, P., SINGHAL, M. (1992). Load Distribution for Locally Distributed Systems. IEEE Computer, 25:33-44.

[Skhellum et al., 1994] SKHELLUM, A., SIMTH, S. G., DOSS, N. E., LEUNG, A. P., MORARI, M. (1994). The Design and Evolution of Zipcode. Parallel Computing, 20:565596.

[Snir et al., 1996] SNIR, M., OTTO, S., STEVEN, H., WALKER, D., DONGARRA, J. J. (1996). MPI: The Complete Reference. The MIT Press, Massachussets.

[Snow, 1992] SNOW, C. R. (1992). Concurrent Programming. Cambridge University Press, Cambridge.

[Souza, 1996a] SOUZA, M. A. (1996a). Avaliação das Rotinas de Comunicação Pontoa-Ponto do MPI. Dissertação de Mestrado, Instituto de Ciências Matemáticas e de Computação da Universidade de São Paulo, São Carlos-SP.

[Souza, 1996b] SOUZA, P. S. L. (1996b). Máquina Paralela Virtual em Ambiente Windows. Dissertação de Mestrado, Instituto de Ciências Matemáticas e de Computação da Universidade de São Paulo, São Carlos-SP.

[Souza, 2000] SOUZA, P. S. L. (2000). AMIGO: Um Ambiente de Escalonamento Flexivel e Dinâmico. Tese de Doutorado, Instituto de Física de São Carlos da Universidade de São Paulo, São Carlos-SP.

[Souza et al., 1999a] SOUZA, P. S. L., SANTANA, M. J., SANTANA, R. C. H. (1999a). AMIGO - A Dynamical Flexible Scheduling Environment. 5th International Conference on Information Systems, Analisys and Synthesis: ISAS'g9.

[Souza et al., 1999b] SOUZA; P. S. L., SANTANA, M. J., SANTANA, R. C. H. (1999b). PVM and Viable and Flexible Scheduling. 11th IASTED International Conference on Parallel and Distributed Computing and Systems - PDCS'g9.

[Souza et al., 2000] SOUZA, P. S. L., SANTANA, M. J., SANTANA, R. H. C. (2000). Escalonamento de Processos: Uma contribuição para a convergência da área. Relatório Técnico 46, Instituto de Ciências Matemáticas e de Computação, São Carlos.

[Stevens, 1996] STEVENS, W. R. (1996). Advanced Programming in the UNIX Environment. Addison-Wesley, Reading. 
[Sunderam et al., 1994] SUNDERAM, V. S., GEIST, G. A., DONGARRA, J., MANCHEK, R. (1994). The PVM Concurrent Computing System: Evolution, Experiences, and Trends. Parallel Computing, 20(4):531-545.

[Suplick, 1994] SUPLICK, J. (1994). An Analysis of Load Balancing Technology. Relatório técnico, CXSOFT Technical Report, Richardson - Texas.

[Tanenbaum, 1995] TANENBAUM, A. S. (1995). Distributed Operating Systems. PrenticeHall, New Jersey.

[Tanenbaum \& Renesse, 1985] TANENBAUM, A. S., RENESSE, R. V. (1985). Distributed Operating Systems. Computing Surveys, 17(4).

[Terada, 1991] TERADA, R. (1991). Desenvolvimento de Algoritmos e Estruturas de Dados. Makron Books, Rio de Janeiro.

[Vinoski, 1997] VINOSKI, S. (1997). CORBA: Integrating Diverse Applications Within Distributed Heterogeneous Environments. IEEE Communications Magazine, 35(2).

[Vinoski, 1998] VINOSKI, S. (1998). New Features for CORBA 3.0. Communications of the $A C M, 41(10)$.

[Vinoski \& Henning, 1999] VINOSKI, S., HENNING, M. (1999). Advanced CORBA Programming with $\mathrm{C}++$. Addison-Wesley, Reading.

[Xu \& He, 2000] XU, C. W., HE, B. (2000). PCB - A Distributed Computing System in CORBA. Journal of Parallel and Distributed Computing, 60:1293-1310. 
Apêndice

\section{Descrição das mensagens definidas e utilizadas pelo AMIGO}

$\mathrm{Na}$ Tabela A.1 são apresentadas as mensagens que podem ser trocadas entre o o software que gerencia as aplicações do usuário e o AMIGOD (AMIGO Daemon).

Tabela A.1: Mensagens trocadas entre o(s) software(s) que gerencia(m) as aplicações e o AMIGOD

\begin{tabular}{||c|l||}
\hline Código & Descrição \\
\hline AM_REM & Indica que o AMIGOD local deve ser retirado de execução \\
\hline AM_SCHED & Requisita as máquinas que serão utilizadas no escalonamento \\
\hline
\end{tabular}

A Tabela A.2 são descritas as mensagens que podem ser trocadas entre quaisquer AMIGODs em execução na plataforma computacional.

As mensagens trocadas entre o AMIGOD e a política de escalonamento local são apresentadas na Tabela A.3. Essas mensagens podem ser utilizadas no sentido AMIGOD $\rightarrow$ POLÍTICA, assim como, POLÍTICA $\rightarrow$ AMIGOD. 
Tabela A.2: Mensagens trocadas entre AMIGODs

\begin{tabular}{||c|l||}
\hline Código & Descrição \\
\hline AA_ADD & $\begin{array}{l}\text { Insere uma nova entrada (novo host) na lista de máquinas do AMIGOD } \\
\text { que recebeu a mensagem }\end{array}$ \\
\hline AA_REM & $\begin{array}{l}\text { Remove uma entrada na lista de máquinas do AMIGOD que recebeu a } \\
\text { mensagem }\end{array}$ \\
\hline AA_GETLOAD & $\begin{array}{l}\text { Obtém a "carga" utilizada pela política de escalonamento local e envia } \\
\text { esse valor para o AMIGOD que enviou a mensagem }\end{array}$ \\
\hline AA_PUTLOAD & Atualiza a "carga" da política de escalonamento local \\
\hline
\end{tabular}

Tabela A.3: Mensagens trocadas entre o AMIGOD e a política de escalonamento local

\begin{tabular}{||c|l||}
\hline \multicolumn{1}{|c|}{ Código } & Descrição \\
\hline AP_GETLOADREMOTE & $\begin{array}{l}\text { Indica que o AMIGOD local deve enviar uma mensagem para } \\
\text { os outros AMIGODs em execução, solicitando a "carga" } \\
\text { utilizada por suas politicas de escalonamento }\end{array}$ \\
\hline AP_PUTLOADLOCAL & $\begin{array}{l}\text { O AMIGOD deve enviar a carga utilizada pela política de } \\
\text { escalonamento para outros AMIGODs }\end{array}$ \\
\hline AP_GETLOADLOCAL & O AMIGOD solicita a "carga" da política de escalonamento \\
\hline AP_SCHEDACK & $\begin{array}{l}\text { A política de escalonamento envia para o AMIGOD, as } \\
\text { máquinas que podem fazer parte do escalonamento }\end{array}$ \\
\hline AP_GETTABLE & $\begin{array}{l}\text { O AMIGOD envia sua lista de máquinas para a política de } \\
\text { escalonamento }\end{array}$ \\
\hline
\end{tabular}


Apêndice

$B$

\section{Testes de Hipóteses realizados}

Os valores dos Testes de Hipóteses realizados nos experimentos (apresentados no Capítulo 6) deste trabalho, são apresentados nas Tabelas B.1 à B.12. Em todos os testes, foi considerado um nível de significância $(\alpha)$ igual à 0,01 . Assim, de acordo com esse nível de significância e a Tabela de valores críticos apresentada por [Francisco, 1995], para considaderar que a diferença entre as médias não é significativa, o valor obtido pelo Teste de Hipótese deve estar entre $-2,57$ e 2, 57 .

Tabela B.1: Estatística realizada para o desempenho obtido com a aplicação do trapézio composto utilizando TAO com diferentes políticas de escalonamento em um sistema ocioso

\begin{tabular}{||r|r|r||}
\hline & TAO-RR & TAO-AMIGO \\
\hline Média & 1,94240493 & 1,94480883 \\
\hline Variância & 0,01402576 & 0,00865216 \\
\hline Desvio Padrão & 0,1184304 & 0,09301697 \\
\hline Hipótese: $\alpha=0,01$ & \multicolumn{2}{|c||}{$-0,087433014$} \\
\hline
\end{tabular}


Tabela B.2: Estatística realizada para o desempenho obtido com a aplicação do trapézio composto utilizando PVM com diferentes políticas de escalonamento em um sistema ocioso

\begin{tabular}{||r|r|r||}
\hline & PVM-RR & PVM-AMIGO \\
\hline Média & 1,204855833 & 1,222753077 \\
\hline Variância & 0,0000564168248 & 0,00001210415 \\
\hline Desvio Padrão & 0,007511113 & 0,003479102 \\
\hline Hipótese: $\alpha=0,01$ & \multicolumn{2}{|c|}{$-11,84227125$} \\
\hline
\end{tabular}

Tabela B.3: Estatística realizada para o desempenho obtido com a aplicação do trapézio composto utilizando LAM-MPI com diferentes políticas de escalonamento em um sistema ocioso

\begin{tabular}{||r|r|r||}
\hline & LAM-RR & LAM-AMIGO \\
\hline Média & 0,647252267 & 1,241640931 \\
\hline Variância & 0,000018646374 & 0,006446984 \\
\hline Desvio Padrão & 0,004318145 & 0,08029311 \\
\hline Hipótese: $\alpha=0,01$ & \multicolumn{2}{|c|}{$-7,402378756$} \\
\hline
\end{tabular}

Tabela B.4: Estatística realizada para o desempenho obtido com a aplicação do caixeiro viajante utilizando TAO diferentes políticas de escalonamento em um sistema ocioso

\begin{tabular}{||r|r|r||}
\hline & TAO-RR & TAO-AMIGO \\
\hline Média & 13,2022022 & 13,2256721 \\
Variância & 0,00637595 & 0,0065735 \\
\hline Desvio Padrão & 0,07984956 & \multicolumn{1}{|c||}{0,0810771} \\
\hline Hipótese: $\alpha=0,01$ & \multicolumn{2}{|c|}{$-1,129656106$} \\
\hline
\end{tabular}

Tabela B.5: Estatística realizada para o desempenho obtido com a aplicação do caixeiro viajante utilizando PVM com diferentes políticas de escalonamento em um sistema ocioso

\begin{tabular}{||r|r|r||}
\hline & PVM-RR & PVM-AMIGO \\
\hline Média & 16,278003 & 16,34781832 \\
\hline Variância & 0,0343435 & 0,000007378 \\
Desvio Padrão & 0,18532 & 0,002716241 \\
\hline Hipótese: $\alpha=0,01$ & \multicolumn{2}{|c|}{$-2,063214367$} \\
\hline
\end{tabular}


Tabela B.6: Valores calculados para o desempenho obtido com a aplicação do caixeiro viajante utilizando LAM-MPI com diferentes políticas de escalonamento em um sistema ocioso

\begin{tabular}{||r|r|r||}
\hline & LAM-RR & LAM-AMIGO \\
\hline Média & 15,42873033 & 15,79595292 \\
\hline Variância & 0,000028075 & 0,0000906362 \\
\hline Desvio Padrão & 0,005298571 & 0,009520306 \\
\hline Hipótese: $\alpha=0,01$ & \multicolumn{2}{|c|}{$-184,6053957$} \\
\hline
\end{tabular}

Tabela B.7: Valores calculados para o desempenho obtido com uma aplicação TAO do trapezio composto com escalonamento round-robin e o AMIGO em um sistema com perfis de carga diferentes

\begin{tabular}{|c|c|c|c|c|c|c|c|c|}
\hline & \multicolumn{2}{|c|}{ Menos potentes } & \multicolumn{2}{|c|}{ Mais potentes } & \multicolumn{2}{|c|}{ Balanceado } & \multicolumn{2}{|c|}{ Desbalanceado } \\
\hline & RR & AMIGO & $\mathbf{R R}$ & AMIGO & RR & AMIGO & RR & AMIGO \\
\hline Média & 11,19926 & 3,08314 & 9,55160 & 5,92640 & 6,98734 & 7,03108 & 11,11396 & 7,11497 \\
\hline Variância & 0,57461 & 0,00913 & 0,76500 & 0,49198 & 0,40892 & 0,42091 & 0,52436 & 0,04485 \\
\hline Desvio Padrão & 0,75803 & 0,09559 & 0,87464 & 0,70141 & 0,63947 & 0,64878 & 0,72413 & 0,21179 \\
\hline Hipótese: $\alpha=0,01$ & \multicolumn{2}{|c|}{58,18252149} & \multicolumn{2}{|c|}{17,71033854} & \multicolumn{2}{|c|}{$-0,263034724$} & \multicolumn{2}{|c|}{29,03148022} \\
\hline
\end{tabular}

Tabela B.8: Valores calculados para o desempenho obtido com a aplicação PVM do trapézio composto com escalonamento round-robin e o AMIGO em um sistema com perfis de carga diferentes

\begin{tabular}{||r|r|r|r|r|r|r|r|r||}
\hline & \multicolumn{2}{|c|}{ Menos potentes } & \multicolumn{2}{c|}{ Mais potentes } & \multicolumn{2}{c|}{ Balanceado } & \multicolumn{2}{c|}{ Desbalanceado } \\
\hline & RR & AMIGO & RR & AMIGO & RR & AMIGO & RR & AMIGO \\
\hline Média & 3,85097 & 1,68667 & 3,09578 & 1,840708 & 2,12021 & 2,01309 & 3,88274 & 3,63866 \\
\hline Variância & 0,15373 & 0,000057 & 0,30774 & 0,00238 & 0,09009 & 0,11012 & 0,14119 & 0,130806 \\
\hline Desvio Padrão & 0,39209 & 0,00760 & 0,55475 & 0,04879 & 0,30015 & 0,33184 & 0,37575 & 0,36167 \\
\hline Hipótese: $\alpha=0,01$ & \multicolumn{3}{|c|}{30,22817526} & \multicolumn{2}{|c|}{12,34409502} & \multicolumn{1}{|c|}{1,311246085} & 2,563314559 \\
\hline
\end{tabular}

Tabela B.9: Valores calculados para o desempenho obtido com a aplicação LAM-MPI do trapézio composto com o escalonamento round-robin e o AMIGO em um sistema com perfis de carga diferentes

\begin{tabular}{||r|r|r|r|r|r|r|r|r||}
\hline & \multicolumn{2}{|c|}{ Menos potentes } & \multicolumn{2}{c|}{ Mais potentes } & \multicolumn{2}{c||}{ Balanceado } & \multicolumn{2}{c|}{ Desbalanceado } \\
\hline & RR & AMIGO & RR & AMIGO & RR & AMIGO & RR & AMIGO \\
\hline Média & 3,04474 & 1,660501 & 2,40921 & 1,851908 & 1,880607 & 2,22492 & 2,990457 & 2,76943 \\
\hline Variância & 0,192247 & 0,060092 & 0,1852 & 0,00289 & 0,07217 & 0,13461 & 0,25577 & 0,061108 \\
\hline Desvio Padrão & 0,43846 & 0,24513 & 0,430348 & 0,05378 & 0,26865 & 0,36689 & 0,50574 & 0,247202 \\
\hline Hipótese: $\alpha=0,01$ & \multicolumn{2}{|c|}{15,093177} & \multicolumn{2}{|c|}{7,038267063} & \multicolumn{2}{|c|}{0,147317822} & 2,150528268 \\
\hline
\end{tabular}


Tabela B.10: Valores calculados para o desempenho obtido com a aplicação TAO do caixeiro viajante com o escalonamento round-robin e o AMIGO em um sistema com perfis de carga diferentes

\begin{tabular}{||r|r|r|r|r|r|r|r|r||}
\hline & \multicolumn{2}{|c|}{ Menos potentes } & \multicolumn{2}{c|}{ Mais. potentes } & \multicolumn{2}{c||}{ Balanceado } & \multicolumn{2}{c||}{ Desbalanceado } \\
\hline & RR & AMIGO & RR & AMIGO & RR & AMIGO & RR & AMIGO \\
\hline Média & 54,65054 & 21,63147 & 51,07821 & 32,44318 & 38,35041 & 37,67303 & 54,26405 & 52,42921 \\
\hline Variância & 0,37890 & 1,08278 & 0,26327 & 0,51256 & 0,57307 & 1,94710 & 0,25232 & 1,22859 \\
\hline Desvio Padrão & 0,61554 & 1,04056 & 0,51310 & 0,71593 & 0,75701 & 1,39538 & 0,50231 & 1,10842 \\
\hline Hipótese: $\alpha=0,01$ & \multicolumn{2}{|c|}{149,58868} & \multicolumn{2}{|c|}{115,87883} & \multicolumn{2}{|c|}{2,33708} & \multicolumn{2}{|c|}{8,25836} \\
\hline
\end{tabular}

Tabela B.11: Valores calculados para o desempenho obtido com a aplicação PVM do caixeiro viajante com o escalonamento round-robin e o AMIGO em um sistema com perfis de carga diferentes

\begin{tabular}{||r|r|r|r|r|r|r|r|r||}
\hline & \multicolumn{2}{|c|}{ Menos potentes } & \multicolumn{2}{c|}{ Mais potentes } & \multicolumn{2}{c||}{ Balanceado } & \multicolumn{2}{c||}{ Desbalanceado } \\
\hline & RR & AMIGO & RR & AMIGO & RR & AMIGO & RR & AMIGO \\
\hline Média & 55,6236 & 22,51961 & 44,86539 & 32,83399 & 32,36203 & 37,25091 & 55,529246 & 47,09024 \\
\hline Variância & 0,07962 & 0,61241 & 0,15463 & 0,06353 & 0,11302 & 13,42405 & 0,05836 & 3,71406 \\
\hline Desvio Padrão & 0,28217 & 0,78257 & 0,39324 & 0,25207 & 0,33618 & 3,66388 & 0,24158 & 1,92719 \\
\hline Hipótese: $\alpha=0,01$ & \multicolumn{2}{|c|}{217,95959} & \multicolumn{2}{|c|}{141,0814605} & $-7,277931544$ & 23,79804646 \\
\hline
\end{tabular}

Tabela B.12: Valores calculados para o desempenho obtido com a aplicação LAM-MPI do caixeiro viajante com o escalonamento round-robin e o AMIGO em um sistema com perfis de carga diferentes

\begin{tabular}{||r|r|r|r|r|r|r|r|r||}
\hline & \multicolumn{2}{|c|}{ Menos potentes } & \multicolumn{2}{c|}{ Mais potentes } & \multicolumn{2}{c|}{ Balanceado } & \multicolumn{2}{c||}{ Desbalanceado } \\
\hline & RR & AMIGO & RR & AMIGO & RR & AMIGO & RR & AMIGO \\
\hline Média & 53,71877 & 21,08113 & 42,12549 & 31,78154 & 30,11399 & 34,44401 & 53,5676 & 42,56073 \\
\hline Variância & 0,07228 & 0,03849 & 0,15347 & 0,034007 & 0,08382 & 4,81225 & 0,21592 & 1,09411 \\
\hline Desvio Padrāo & 0,26885 & 0,19618 & 0,39176 & 0,18441 & 0,28953 & 2,19368 & 0,46467 & 1,04599 \\
\hline Hipótese: $\alpha=0,01$ & \multicolumn{3}{|c|}{120,3316436} & \multicolumn{2}{|c|}{130,846484} & $-10,71833068$ & 52,6723591 \\
\hline
\end{tabular}




\section{Código fonte das aplicações LAM-MPI, TAO e PVM}

Os trechos de código apresentados a seguir, correspondem às aplicações do trapézio composto e do caixeiro viajante, utilizadas nos experimentos apresentados no Capítulo 6.

// Arquivo de definição da Interface (IDL) na ferramenta TAO

// Nome: trapezio.idl

interface trapeziof

float integral (in double lim_sup, in double lim_inf);

\};

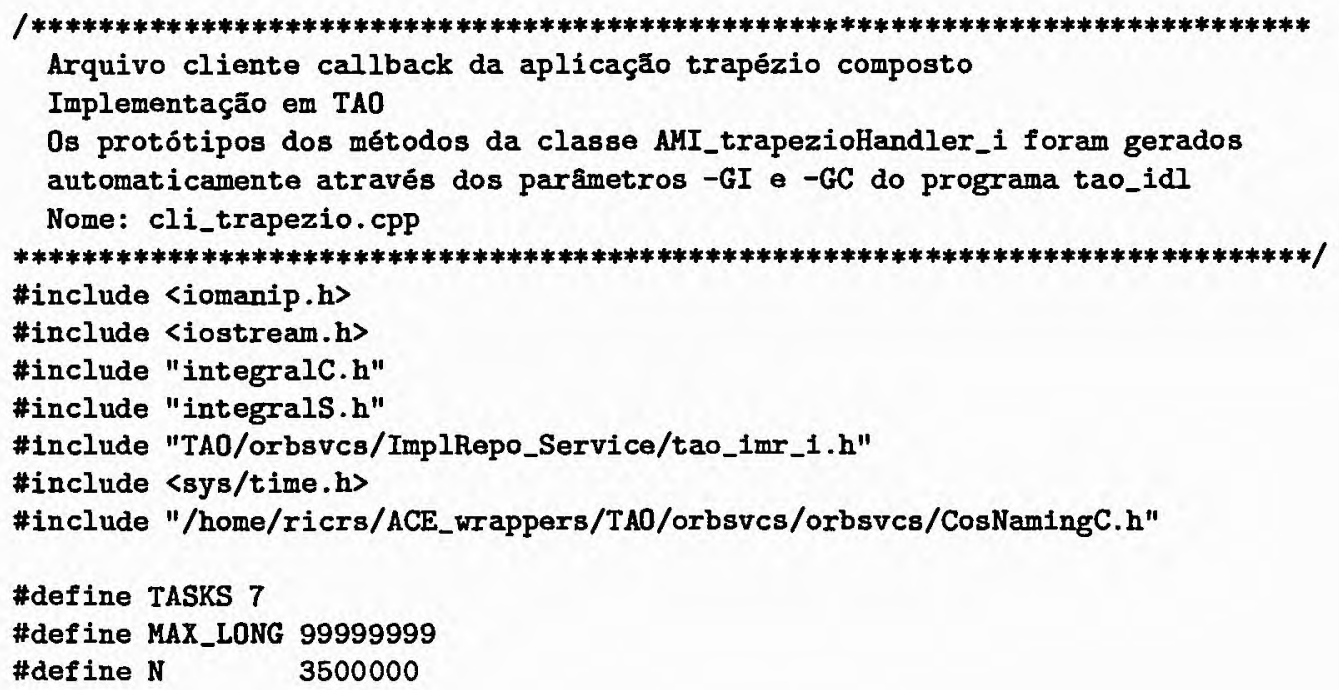




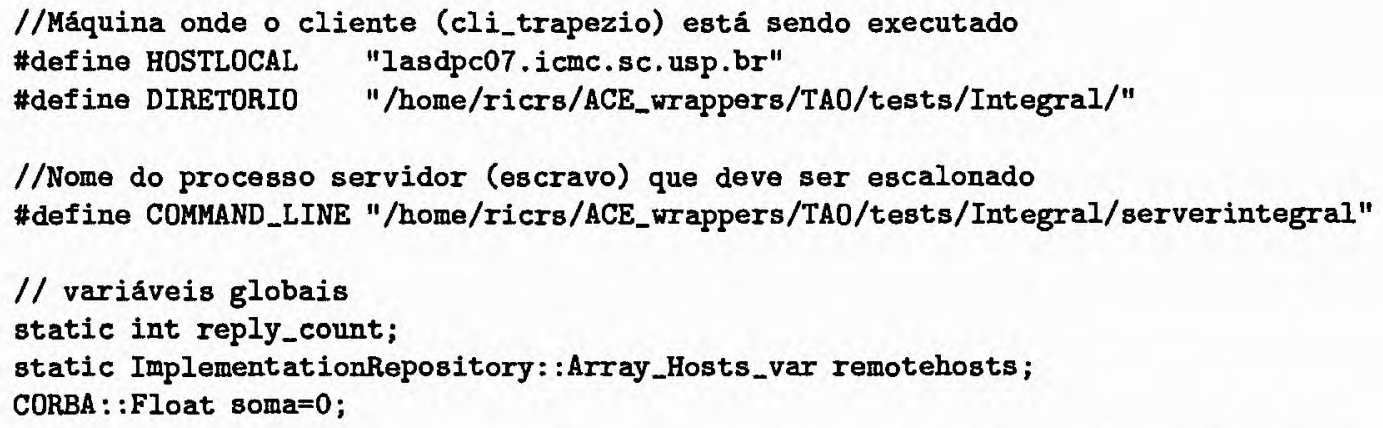




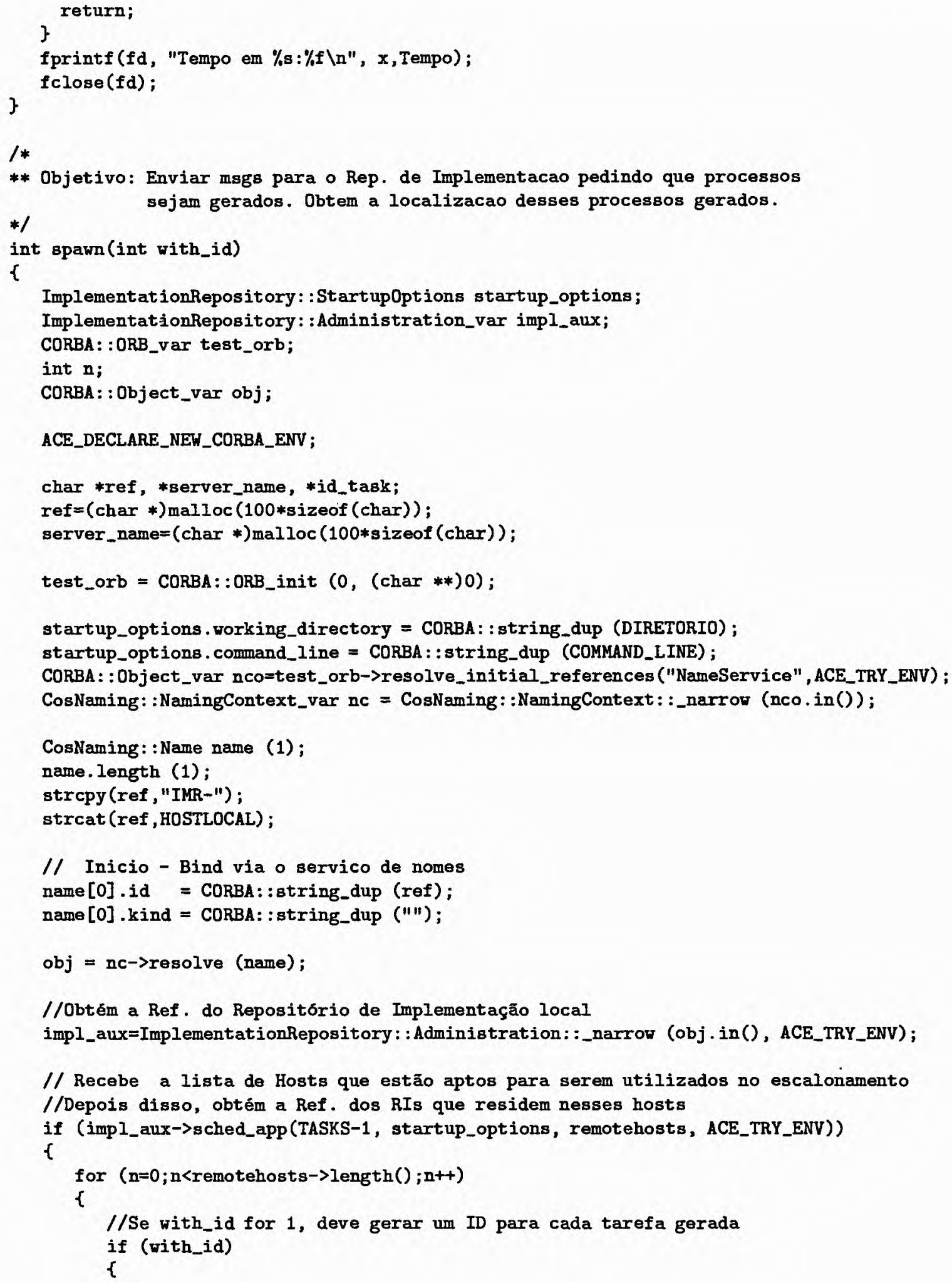




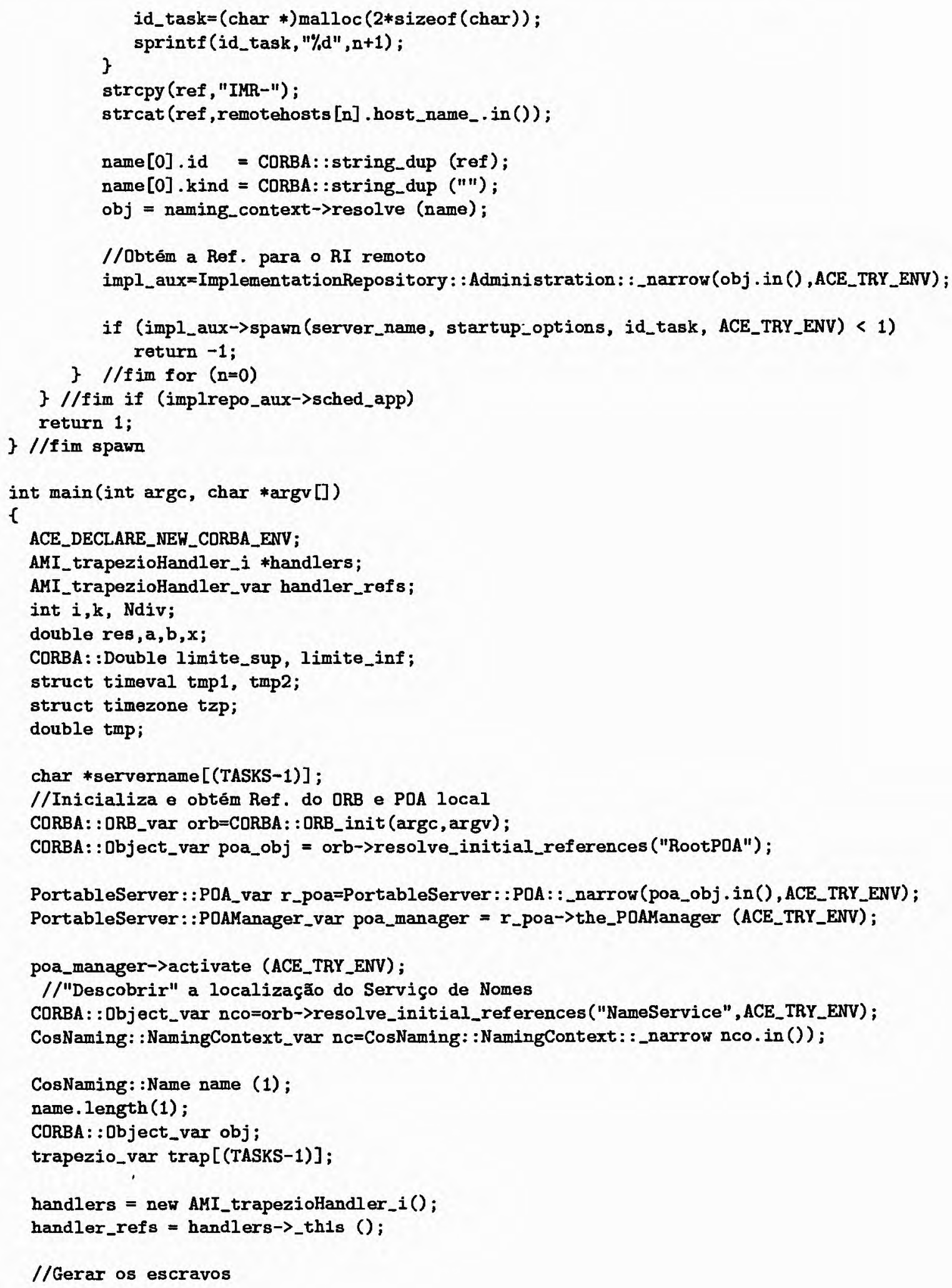




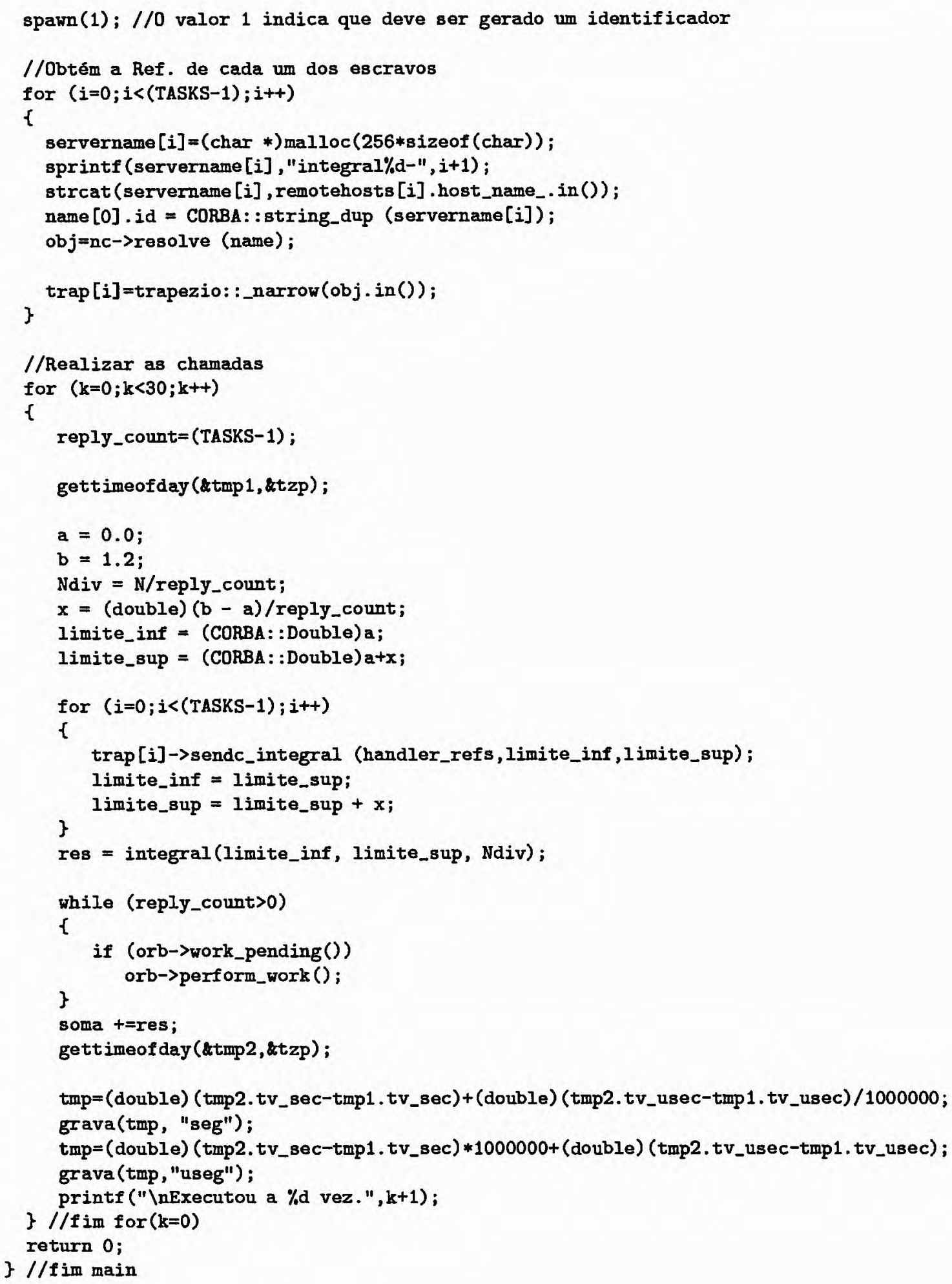




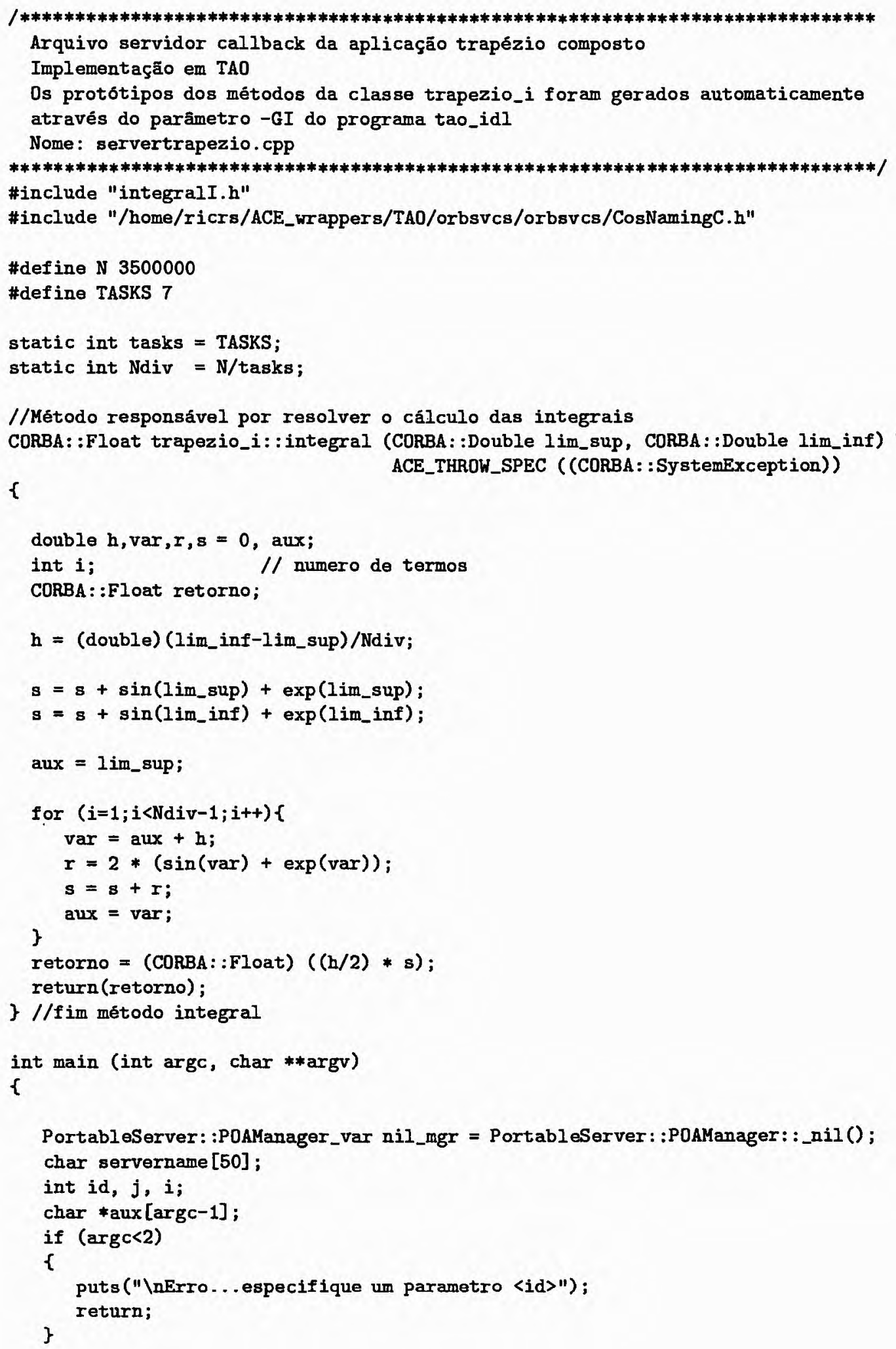




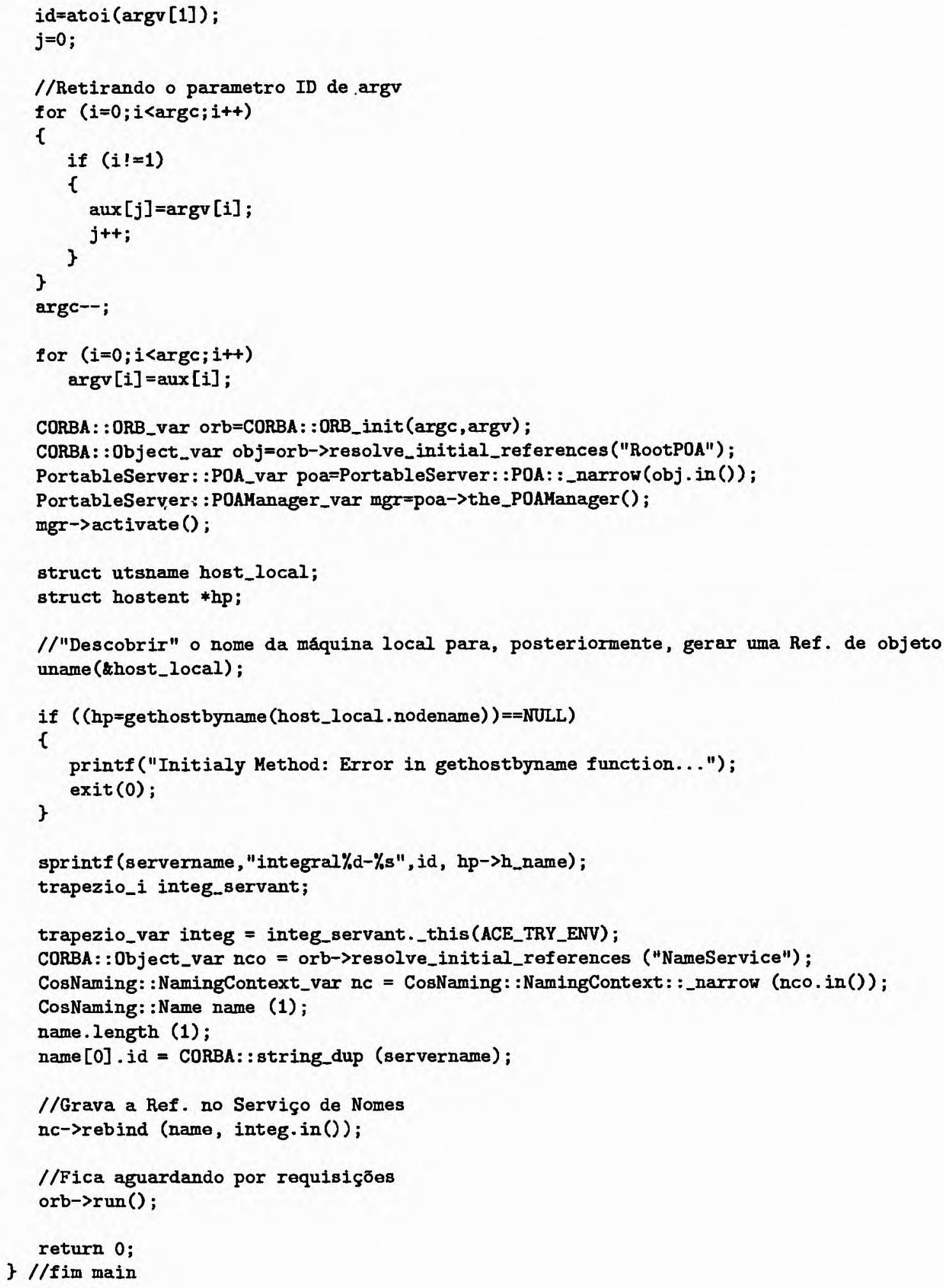

\} //fin main 


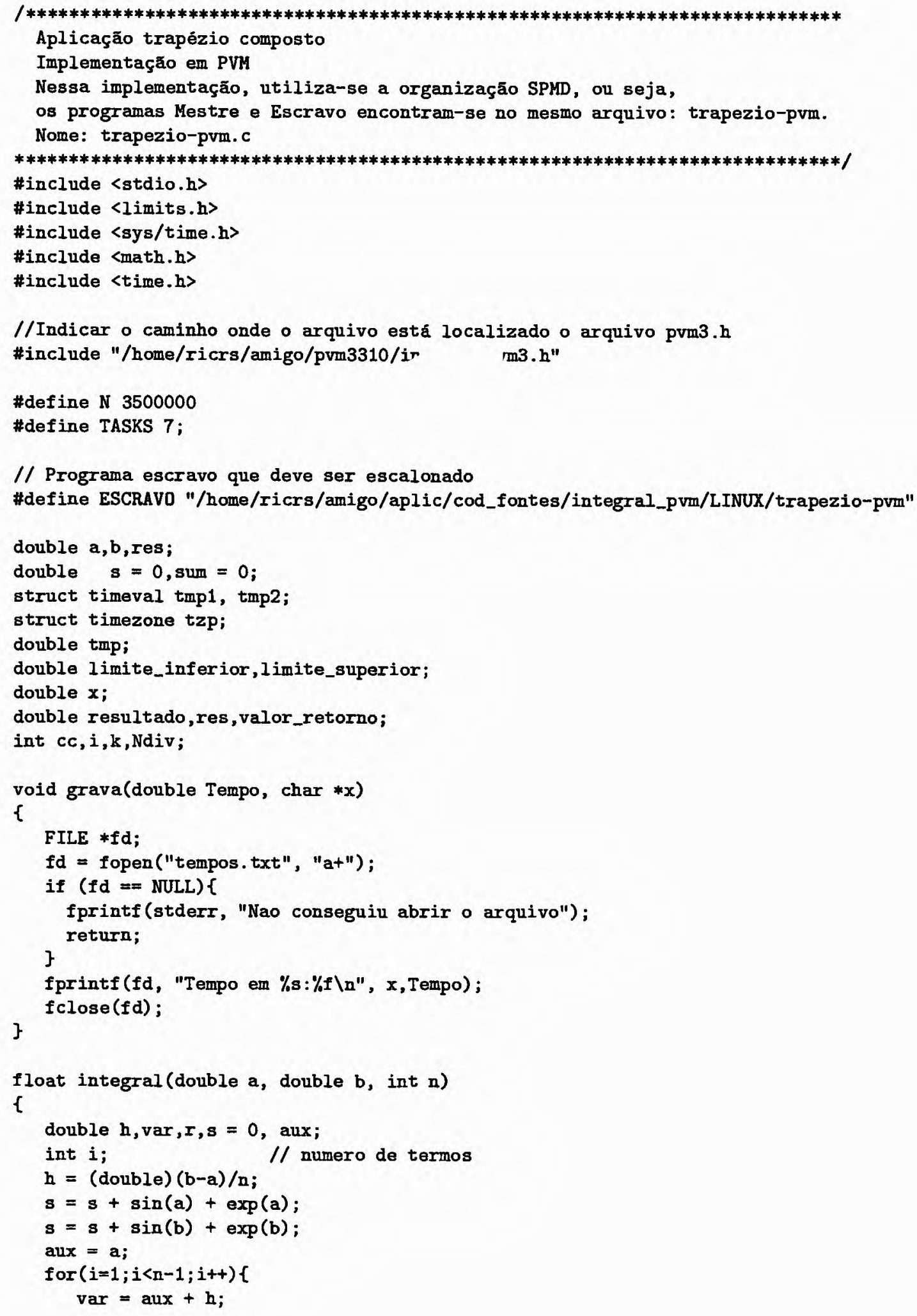




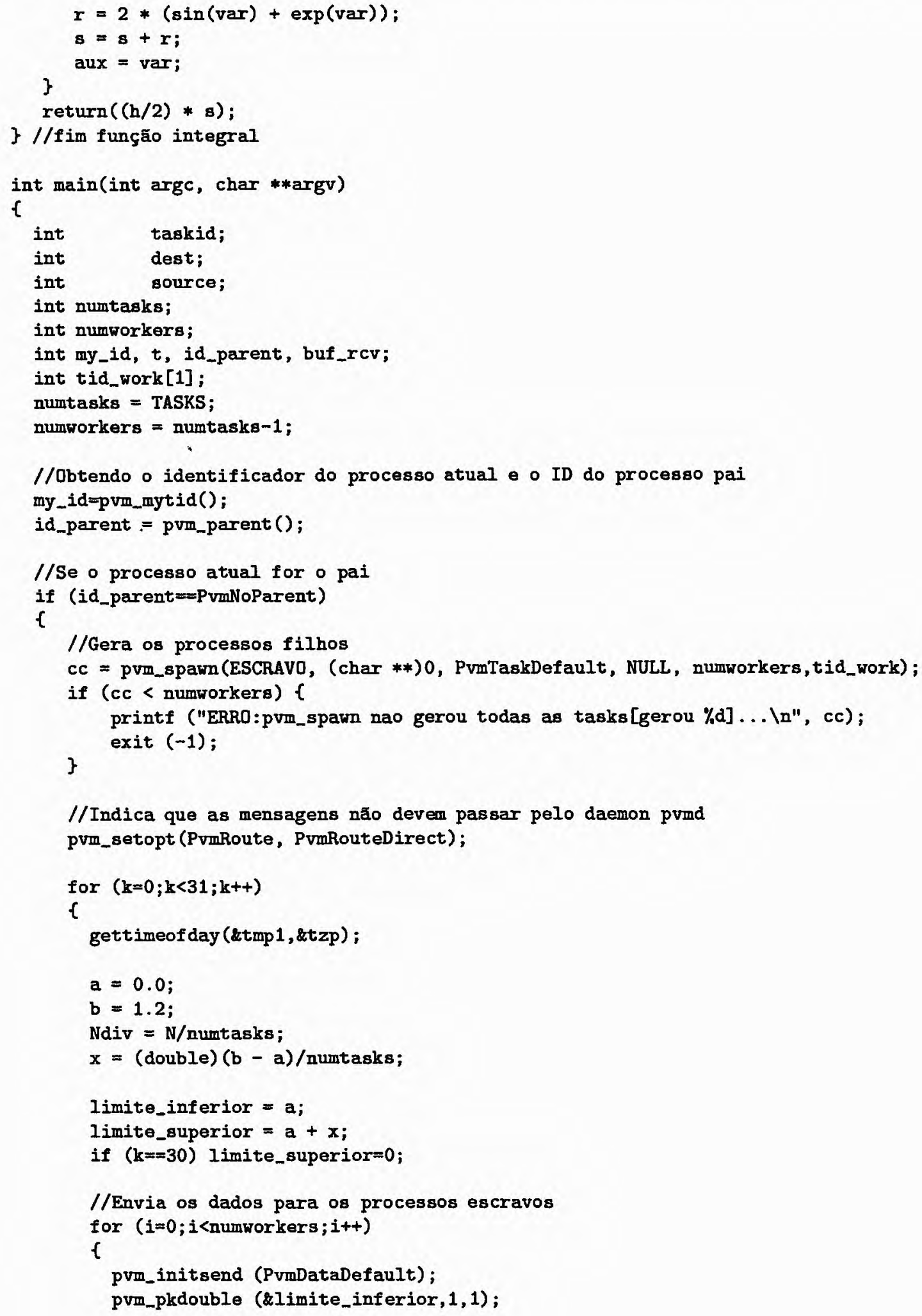




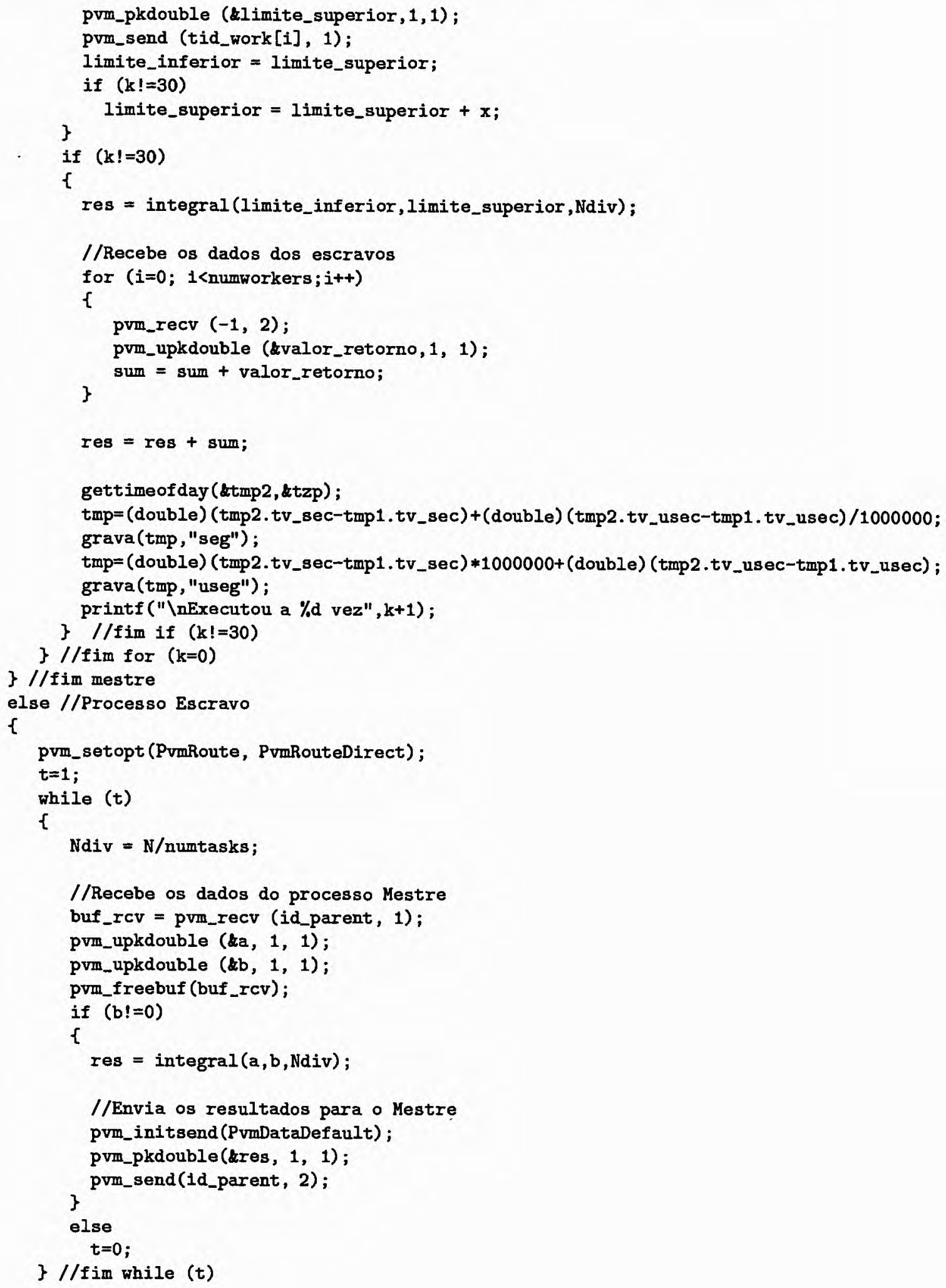




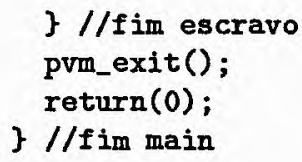

\} //fim main

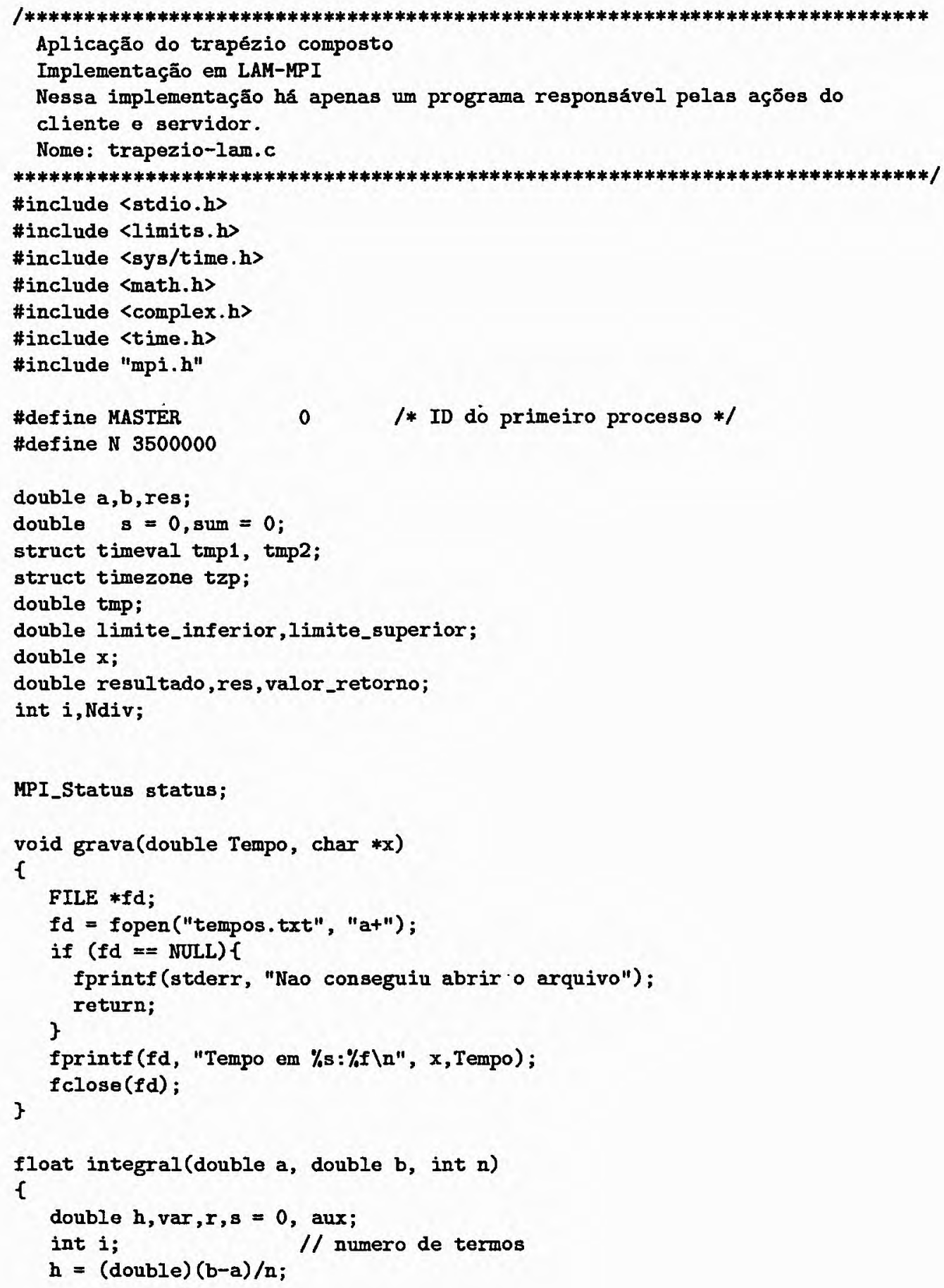




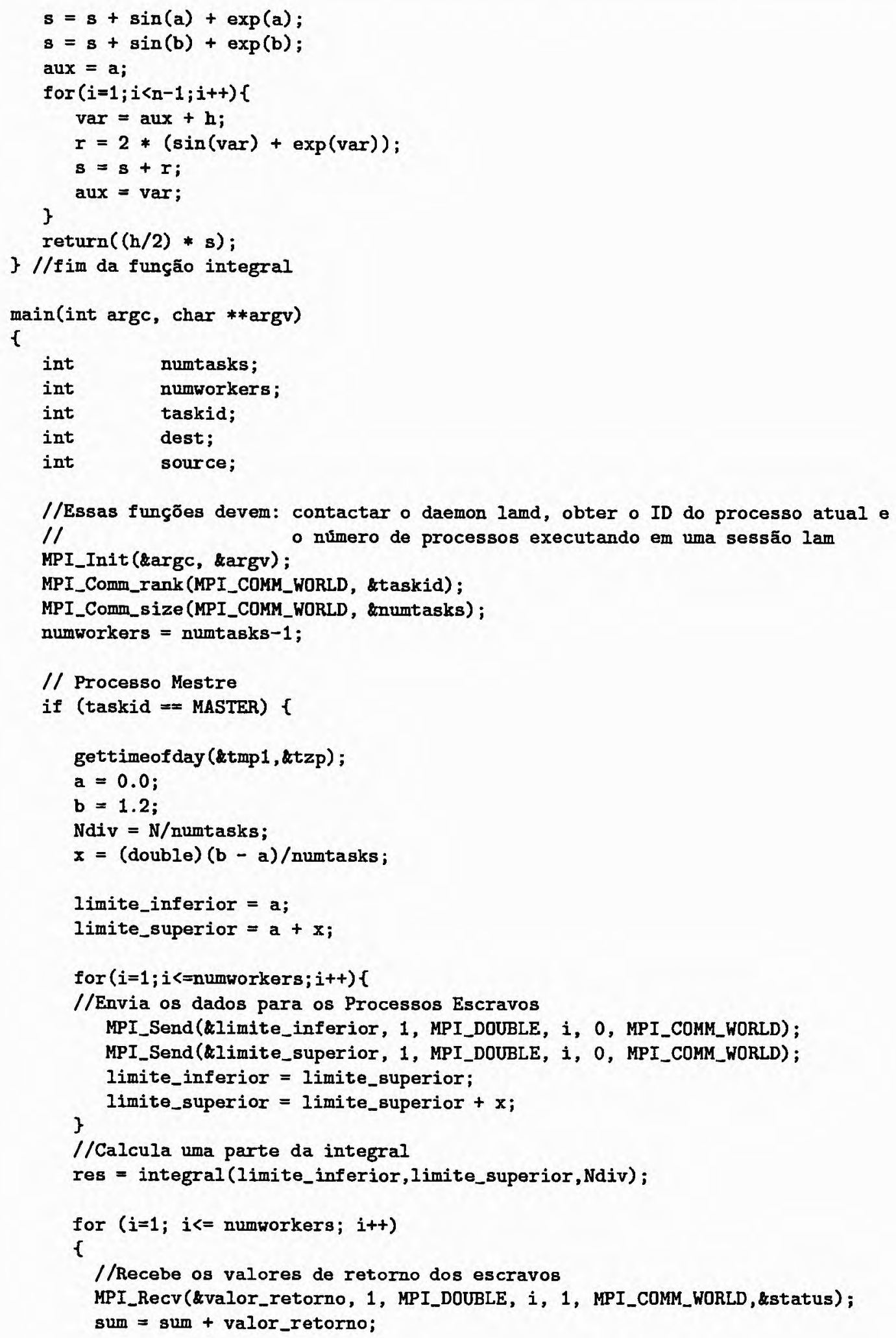




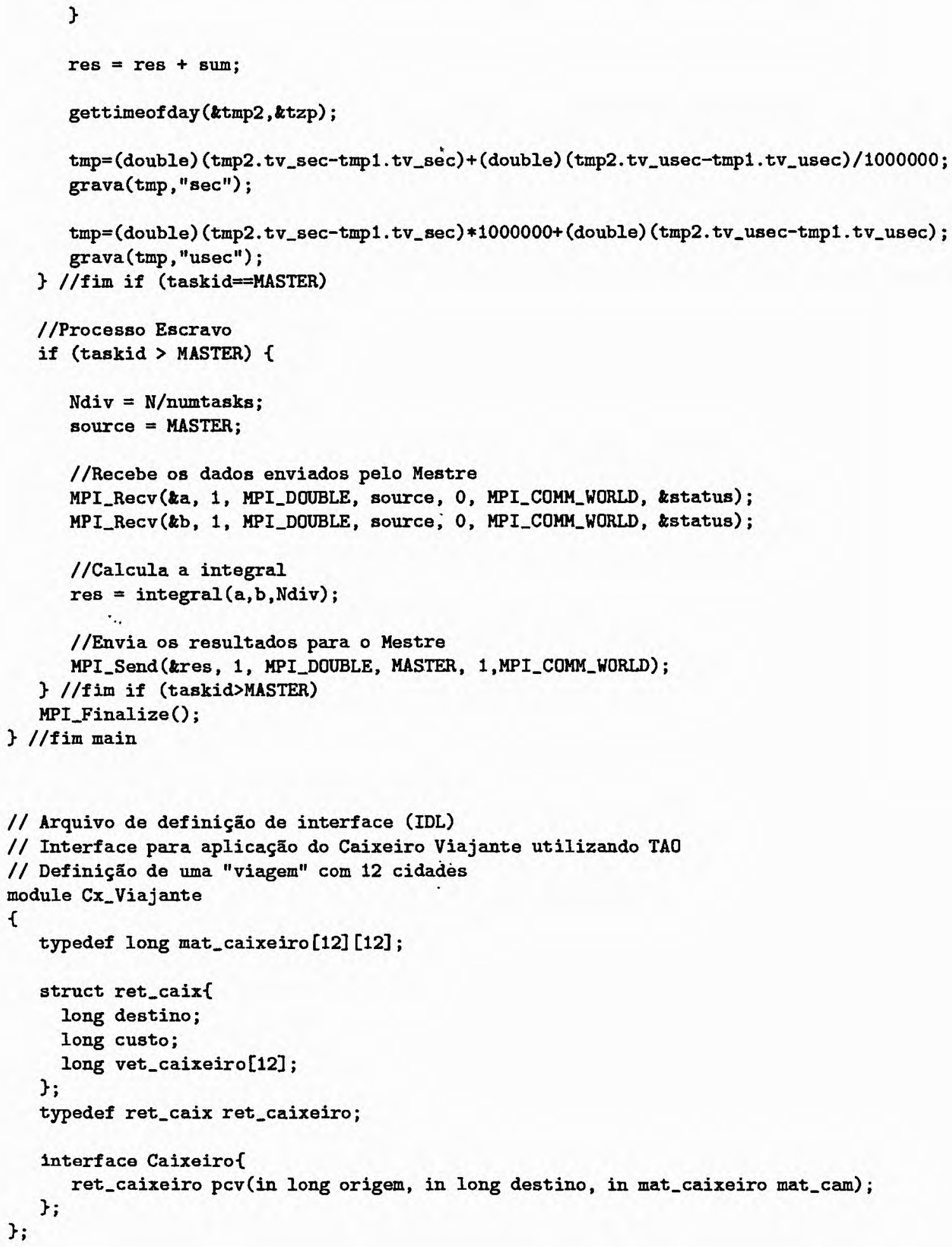




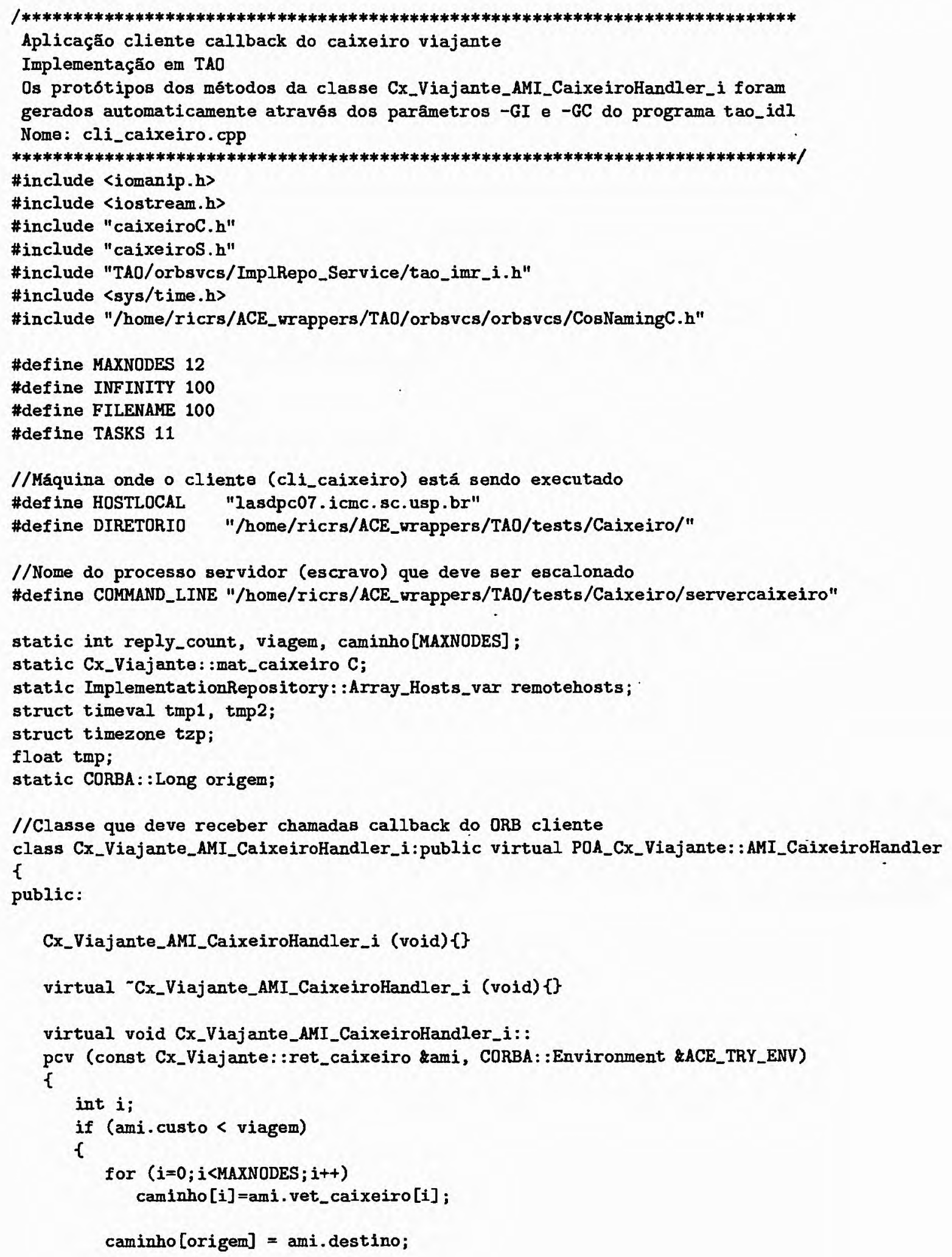




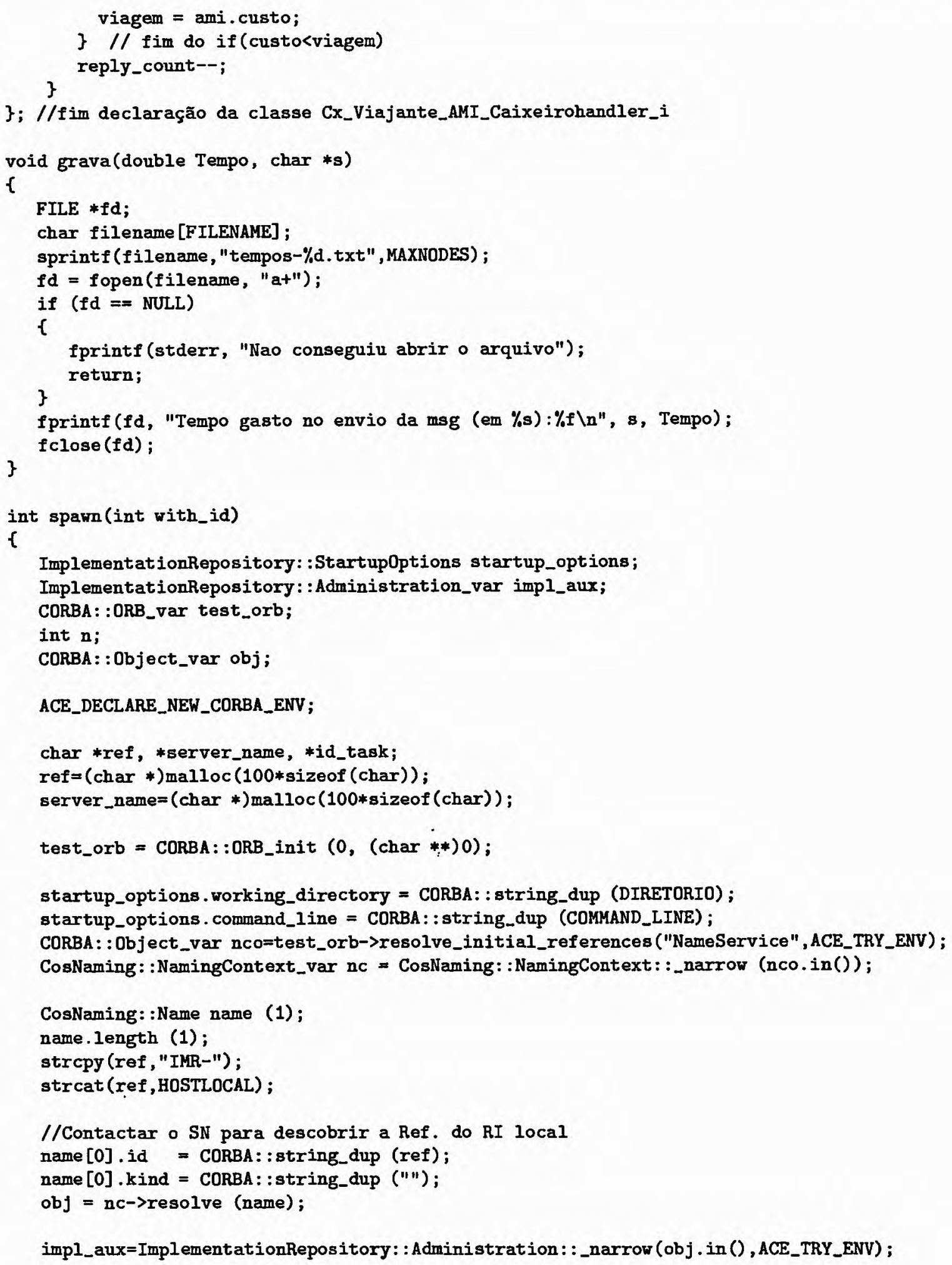




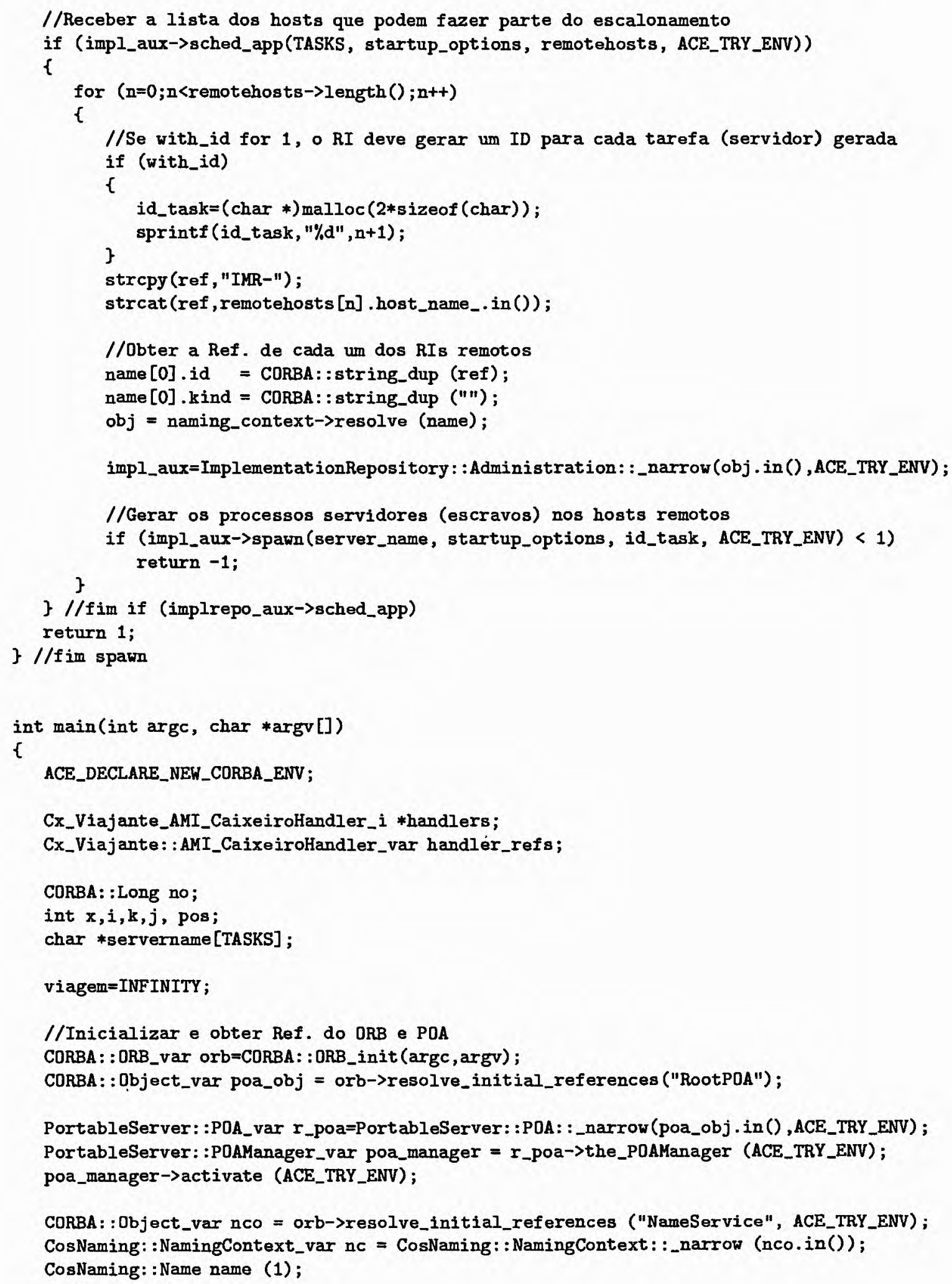




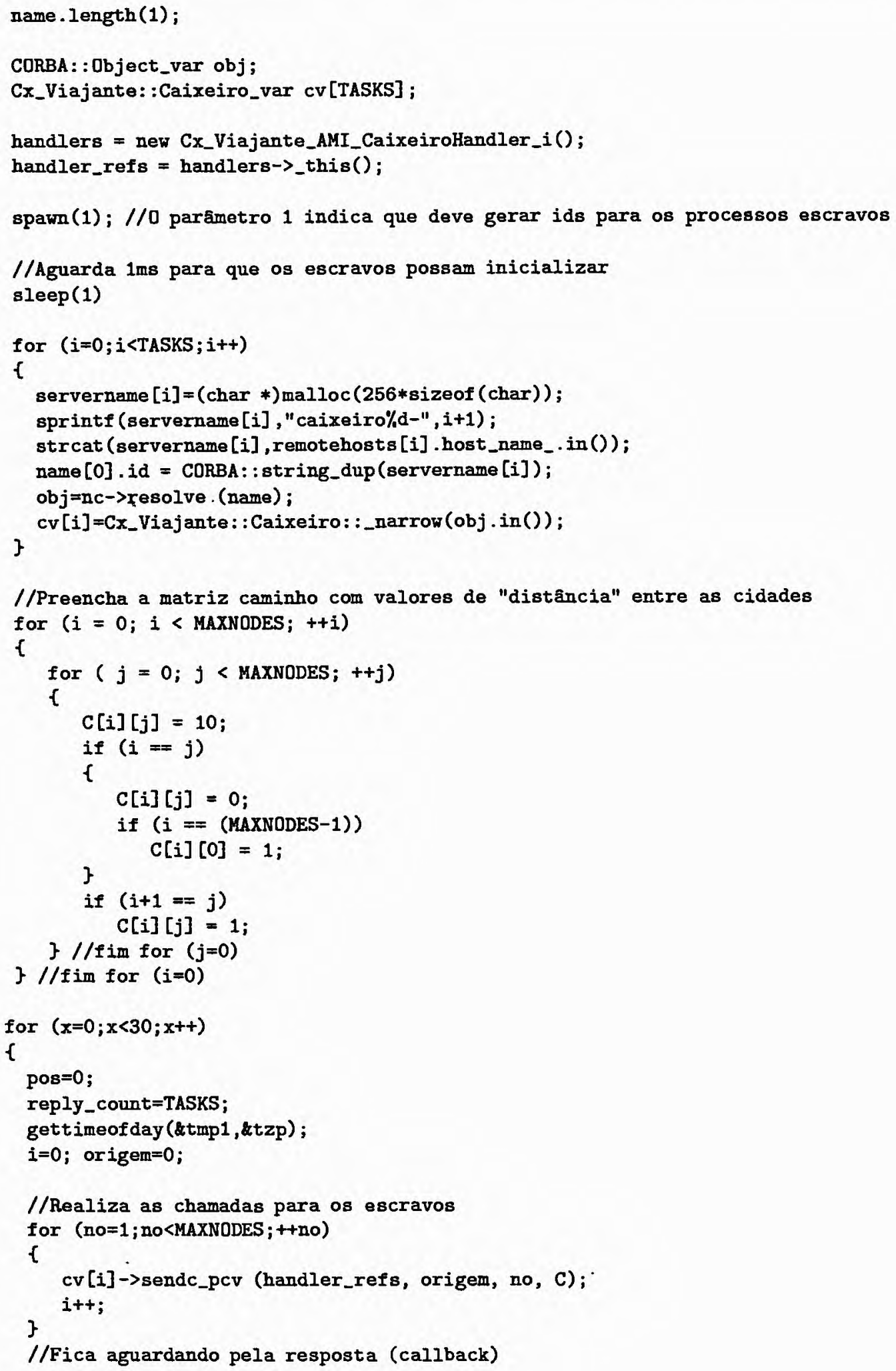




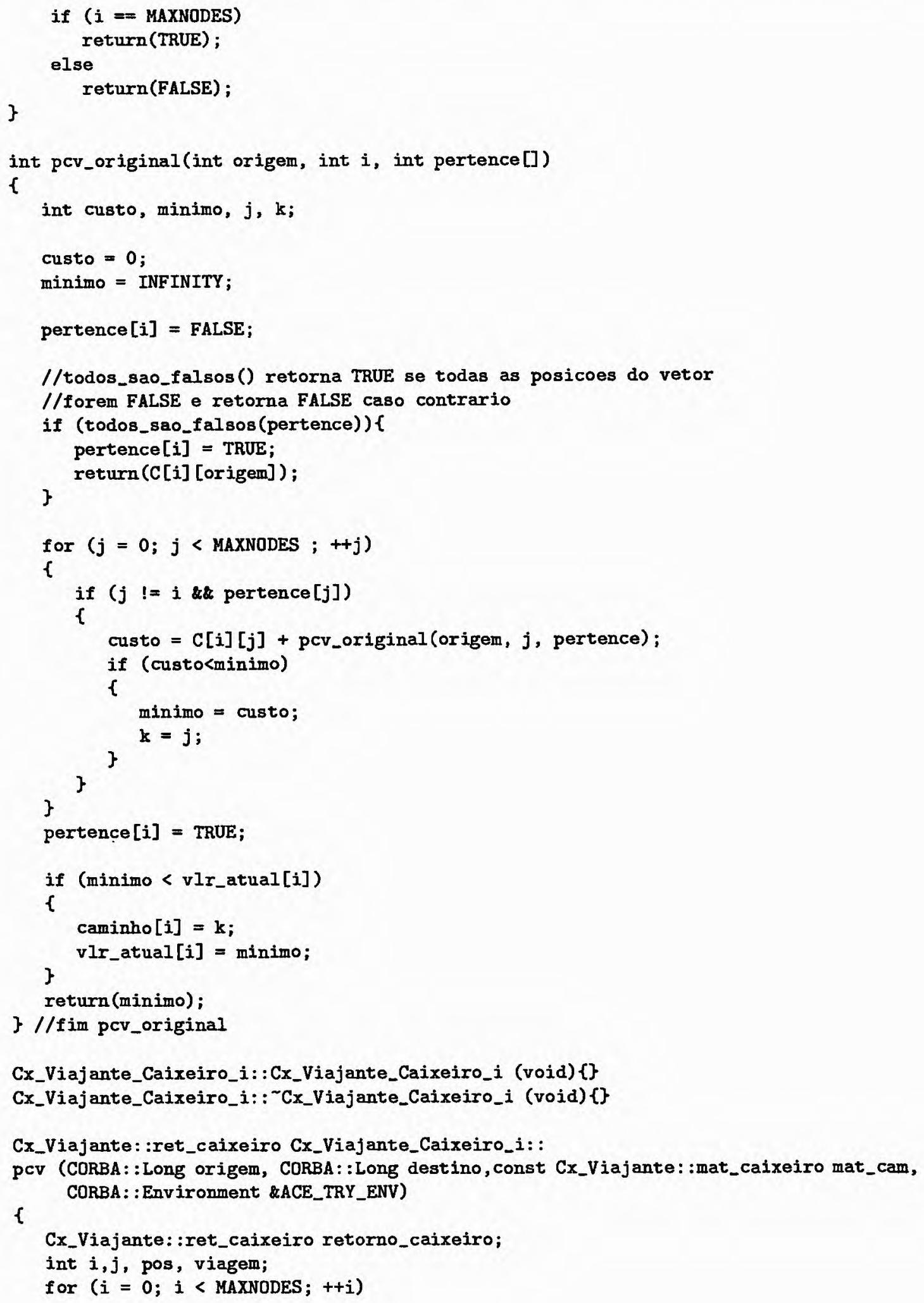




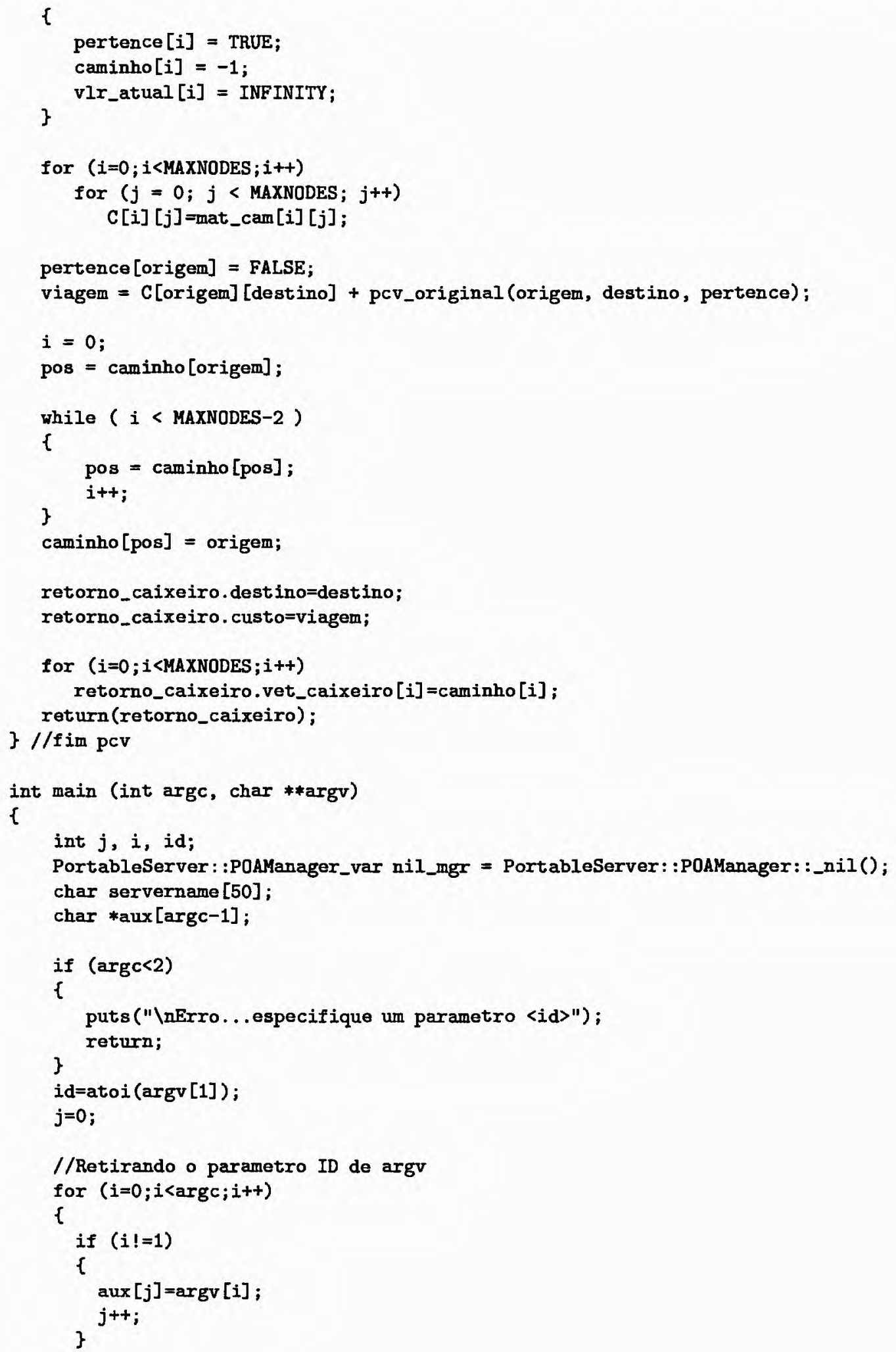


\}

argc--;

for $(i=0 ; i<\operatorname{argc} ; i++)$

$\operatorname{argv}[i]=\operatorname{aux}[i]$;

//Inicializando e Obtendo a Ref. do ORB e POA

CORBA : : ORB_var orb=CORBA : :ORB_init (argc, argv);

CORBA : : Object_var obj=orb->resolve_initial_references ("RootPOA");

PortableServer: :POA_var poa=PortableServer: :POA: :_narrow (obj.in ()$)$;

PortableServer: :POAManager_var mgr=poa_the_POAManager();

mgr->activate();

struct utsname host_local;

struct hostent *hp;

//"Descobre" e utiliza o nome da máquina, para formar a Ref. de obj. uname(\&host_local);

if $((\mathrm{hp}=$ gethostbyname (host_local.nodename) $)==$ NULL)

printf("Initialy Method: Error in gethostbyname function...");

\} $\operatorname{exit}(0)$;

sprintf (servername, "caixeiro\%d-\%s",id, hp->h_name);

Cx_Viajante_Caixeiro_i caix_servant;

Cx_Viajante: :Caixeiro_var caixeiro = caix_servant._this (ACE_TRY_ENV);

CORBA : : Object_var nco = orb->resolve_initial_references ("NameService");

CosNaming : :NamingContext_var nc = CosNaming: : NamingContext: :_narrow (nco.in());

CosNaming: : Name name (1);

name. length (1);

name[0] .id = CORBA: : string_dup (servername);

//Grava a Ref. de obj. no SN

naming_context $\rightarrow$ rebind (name, caixeiro.in());

//Aguarda por requisiçōes do Mestre

orb->run();

return 0 ;

\} //fim main

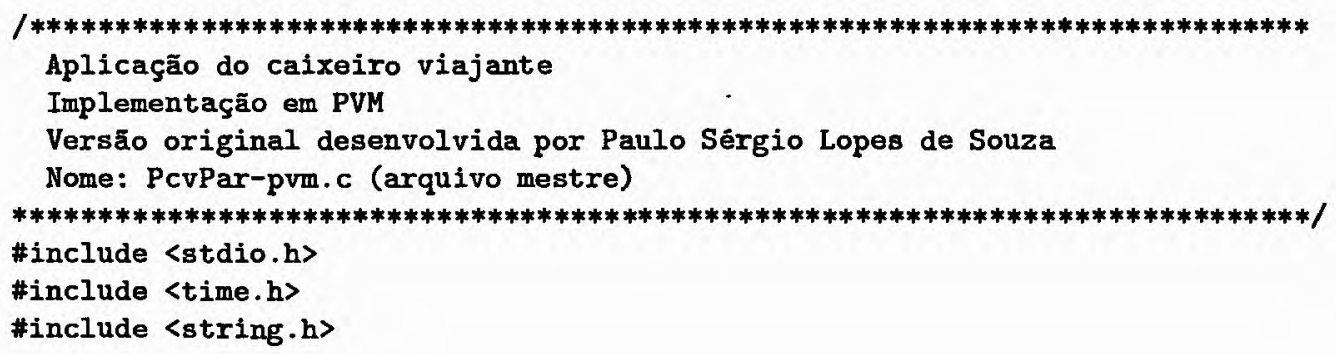




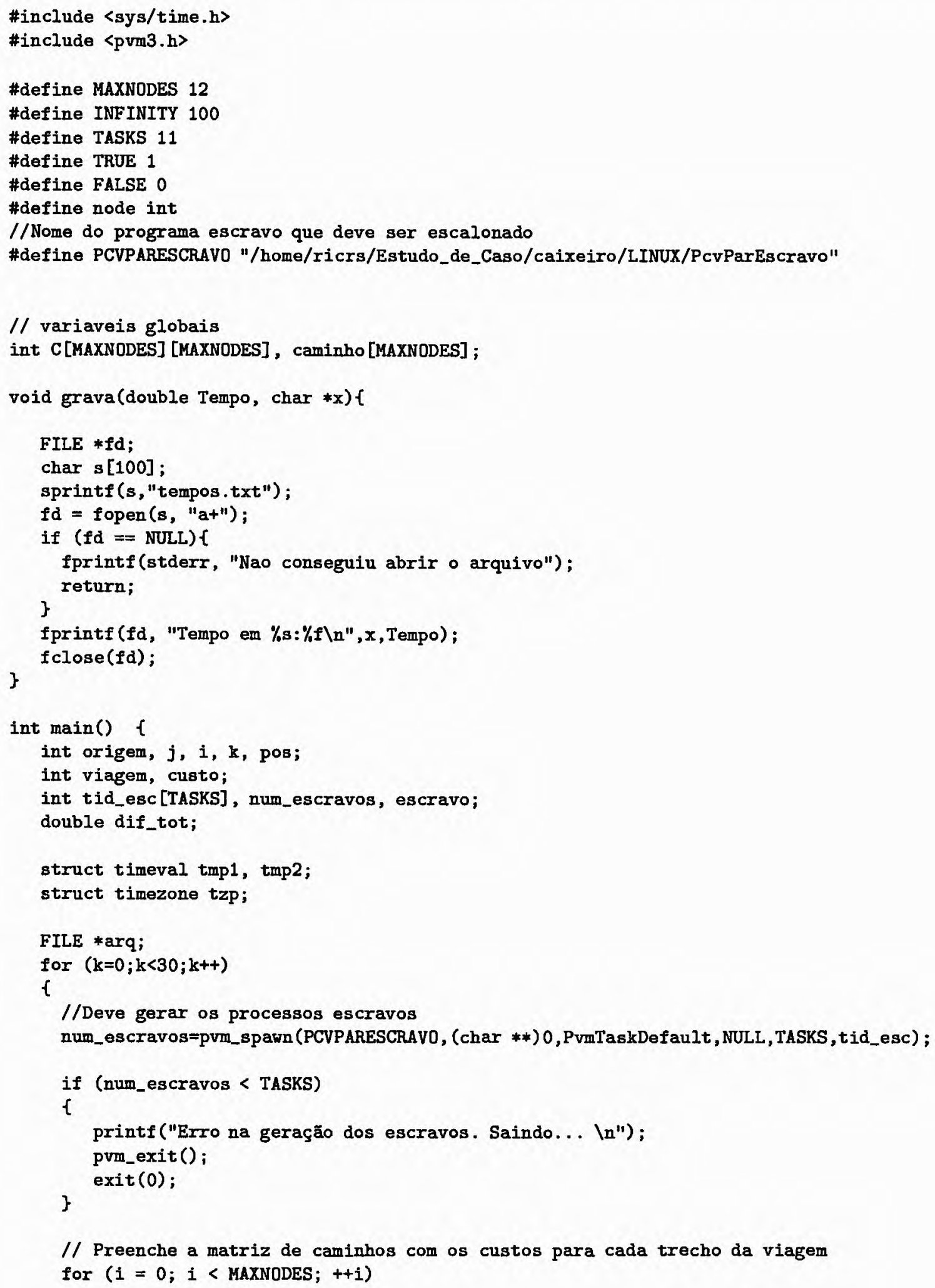




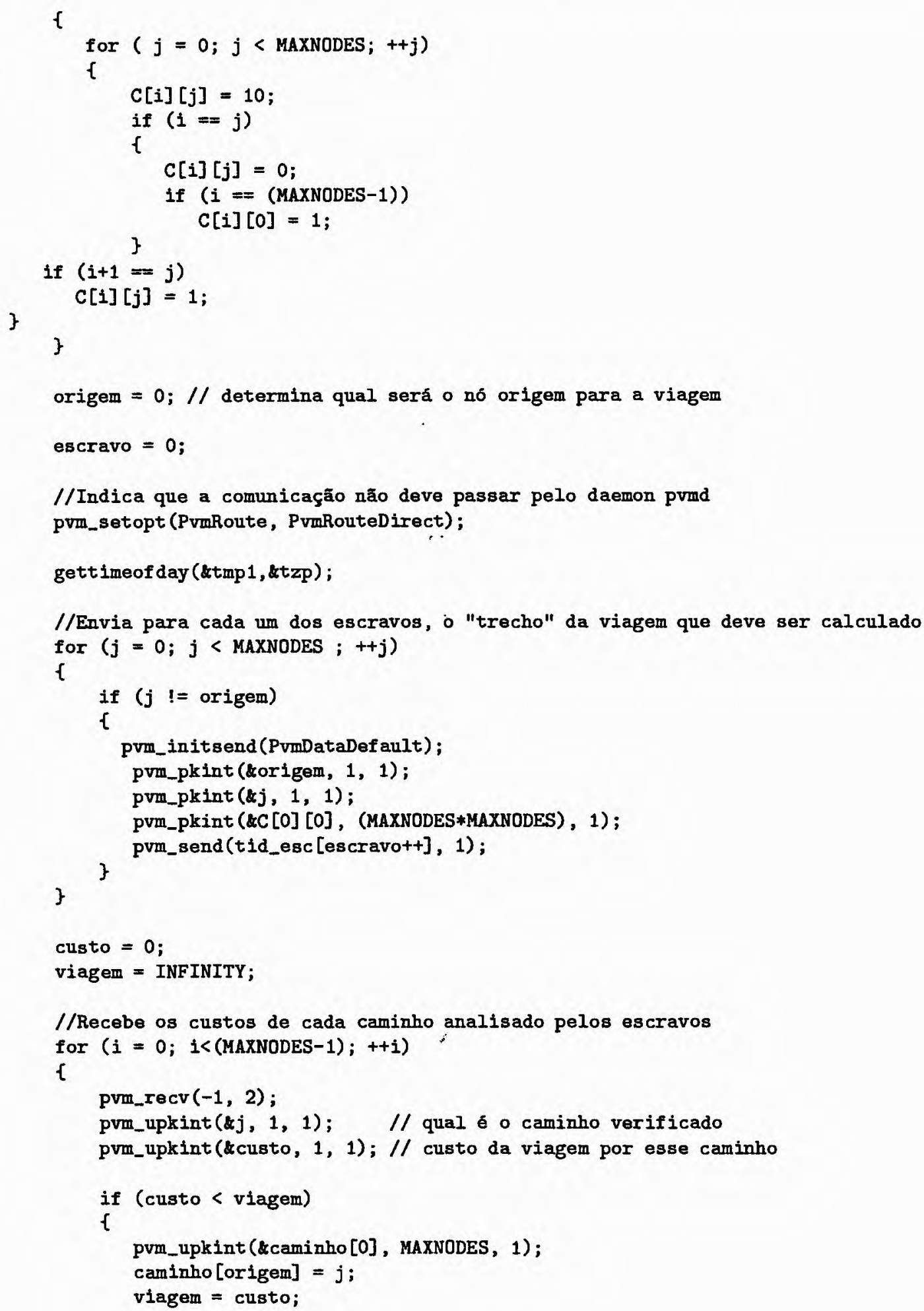




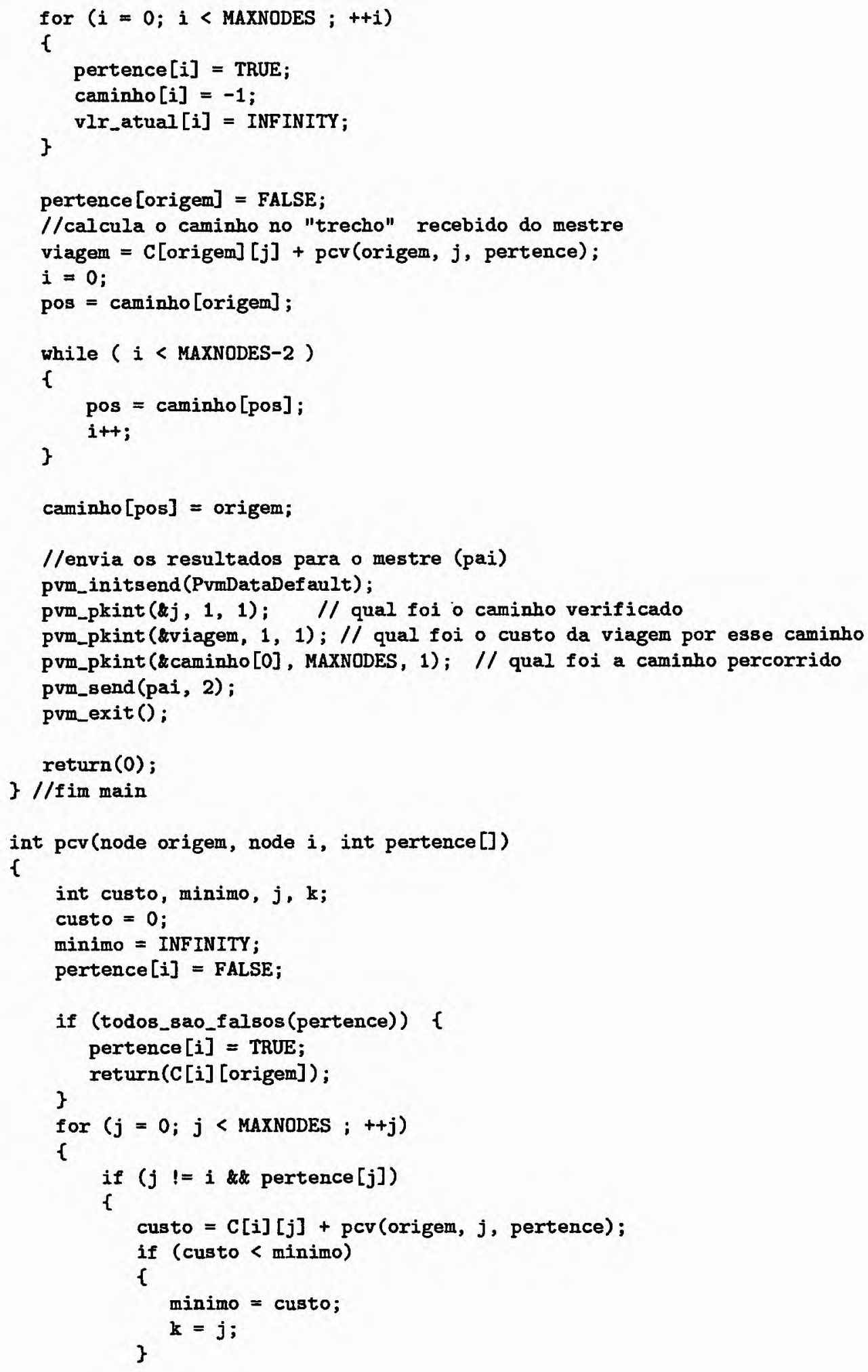




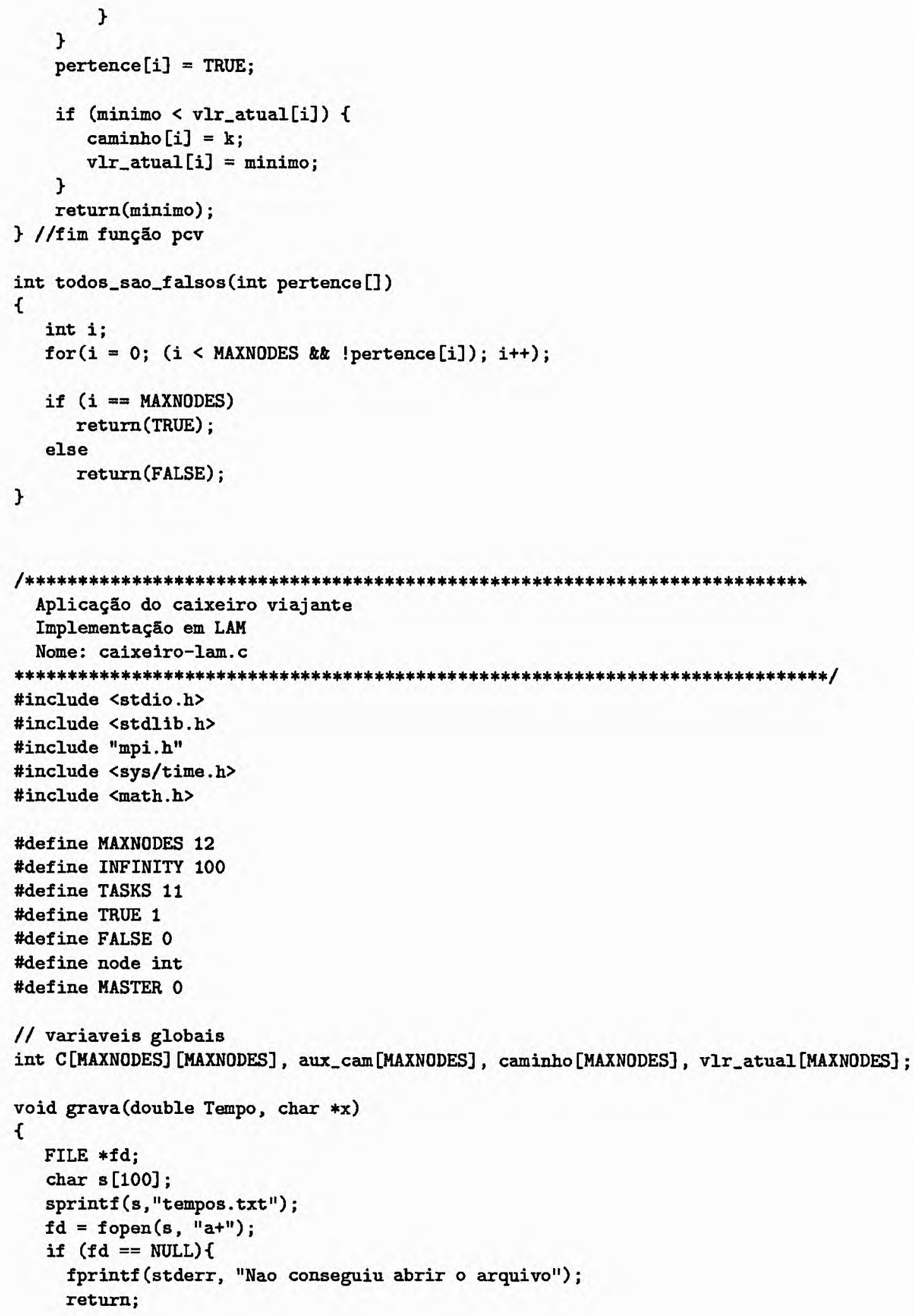




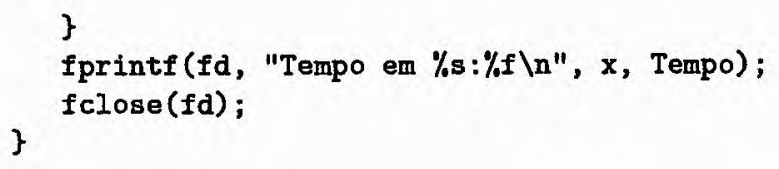

// determina qual será o nó origem para a viagem origem $=0$; gettimeofday (\&tmp 1, \&tzp);

for $(j=1 ; j<$ MAXNODES; $j++)$ 


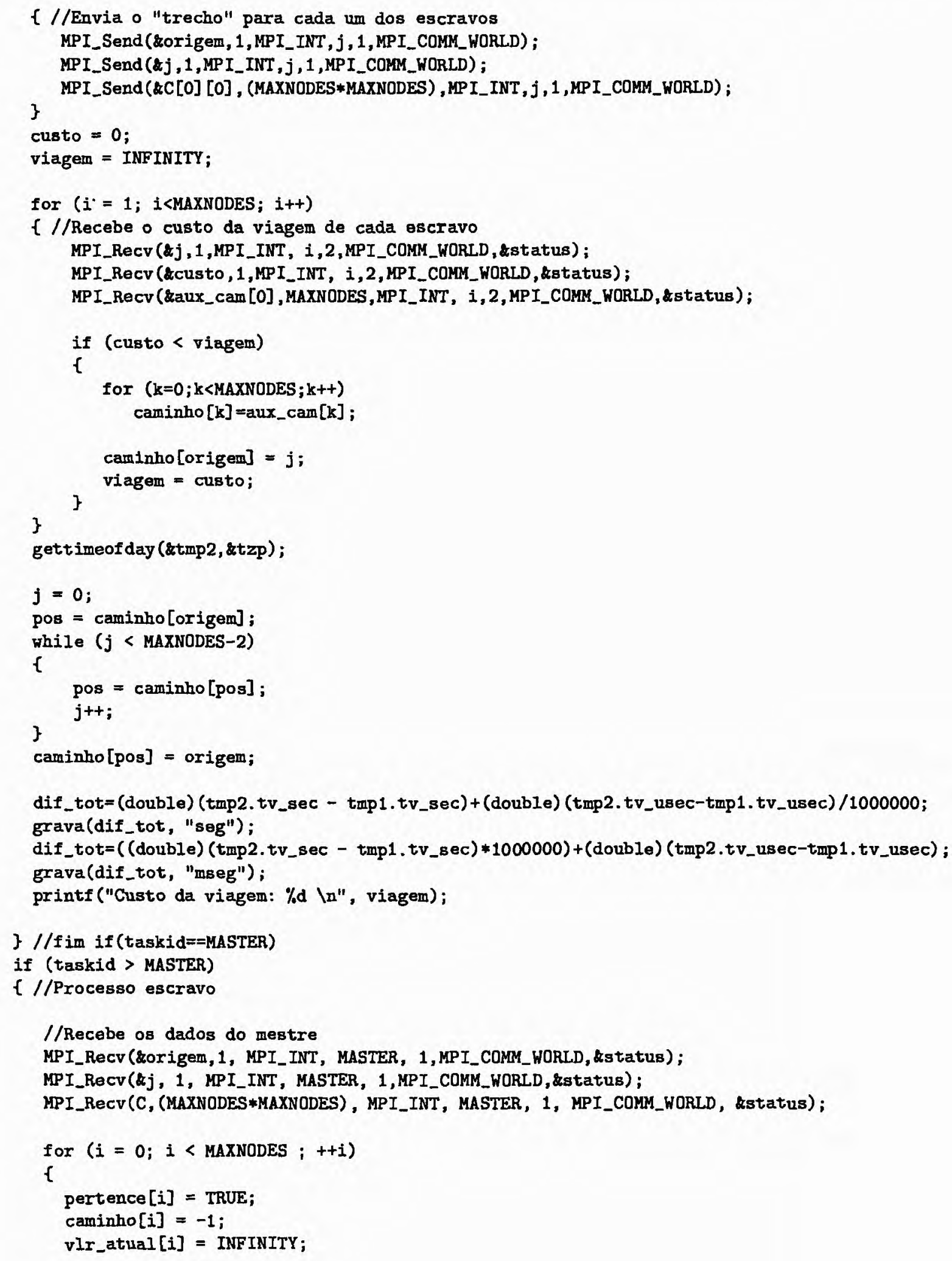


\}

pertence $[$ origem $]=$ FALSE;

//Calcula o custo da viagem

viagem $=c[$ origem $[j]+$ pcv (origem, $j$, pertence);

$i=0$;

pos = caminho [origem $]$;

while ( $i$ < MAXNODES-2)

\{

pos $=$ caminho[pos $] ;$

\}

i++;

caminho[pos] = origem;

//Envia os resultados para o mestre

MPI_Send ( $\%$ j, 1 , MPI_INT, MASTER, 2,MPI_COMM_WORLD);

MPI_Send (\&viagem, 1 , MPI_INT , MASTER, 2 , MPI_COMM_WORLD) ;

MPI_Send (\&caminho [0], MAXNODES, MPI_INT, MASTER , 2, MPI_COMM_WORLD) ;

\} //fim (if taskid>MASTER)

MPI_Finalize(); //Indica ao daemon lamd que o processo atual está saindo da sessão LAM

\} //fim main

//Funções para resolução do PCV

int pcv(node origem, node $i$, int pertence [])

\{

int custo, minimo, $j, k$;

custo $=0$;

minimo $=$ INFINITY;

pertence $[i]=$ FALSE;

if (todos_sao_falsos(pertence)) \{ pertence $[i]=$ TRUE;

\}

return(C[i] [origem]);

for $(j=0 ; j<$ MAXNODES $;++j)$

\{

if $(j !=i$ sertence $[j])$

\{

cus to $=c[i][j]+\operatorname{pcv}($ origem, $j$, pertence) $;$

if (custo $<$ minimo)

\{

minimo = custo;

\}

$k=j$;

\}

\}

pertence $[i]=$ TRUE;

if (minimo < vlr_atual[i]) \{

caminho[i] $=\mathbf{k}$;

vir_atual[i] = minimo; 
\}

return(minimo);

\} //fim função pcv

int todos_sao_falsos (int pertence [])

t

int i;

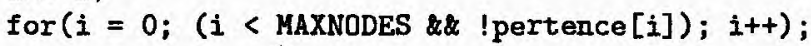

if ( $i==$ MAXNODES)

return (TRUE) ;

else

\}

return(FALSE); 